\title{
Aufsätze
}

\section{Die Ordnung der Römischen Republik}

von Christian Meier

Der Universität Salzburg zum Dank

Die Ordnung der Römischen Republik ${ }^{\mathrm{I}}$ ist, wie man weiß, nicht in einem Akt gesetzt worden, also etwa in Form einer Verfassungsgebung, wie sie in den Staaten der Neuzeit üblich geworden ist. Man hat sie auch nicht durch eine Reihe von Gesetzen zustandegebracht, wie sie etwa in Athen die konsequente Volksherrschaft herauf-

I Dieser Aufsatz geht auf Vorträge an der Humboldt-Universität Berlin sowie an den Universitäten Dresden, Heidelberg (auf Einladung der Fachschaft), Würzburg und auf Vorlesungen in München zurück. Es soll in ihm skizzenhaft der nahezu 50 Jahre alte Plan verwirklicht werden, die römische Ordnung zu begreifen. Das hätte eigentlich nach vorangegangenen Annäherungen in den I $980 e r$ Jahren geschehen sollen innerhalb von Wolfgang Kunkels Handbuch „Römische Staatsordnung und Staatspraxis“, für die ich I 980 unter anderm „Die Ordnung der Republik als ,gewachsene‘ Verfassung“ (Einleitung 2), ihr „religiöses Fundament“ (Einleitung 3) sowie „Funktionieren und Krise der republikanischen Ordnung“ (Abschnitt 8) übernommen hatte. Kunkel selbst wußte damals schon, daß er über die Abschnitte 5 und 6 (Magistratur) nicht mehr hinausgelangen konnte. Dadurch, daß diese allein veröffentlicht werden konnten (Staatsordnung und Staatspraxis der Römischen Republik. Zweiter Abschnitt: Wolfgang Kunkel/Roland Wittmann, Die Magistratur. München I995), ist ein falscher Eindruck von seiner Konzeption (Nähe zu Mommsen) entstanden. Die Vollendung des Werks scheint - ich habe nichts mehr darüber gehört - ad Kalendas Graecas vertagt worden zu sein. Für die Annäherungen s. Wilfried Nippel, Regel und Ausnahme in der römischen Verfassung, in: Monika Bernett/Wilfried Nippel/Aloys Winterling (Hrsg.), Christian Meier zur Diskussion. Stuttgart 2008, I 2 I-I42. Dazu Christian Meier, Antworten, in: ebd.259-3 Io, hier 279, sowie ders., Die loca intercessionis bei Rogationen. Zugleich ein Beitrag zum Problem der Bedingungen der tribunicischen Intercession, in: Museum Helveticum 25, I968, 86-I00. I 986 hielt ich vor der Wiener Rechtsgeschichtlichen Gesellschaft erstmals einen Vortrag: „Die Ordnung der Römischen Republik. Zum Problem, eine, gewachsene Verfassung‘ zu begreifen“. 
geführt und geregelt haben. Sie ist vielmehr allmählich, und zwar auf dem Boden alten, weitgehend maßgebenden Herkommens „herangewachsen“; insofern eine gewachsene Verfassung. ${ }^{2}$

Mitunter wurden Veränderungen der Ordnung durch Gesetze bewirkt. So konnten Verfahren, gelegentlich auch Ausgrenzungen aus einem weiten Bereich selbstverständlich gehandhabter Befugnisse, festgelegt werden. Hier und da werden Senatsbeschlüsse oder magistratische Anordnungen vielleicht nur für einen einzelnen Fall etwas geregelt haben, was andere übernahmen, so daß es sich einwurzelte - unter Umständen in einem Prozeß tastender Annäherung an eine schließlich gefundene Lösung. ${ }^{3}$

Anderes, was sich auf die Dauer als maßgebend (wenn auch nicht unbedingt bindend) erwies, hat sich in der Praxis eingestellt. Die sogenannten mores etwa. Manches war Nebenwirkung von Handlungen, die zunächst nichts als das Erreichen irgendwelcher Ziele - oder deren Verhinderung - innerhalb irgendwelcher Situationen bezweckten und dann als (sei es zu befolgende, sei es abschreckende) Beispiele fortwirkten; insofern als Teil der Ordnung, jedenfalls bis auf weiteres. Andere Beispiele könnten bewußt vorexerziert worden sein. Bei vielen Institutionen wissen wir nicht, wie sie entstanden sind.

Was immer jedoch bewußt gesetzt wurde oder beispielhaft sich einführte, betraf fast ausschließlich einzelne Züge der Ordnung. Deren wesentliche Elemente und deren Ganzes und das heißt zugleich deren Basis galt in den uns zugänglichen Zeiten als seit mehr oder weniger unvordenklicher Vergangenheit gegeben, als selbstverständlich, um dann weiter praktiziert und eventuell modifiziert zu werden. Eine ganze Reihe intellektueller und mentaler Dispositionen ${ }^{4}$ eingeschlossen, die die Handhabung der Ordnung durchwalteten.

Nur eine große Ausnahme ist zu verzeichnen. Das war die Konstituierung der römischen Plebs, der Zusammenschluß also weiter Teile der breiten Schichten zum

2 Cicero, de re publica 2,2 f.; Christian Meier, Res publica amissa. Eine Studie zu Verfassung und Geschichte der späten römischen Republik. Wiesbaden I966/Frankfurt am Main I980, 56 f. (künftig: RPA); Wolfgang Kunkel, Gesetzesrecht und Gewohnheitsrecht in der Verfassung der römischen Republik (I970), in: ders., Kleine Schriften. Weimar I974, 367-382, hier 367; Matthias Gelzer, Cicero Ein biographischer Versuch. Wiesbaden I969, 349 Anm. 29 (aber schon ders., Kleine Schriften I. Wiesbaden I962, 292). Andrew W. Lintott, The Constitution of the Roman Republic. Oxford I999, 2.

3 Z.B. Günther Rögler, Die Lex Villia annalis, in: Klio 40, I962, 76-I 23.

4 Walter Bagehot spricht für England von „prerequisites“: The English Constitution. London I958, 225. 
Zweck der Sicherung und Verbesserung der persönlichen Rechte ihrer Angehörigen und ihrer wirtschaftlichen Lage. Da ist einmal - sehr früh - ein Schnitt erfolgt. Er hat wichtige Konsequenzen gehabt. Eigentümlicherweise jedoch ist die frühe, aristokratisch geprägte Ordnung infolge davon zwar ergänzt und modifiziert, aber zugleich in ihren wesentlichen Teilen als selbstverständlich weitergeführt, ja befestigt worden. Die Institutionen der Plebs - zumal das Volkstribunat mitsamt den von ihm ertrotzten Rechten - haben sich also dieser Ordnung mehr oder weniger eingepaßt. Und sie haben sich bald ebenso als mehr oder weniger unvordenklich erwiesen wie nahezu alles andere, worauf es ankam.

Indes - bei all diesen Unterschieden, die ins Auge stechen, wenn man Herkunft sowie Geltungsgrund und -weise römischer Institutionen gegen die der Neuzeit oder des demokratischen Athens hält, ist eines noch gar nicht bedacht: Wir haben es bei der römischen Ordnung nicht nur mit andern Institutionen und zumeist andern Entstehungs- und Funktionsweisen von Institutionen zu tun als heute - vielmehr ist zunächst einmal zu fragen, ob es überhaupt angebracht ist, für Rom ein Ensemble von Institutionen als „Verfassung“ auszusondern, das, und sei es entfernt, dem moderner Verfassungen entspräche.

I.

In dieser Ordnung durchdrangen sich, um es mit unsern Kategorien analytisch aufzudröseln, „politische“ und „gesellschaftliche“ Verhältnisse samt Ausprägungen der Mentalität bis zur Unentwirrbarkeit. Sie muß auf dem, was wir gesellschaftliche Verhältnisse nennen würden, nicht einfach beruht, sondern darin bestanden haben, zum guten Teil. Hier ist nie eine politische Ordnung (wie in Athen) aus einer gesellschaftlichen ausgegliedert und gegen die gesellschaftliche, es ist politische Gleichheit der Bürger nicht (oder nur ganz begrenzt) gegen gesellschaftliche Ungleichheit - und gesellschaftliche Zwänge - gesetzt worden. Wie ja auch kein Staat sich aus dem Ganzen herausgehoben und die Gesellschaft zur Gesellschaft gemacht hat (um dann eventuell anschließend von der Gesellschaft aufgrund einer geschriebenen Verfassung wesentlich mitbestimmt zu werden).

Anders gesagt: Es hat sich nie politische Verfügung auf die Grundlagen der Ordnung erstreckt. Die faktisch überlegene oberste Schicht, der Adel also, ist nie um ihre Legitimation zur Führung des Gemeinwesens gebracht worden. Es ist nie jene Art 
Bruch mit dem „naturwüchsigen“ Herkommen erfolgt, die es ermöglicht (vielleicht gar erfordert), eine künstliche Verfassungsbasis zu errichten, auf der allein breite Schichten ihre quantitative Überlegenheit politisch regelmäßig (direkt oder indirekt) zur Geltung bringen, auf der ihre Mitglieder insgesamt gleichberechtigte Teilhaber am Gemeinwesen werden können. Und es ist diese Basis auch nicht mit der Zeit herangewachsen wie etwa in England.

Nie hat sich in Bezug auf das Ganze des Gemeinwesens eine horizontale Solidarität herausgebildet, jene Solidarität der Angehörigen breiterer Schichten mit ihresgleichen, die gemeinsam etwas erreichen und vor allem sichern will, was ihr politisches Gewicht nennenswert und auf Dauer erhöht; und zwar in Hinsicht auf das Ganze. Wodurch es möglich geworden wäre, daß sich situationsübergreifend ein politischer Eigenwille des Volkes (insgesamt oder mit wechselnden Mehrheiten) hätte bilden und durchsetzen können. Denn was jener Teil des Volkes, der sich als plebs konstituierte, über einzelne Situationen der Empörung hinaus an horizontaler Solidarität hervorbrachte, zielte nur auf Freiheitsrechte und wirtschaftliche Interessen der breiten Schichten innerhalb der aristokratischen Ordnung (oder wurde bald in sie eingefangen).

Darüber hinaus pflegten sich die Angehörigen dieser Schichten in Rom damit zu begnügen, daß für ihre je besonderen (in aller Regel vereinzelten) Bedürfnisse und Interessen, soweit sie dafür der Unterstützung bedurften, vertikale Solidaritäten, also Bindungen zwischen Hoch und Niedrig sorgten. Die aber sind in der Regel so gestaltet, daß der politische Gewinn daraus an die Höheren geht.

So konnte in der Römischen Republik die von Anfang an gegebene selbstverständliche Überlegenheit der Adligen durchhalten. Weite Teile der Bürgerschaft blieben in einer Weise an sie gebunden und politisch von ihnen abhängig, daß sie sich zwar gelegentlich, bei gegebenem Anlaß, empören, auch einige Rechte ertrotzen, aber gar nicht auf die Idee kommen konnten, die Tatsache und die Berechtigung der Führung durch den Adel anzuzweifeln. Hätte sich ein Zweifel geregt, so hätte er kaum Aussicht auf irgend nachhaltige Resonanz gehabt. Es hätte sich also kein Ansatzpunkt gefunden, um etwas anderes ernsthaft auch nur für möglich zu halten. So dicht bestimmte die gesamte Wirklichkeit, in der diese Bürgerschaft befangen war, das Denken und das Vorstellen. Es tat sich kein Spalt zwischen ihr und eventuell denkbaren anderen Möglichkeiten auf.

Der Adel hatte eine umfassende Statuskongruenz aufzuweisen. ${ }^{5}$ Macht, Reichtum, Wissen, Verbindungen, politische und militärische Führungskompetenz, 
nicht zuletzt diejenige, göttlichen Willen zu erfragen und zu deuten, die Befähigung zu öffentlicher Rede ${ }^{6}$, überhaupt zu respektgebietendem Auftreten in der Öffentlichkeit, Ruhm und Ehre ohnehin sowie ganze Bereiche der Kultur konzentrierten sich mehr oder weniger in den Händen eines kleinen Kreises von Männern, die zu allermeist auch von prominenter Abstammung waren.

Jene Statuskongruenz läßt sich zwar in gewissem Sinn auch beim frühen griechischen Adel beobachten. Dort jedoch war einer ihrer zentralen Bestandteile mit der Zeit an verschiedenen Orten brüchig geworden: Adliges Machtstreben durchstieß verschiedentlich Grenzen, innerhalb derer Adelsregime sich von selbst verstehen können. Die Führung durch den Adel, anders: seine Herrschaft verlor an Selbstverständlichkeit. Sie wurde vielerorts als ungerecht durchschaut. Und vor allem: Gerechtigkeit, jenes potentiell höchst empfindliche Bedürfnis, wurde zum Problem und - zum Maßstab, an dem Ordnungen explizit gemessen wurden. ${ }^{7}$ Da konnten große Gegensätze, grob gesagt, zwischen Adel und Volk virulent werden. Da tat sich jene Distanz zum Herkommen auf, die größere Veränderungen möglich macht. Schließlich konnte sogar zwischen Alternativen gewählt werden, je nachdem, wer herrschen sollte, Adel oder Volk.

Eben dazu aber ist es in Rom nicht einmal in Ansätzen gekommen. Das heißt aber zugleich, daß die „gesellschaftlichen“ und „mentalen“ Voraussetzungen adligen Vorrangs, ja der Herrschaft des Adels dort unmittelbarer Teil der Ordnung waren und blieben; gar nicht ablösbar von den Organen der „Verfassung“ und den Weisen, in denen sie verfuhren.

Wie unauftrennbar ein solches Konglomerat eindeutiger Überlegenheit für den Adel gegeben war, zeigte sich, als eine zweite Schicht, die sogenannten Ritter, beträchtlichen Reichtum und Wissen ansammelte: Da blieb die Führung durch den alten Adel (und dessen nicht formales, aber doch weitgehendes Monopol auf die politischen Ämter) fast unbeeinträchtigt bestehen - bis in die späte Republik. ${ }^{8}$ Noch in

\footnotetext{
5 Dazu Niklas Luhmann, Rechtssoziologie. Reinbek I972, I70f.

6 Karl-Joachim Hölkeskamp, Senatus Populusque Romanus. Die politische Kultur der Republik - Dimensionen und Deutungen. Stuttgart 2004, 219-256.

7 Während dikaiosyne in der vordersten Reihe griechischer Tugenden ihren Platz fand, stand dort in Rom fides. Iustitia erlangte ihre Bedeutung erst unter griechischem Einfluß.

8 Bei möglichen Ausnahmen nach Iog sowie nach dem Bundesgenossenkrieg zeigt sich, daß die Regel ein Stück weit, aber nicht nachhaltig durchbrochen werden konnte: Meier, RPA (wie Anm. 2), 79ff., 83f., I 35 ff., 2 I 6 ff., 253.
} 
der großen Krise blieb es, all deren Versagen zum Trotz, bei umfassender Festlegung alles Denkens auf die bestehende, in Jahrhunderten herangewachsene Ordnung.

II.

I. Die Frage ist, wie man die „gewachsene Verfassung“ der Römer genauer fassen oder gar begreifen kann. Als unbewußt - und streckenweise in diesem und jenem wohl auch bewußt - in gewissen Bahnen gehaltene und eingeschärfte, insgesamt praktizierte, gelebte, befolgte, mit der Zeit auch sich modifizierende, aber stets selbstverständliche Ordnung einer Bürgerschaft (deren Versagen während der späten Republik folglich in jahrzehntelange allgemeine Ratlosigkeit versetzte). ${ }^{9}$ Und die gut funktionierende Ordnung eines ungewöhnlich erfolgreichen Gemeinwesens obendrein.

Matthias Gelzer sprach für Rom von einer „staatsrechtlichen Logik“, die „recht mangelhaft“ gewesen sei. Er fand, das Studium der „Gesellschaftsgeschichte“ belehre uns eines ganz anderen. Mit andern Worten steht das gleiche bei Alfred Heuß. Man habe es mit einer „höchst unvollkommenen äußeren Verfassungsapparatur“ zu tun, deren „,richtiger Gebrauch“ durch eine hinter ihr stehende „ordnende ausrichtende Kraft“ gewährleistet werden mußte. Die fand er in der „römischen Gesellschaft mit dem ihr innewohnenden Regulationsvermögen“. ${ }^{\text {Io }}$ Beide unterscheiden also Gesellschaft von Staatsrecht respektive Verfassung.

Jochen Bleicken hat die Problematik in seinem großen Buch „Lex Publica“ (I975) zum Thema eingehender Untersuchungen gemacht. Er rechnet mit einer „Rechtsordnung“, die er einerseits deutlich von einer „Sozialordnung“ unterscheidet, von

\footnotetext{
9 Ebd.306.

Io Gelzer, Kleine Schriften I (wie Anm. 2), I56, I58, I63, I70, 292 f.; Alfred Heuß, Römische Geschichte. Braunschweig I960, 37 f. Zugrunde lag dem die moderne Scheidung zwischen Staat und Gesellschaft, mit der aber für Rom gar nicht zu rechnen ist. Vgl. auch Karl-Joachim Hölkeskamp, Ein „Gegensatz von Form und Inhalt“. Theodor Mommsens Konzept des republikanischen „Senatsregiments“ - Hindernis oder Herausforderung?, in: Wilfried Nippel/Bernd Seidensticker (Hrsg.), Theodor Mommsens langer Schatten. Das Römische Staatsrecht als bleibende Herausforderung für die Forschung. Hildesheim u.a. 2005, 87-I30, hier I 7 ff.; Christian Meier, Matthias Gelzers Beitrag zur Erkenntnis der Struktur von Gesellschaft und Politik der späten römischen Republik, in: Jochen Bleicken/Christian Meier/Hermann Strasburger, Matthias Gelzer und die Römische Geschichte. (Frankfurter Althistorische Studien.) Kallmünz 1977, 29-56, hier 48 Anm. 84.
} 
der er andererseits feststellt, sie stünde „in einem unlöslichen Sinnzusammenhang“ damit. „Es kann kein positives Recht geben, das gegen die Sozialordnung steht. Wer daher sein positives Recht gegen die soziale Ordnung gebraucht, verstößt gegen den Sinn des Rechts“. II

Franz Wieacker ${ }^{12}$ nennt die „Verfassung der Römischen Republik“ einen „überlieferten Bestand von Einrichtungen und formalisierten Handlungsregeln, die, hier und da durch Einzelgesetze bekräftigt, reformiert oder fortgebildet, im ganzen als rechtlich bindende Organisation verstanden und angewendet wurden“. „Als historische Realität“ sei sie „ein ständiger Prozeß, dessen Verständnis die Vergegenwärtigung seiner politischen und sozialen Bindungen, besonders der politischen und sozialen Gruppenbildungen und der Dynamik ihrer Veränderungen voraussetzt“. Zu den „Konstanten dieses Prozesses“ gehöre auch „ein fester Bestand von vorrechtlichen Leitvorstellungen der Moral des öffentlichen Handelns, wie mos maiorum, auctoritas, gratia, honor, dignitas, die, selbst nicht Bestandteil der öffentlichen Rechtsordnung (ius publicum), doch als sozial verpflichtende Maßstäbe des öffentlichen Verhaltens und oft auch der Rechtsanwendung anerkannt werden“.

Diese Äußerungen stehen allesamt im Banne des gewaltigen Systems, zu dem Theodor Mommsen das „Römische Staatsrecht“ geformt hat. Auch er wußte zwar, daß dessen „Inhalte“ keineswegs unbedingt dessen „Formen“ entsprachen. Folglich hat er zahlreiche Abweichungen von seinem System vermerkt. ${ }^{13}$ Doch wurde seine Konzeption des Staatsrechts davon im ganzen nicht berührt. Und man mußte sehen,

\footnotetext{
I I Jochen Bleicken, Lex Publica. Gesetz und Recht in der römischen Republik. Berlin/New York I975, 3 Io. Vgl. meine Rezension: ZRG RA 95, I978, 378-390. In den Erwägungen, die Bleicken anstellt, um die auctoritas senatus als (nicht-rechtliche, sondern) soziale Norm zu erweisen, wird beispielhaft deutlich, zu welchen Konsequenzen man gelangt, wenn man eine so genaue Scheidung von Rechts- und Sozialordnung trifft. Das Merkmal „rechtliche Verbindlichkeit“ ist klar in der Unterscheidung zwischen Volks- und Senatsbeschlüssen. Aber wenn senatus consulta unendlich viel bedeutsamer waren, ja wenn in Rom ein Senatsregime herrschte - konnte das nur eine Sache der sozialen Ordnung sein? Was ist von einer „Rechtsordnung“ zu halten, nach deren Kriterien das jahrhundertelang unter allgemeiner Anerkennung herrschende Organ nicht handlungsfähig war? Nach meinem Urteil besteht für Rom vor der späten Republik auch keine Möglichkeit, sinnvoll mit dem Begriff „Verfassungswirklichkeit“ zu operieren. Die Ordnung der Republik war so umfassend, daß allenfalls in einzelnen jeweils neuralgischen Punkten zwischen „Norm“ und Wirklichkeit zu unterscheiden wäre (wobei die Meinungen differieren mochten).

I2 Franz Wieacker, Römische Rechtsgeschichte. Erster Abschnitt: Einleitung, Quellenkunde. Frühzeit und Republik. München I988, 353f.

I3 Hölkeskamp, Gegensatz (wie Anm. Io), 87 ff.
} 
wie man all die Kenntnisse, die man von der „sozialen Ordnung“ der Republik und ihrer Bedeutung erwarb, damit in Einklang brachte.

Ich möchte dagegen fragen, ob wir mit solchen Entgegensetzungen nicht auf dem Holzweg sind. Ob die Konstruktion eines „Staatsrechts“ oder einer „Rechtsordnung“ uns nicht daran hindert, der Eigenart der römischen Ordnung als einer „gewachsenen Verfassung“ gerecht zu werden. Ob also etwa die verschiedenen „Verfassungsinstitutionen“, Senat, Magistrate, Volksversammlungen, nicht so dicht auf tiefbegründeten Voraussetzungen von ständischer Schichtung, Disziplinierung, Denkungsart aufsitzen und mit ihnen verwoben, in sie eingeknüpft sind, daß es geradezu als gekünstelt erscheinen muß, eine spezifische „Rechtsordnung“ aus dem Ganzen dieser Ordnung herauszufiltern.

Wo das Recht zum guten Teil nicht vermittels Beschlüssen gleichsam aus der Bürgerschaft herausgesetzt wurde, mußte es sich auch in deren Mitte je neu herausstellen, sich in festen Gegebenheiten, Überzeugungen - vielleicht sagt man besser: Selbstverständlichkeiten - und Regeln niederschlagen, die vielfach unauslotbar tief in der Gesamtheit verwurzelt waren.

Irgendwie muß diese Ordnung doch ein Ganzes gebildet haben. Muß sie als Ganzes begreifbar sein. Nicht als Typus, aber eben als sehr spezifische Ordnung eines sehr spezifischen Gemeinwesens. Dabei scheint mir schon ihre Klassifizierung, etwa als politische, aufgrund der mangelnden Scheidbarkeit von „politisch“ und „gesellschaftlich“ nicht angebracht zu sein. Daher die Überschrift: Die Ordnung der Römischen Republik.

2. Unser ältester Zeuge, der Grieche Polybios, welcher sich in der Mitte des zweiten Jahrhunderts v. Chr. in Rom umtat, konnte nicht anders als das, was er als Römische Verfassung verstand, mit griechischen Kategorien beschreiben, das heißt vornehmlich danach fragen, wer dort herrsche. Denn das war es ja, was sich unter den Griechen als entscheidendes Merkmal für das Gros der Poleis herausgestellt hatte: Daß sie Monarchie, Aristokratie (respektive Oligarchie) oder Demokratie waren. Betrachte man die Rechte der Volksversammlung, müsse man die Römische Ordnung für eine Demokratie halten. Betrachte man die des Senats, für eine Aristokratie, und die der Obermagistrate, für eine Monarchie. So umfassend seien die Rechte der drei elementaren Organe dieser Ordnung. ${ }^{\text {I4 }}$

I4 Polybios 6, I Iff. Dazu Wilfried Nippel, Mischverfassungstheorie und Verfassungsrealität in Antike und früher Neuzeit. Stuttgart I980, I46ff. 
Nach griechischen Begriffen handelte es sich also um eine gemischte Verfassung. Ob damit für Rom viel gesagt ist, ist zweifelhaft. Immerhin hat Polybios erkannt, daß da checks and balances am Werk waren $(6,15)$. Nur daß er deren Wirken und überhaupt, wie sich die verschiedenen Gewalten zueinander verhielten und untereinander ausglichen - nur sehr begrenzt nämlich durch checks and balances -, kaum wirklich verstanden hat. Daß aber die Rechte, die Verfügungsräume von Volksversammlung, Senat und Obermagistraten für sich, genauer: absolut (oder besser: formal) genommen ungeheuer groß waren, konnte er beobachten, dafür also kann er als Zeuge dienen. Die Frage ist nur, wie weit man sie absolut nehmen konnte.

Müssen zu ihnen nicht, da sie nicht aufgrund einer gestifteten Verfassung galten, mehr oder weniger selbstverständliche Bedingungen hinzugedacht werden, die ihrem Gebrauch jeweils zugrundelagen und/oder ihm gegebenenfalls Grenzen setzten? Bedingungen, die vielleicht zunächst in gewissen vorgegebenen, nicht hinterfragbaren Bindungen der Bürgerschaft an Autoritäten (und der Autoritäten selbst, zum guten Teil jedenfalls, an ebenso vorgegebene Selbstverständlichkeiten oder Regeln) bestanden hätten, so daß die Spielräume schon des Denkbaren begrenzt gewesen sind? Wohl läßt sich bei Machtkämpfen potentiell viel Phantasie entfalten. Aber auch das muß sich im damaligen Rom (übrigens in vermindertem Ausmaß selbst in der Krise der späten Republik) in Grenzen gehalten haben, weil sich Parteiungen, die über das Gegebene hätten hinausführen können, nicht zu bilden pflegten. ${ }^{15}$ Was be-

I5 Dies ist ein ganz entscheidender Punkt. Wir haben keine Belege, die klar für irgend nennenswerte situationsüberdauernde Faktionen sprächen. Vgl. auch unten S.645. Wenn für die späte Republik von factio die Rede ist, so ist damit zumal ein Kreis von Männern gemeint, der sich klüngelhaft (das Wort insinuierte, daß unrechtmäßige, intrigante „Machenschaften“ am Werk seien) darauf kapriziert haben soll, den ganzen Senat zu unterdrücken. Damit war polemisch ausgedrückt, was man andersherum als die Autorität der principes civitatis bezeichnen könnte; vgl. Meier, RPA (wie Anm. 2), I8off., 308. Dazu: Sallust, Jugurtha 3I,4. 4I,6; Historien 3,48. [Sallust], ad Caesarem 2,IO,9ff. Ähnlich Livius 2,27,3; 3,4I,I. Vgl. Cicero, de re publica I,68; 3,23). Entsprechend wird von einer einzigen factio gesprochen, nicht von einem Kampf zwischen mehreren. Bei Livius wird factio vorwiegend für Parteiungen außerhalb Roms benutzt (30 von 44 Belegen), für Rom fast nur für die frühe Zeit der Republik. Wenn für die spätere einmal von einer factio [...] adversa Scipionibus die Rede ist $(38,55,3)$, so handelte es sich offenbar darum, daß starke Persönlichkeiten, wie sie von Zeit zu Zeit begegneten, ihre Gegner veranlaßten, ihnen geschlossen entgegenzutreten; zuweilen. Wenn solche Gruppen, Faktionen also im Sinne nicht nur des gelegentlichen, weithin gegenstandsabhängigen Sich-Gesellens weniger Adliger zwecks gemeinsamer Erreichung beschränkter Ziele, sondern in dem längerfristigen Kampfes auf verschiedenen Feldern zwecks Machtgewinns der Gruppe oder ihrer Führer sich gebildet hätten, hätten die Auseinandersetzungen dynamisiert und die Senatsaristokratie gespalten werden können. Denn gegen eine solche Gruppe hätte sich demnächst eine andere gebildet, und von ihren Auseinan- 
dingt/bedingend damit zusammenhing, daß keine Distanz aufkam, die es (über Einzelheiten hinaus) hätte erlauben können, eine Kluft zwischen dem Gegebenen und anderen Möglichkeiten wahrzunehmen.

Offensichtlich kann als zusammenhängende Ordnung in Rom nur etwas verstanden werden, was auch die Voraussetzungen seines Funktionierens mit umfaßte; all die Praktiken zum Beispiel, die unlöslich mit den Institutionen verknüpft waren. Das könnte durch eingespielte Rituale befördert worden sein. Wie also ist diese Ordnung als zusammenhängendes Ganzes zu begreifen?

Die folgende Betrachtung bezieht sich auf die Ordnung, wie sie sich seit dem Ende der „Ständekämpfe“, also seit dem späteren vierten Jahrhundert einspielte (wobei gewisse Differenzierungen, die sie mit der Zeit erfuhr, einzubeziehen sind). Es sollen zunächst zwei historische Ausgangsbedingungen ins Auge gefaßt werden: das von den Anfängen der Republik (der Erbschaft der Monarchie und dem Patriciat) her Nachwirkende (III) sowie die „Ständekämpfe“ (IV). Im einen wie andern Fall erfolgten überaus wichtige Weichenstellungen für die Zukunft.

Ein erster Schnitt durch die Ordnung, wie sie sich damit herausgebildet hatte, soll sodann bei den Volksversammlungen angesetzt werden, weil verschiedene von deren Besonderheiten dort gut zu beobachten sind (V). Damit wäre ein Ausgangspunkt für die zusammenhängende Betrachtung einiger wichtiger Vor- und Grundbedingungen römischer Ordnung gewonnen (VI). Auf dieser Basis müßte es möglich sein, das Funktionieren der Ordnung zu fassen, womit nicht zuletzt der römische Adel, seine Streitlizenzen und -begrenzungen, seine viel beschworene Disziplin samt der Voraussetzungen seiner Handlungsfähigkeit zum Thema werden (VII). Wie man die

dersetzungen müßten sich Spuren in den Quellen finden (vgl. für die späte Republik Meier, RPA [wie Anm. 2], I63 ff., I 74 ff.). Auch dem Studium von Consullisten und Verwandtschaftsverhältnissen ist, genau besehen, nichts dergleichen zu entnehmen. Zu Friedrich Münzer, Römische Adelsparteien und Adelsfamilien. Stuttgart I920, unten S. 628 sowie jetzt Karl-Joachim Hölkeskamp, Friedrich Münzer - Werk und Wirkung, in: Friedrich Münzer, Kleine Schriften. Hrsg v. Matthias Haake u. Ann-Cathrin Harders. Stuttgart 20I2, XIIIXCVI. Mit den Faktionen fehlten auch die „Binnenräume“, in denen sich unterschiedliche Auffassungen nicht nur über Politik, sondern möglicherweise auch über die Ordnung hätten stabilisieren können. So konnte weithin die Gesamtheit des Senats, wohl auch der Bürgerschaft, die Instanz bleiben, deren Akzeptanz zu suchen war. Die Tatsache, daß (mit einer wenn überhaupt möglichen, so jedenfalls an eine bestimmte Situation gebundenen Ausnahme, unten S. I 16) irgend beachtliche Versuche, mit Hilfe der Volksversammlung gegen die Senatsmehrheit größere Macht zu begründen, nicht vorgekommen sind, spricht deutlich gegen die Existenz solcher Faktionen. Vgl. auch die Bedenken von Peter A. Brunt, Factions, in: ders., The Fall of the Roman Republic. Oxford I988, 443-502. 
ganze Ordnung in möglichst kurzen Formulierungen begreifen kann, sollte am Schluß deutlich werden (VIII).

Die Betrachtung geht notgedrungen über unzählige Einzelheiten hinweg. Sie ist makroskopisch und grobschlächtig. Sie sucht sich vornehmlich auf das kaum Bestreitbare zu stützen. Beruht für die Anfänge wesentlich auf Rückschlüssen aus der gut bezeugten späteren, nicht auf zweifelhaften Quellenaussagen zur früheren Zeit. Vorausgesetzt ist dabei, daß bestimmte Gegebenheiten in der frühen Zeit einfach deswegen vorhanden gewesen sein müssen, weil sie in den Verhältnissen der späteren kaum herangewachsen sein können; sie waren allenfalls noch zu modifizieren. Die Zuverlässigkeit der Rückschlüsse wird dadurch erhöht, daß die Römer dazu tendierten, möglichst vieles seit früher Zeit sehr genau zu bewahren.

Die Elemente der Ordnung sind zumeist bekannt. ${ }^{16}$ Man muß sich ihrer gleichwohl vergewissern, um das zu eruieren, worum es hier geht: die Verhältnisse, zu denen sie sich gefügt haben und in deren Rahmen sie zu verstehen sind, die Zusammenhänge, in denen sie wirken konnten und zugleich ihre Grenze fanden - sowie schließlich den großen Zusammenhang, als der das Ganze dieser Ordnung zu begreifen ist. ${ }^{17}$ Die späte Republik bleibt in der Regel außerhalb der Betrachtung.

III.

Am Anfang der Republik stand der Adel. Da er nicht nur einen König, sondern die Monarchie gestürzt hatte, brauchte er ein Organ, mit dessen Hilfe er alle gemeinsam interessierenden Angelegenheiten regeln konnte. Die Wahrscheinlichkeit spricht dafür, daß es den Senat damals schon gegeben hat. Er muß jedenfalls über kurz oder lang ins Zentrum der Politik gerückt sein, das er, indes in einer langen wechselvollen Geschichte $^{18}$, bis zum Ende der Republik innegehabt hat. Seine Führung, seine Ver-

I6 Die Belege sind in Theodor Mommsen, Römisches Staatsrecht. 3 Bde. in 5. 3.Aufl. Leipzig I887/88, neuerdings vielfach auch bei Kunkel, Staatsordnung (wie Anm. I), leicht zu greifen. Zusätzlich wäre auf Kurt Latte, Römische Religionsgeschichte. München I96o, zu verweisen. Deswegen verzichte ich darauf, sie anzuführen, sofern nicht besonderer Anlaß dafür besteht.

I7 Die Betrachtung hat natürlich vieles einzubeziehen, was Hölkeskamp und andere unter dem Rubrum „politische Kultur“ versammeln; was immer damit genauer gemeint sein mag. Aber ihr Interesse ist eben spezifischer oder allgemeiner, wie man will; jedenfalls auf den Zusammenhang des Ganzen dessen gerichtet, was als Ordnung der Republik zu begreifen ist. 
antwortung scheint schließlich außer Zweifel gestanden zu haben. Beschlossen oder gesetzlich begründet (oder gar eingeschränkt) wurde sie nie.

Zunächst wird der Senat eine Versammlung vornehmlich der Häupter der Adelsgeschlechter gewesen sein. Seit der frühen Mitte des vierten Jahrhunderts jedoch waren es zunehmend die höchsten (und dann auch weitere) Ämter, deren Bekleidung normalerweise über die Zugehörigkeit und bald auch über den Rang in ihm entschied. Zwar waren es auch weiterhin vielfach die Angehörigen des ursprünglichen Adels, des Patriciats, welche die Magistrate innehatten. Aber sie waren dann nicht mehr die einzigen. Und vor allem: es machte einen großen Unterschied, daß die Amtsinhabe für die Zugehörigkeit und zumal für den Rang im Senat maßgeblich wurde.

Eigenartigerweise sind die Obermagistrate, die künftig die Exekutive zu besorgen hatten, zu guten Teilen in die Rolle des Königs eingerückt. Das ergibt sich daraus, daß sie von ihm vermutlich die eigentümliche Mittlerschaft zwischen Gemeinde und übernatürlichen Gewalten, das auspicium, und mit Sicherheit den Amtssessel, eine vereinfachte Form der prächtigen Toga sowie die Liktoren übernahmen, welche ihnen mit ihren Rutenbündeln (anfangs wohl auch mit Beilen darin) eine Tabuzone schaffend voranzugehen pflegten. ${ }^{\text {I9 }}$ Es scheint ein Kapital an Herausgehobenheit vorhanden gewesen zu sein, das wohl nur eine Monarchie ansammeln konnte. In der Hand allein der Obermagistrate lag es in den ersten Jahrhunderten zudem, den Senat einzuberufen (wodurch dessen Handlungsmöglichkeiten verengt waren; wenn der Senat schon aus der Königszeit stammte, meinte man offenbar nicht oder kam nicht darauf, die ursprüngliche Konstellation aufgeben zu können, innerhalb derer der König die Herren einberief, wenn er sich mit ihnen beraten wollte). Vermutlich lag es zunächst auch bei den Obermagistraten, den Senat durch Ernennung neuer Mitglieder zu ergänzen (wobei eventuell Rücksicht auf die Ansprüche großer Geschlechter zu nehmen war). Auch die Volksversammlung konnte nur unter der Leitung des Obermagistrats zusammentreten und beschließen.

Dies alles kann kaum bloß Zierde oder nur formale Befugnis gewesen sein. Vielmehr wird sich in der Aura der Magistrate Überlegenheit und Macht symbolisiert

Die Entstehung der Nobilität. Studien zur sozialen und politischen Geschichte der Römischen Republik im 4.Jh. v.Chr. Stuttgart I987, 2. erw. Aufl. Stuttgart 20 I I.

I9 Karl-Joachim Hölkeskamp, Rekonstruktionen einer Republik. Die politische Kultur des antiken Rom und die Forschung der letzten Jahrzehnte. (HZ, Beihefte, NF., Bd. 38.) München 2004, 64f.; Burkhard Gladigow, Die sakralen Funktionen der Liktoren. Zum Problem von institutioneller Macht und sakraler Präsentation, in: Temporini (Hrsg.), Aufstieg (wie Anm. I8), Bd. I 2, 295-3I 3. 
haben. ${ }^{20}$ Und das wirkte. Die Liktoren waren keine Polizeieinheit. Sie konnten Einzelne verhaften oder bestrafen; gegen eine Menge waren sie hilflos. Insofern waren sie darauf angewiesen, ihrerseits Respekt zu genießen. Wenn das nicht, zumindest in aller Regel, geschehen wäre, hätten sie und ihr Auftreten nicht überdauern können.

Und umgekehrt: So großartig die Magistrate daherkamen und so wenig ihre Befugnisse formal begrenzt waren - mit den ausgeprägten Formen ihrer Herausgehobenheit können, ja müssen doch wohl Eingrenzungen verknüpft gewesen sein, sei es von innen, sei es von außen, die ihre Verfügungsmacht letztlich doch in Grenzen hielten; die es zuließen, innerhalb dieser Grenzen machtvoll zu handeln, die es aber ausschlossen, sich jenseits davon einfach durchzusetzen.

Man kann sich fragen, ob die Römer damals bewußt unterschieden zwischen monarchischer Macht und Prominenz, welche sie als nützlich, vielleicht gar (etwa angesichts äußerer Gefahren) als notwendig erachteten, und der Willkür, mit der das Königtum zuletzt gewaltet haben muß (wenn jedenfalls die Überlieferungen über den letzten König nicht Legende waren). Wahrscheinlicher aber scheint mir, daß man sich eine führende Person überhaupt nicht anders als mit weitgehender Kompetenz - und Amtscharisma - ausgestattet vorstellen konnte. Wobei insbesondere die Auspizien samt der sakralen Aura, die den, der sie einzuholen vermochte, umgab, als unentbehrlich erschienen sein müssen.

Indes konnte man die Macht der Magistrate - wenn nicht sofort, so bald darauf dadurch eingrenzen, daß man sie nur ein Jahr lang amtieren ließ. Gleichzeitig (so die Überlieferung) oder später (so zum Teil die Forschung ${ }^{2 \mathrm{I}}$ ) wurde die Zweistelligkeit des Obermagistrats eingeführt. Mit ihr verband sich ein neues Element, die Collegialität: Grundsätzlich waren beide zusammen für alles, was sie taten, verantwortlich. Praktisch bedeutete das, daß jeder Akt des einen durch den andern verhindert werden konnte (sofern sie am gleichen Platz agierten).

Eine weitere Einschränkung der Macht der Obermagistrate erfolgte später auf Druck von unten: Sie betraf deren zunächst unbegrenzte Polizeigewalt: Die Bürger

20 Alfred Heuß, Zur Entwicklung des Imperiums der römischen Oberbeamten (I944), in: ders., Gesammelte Schriften in 3 Bänden. Stuttgart I995, Bd. 2, 83 I-907, rechnet nach meinem Urteil zu selbstverständlich damit, daß Roms Adlige damals frei waren, die Dinge nach ihrem Gusto zu regeln. Äußerlich waren sie es, schließlich hatten sie alle Macht. Aber wie weit waren sie es in ihren Vorstellungen?

2 I Z.B. Gelzer, Kleine Schriften I (wie Anm. 2), 295; Jochen Bleicken, Die Verfassung der Römischen Republik. Paderborn I975, 76 . 
erhielten durch Gesetz das Recht, dagegen an die Volksversammlung zu appellieren (provocatio). ${ }^{22}$

Vor allem scheint sich in den Händen des Senats große Macht versammelt zu haben. Für ihn fiel ins Gewicht, daß er die zentrale Instanz des Adels war, die die Jahre in weitgehend gleichbleibender (nur durch den Tod von Mitgliedern und das Nachrücken anderer modifizierter) Zusammensetzung überdauerte. Alles, was Rang und Namen hatte, versammelte sich in ihm. Folglich vereinten sich hier Erfahrung, Wissen, Beziehungen, Macht. Die Magistrate müssen in der Regel aus den Reihen der Senatoren hervorgegangen sein und künftig unter ihnen wieder Platz genommen haben.

Voraussetzung für den Einfluß des Senats war freilich, zumindest auf die Dauer, daß er, wenn es darauf ankam, geschlossen zu handeln vermochte. Wenn dem so war, und das scheint der Fall gewesen zu sein, so zeichneten sich erstaunlicherweise in der frühen Republik sowohl der Senat wie die Magistrate durch starke Positionen aus. Um so mehr waren sie aufeinander angewiesen, hatten sich mit Respekt zu begegnen. Beide Seiten waren zudem eingebunden in überkommene Horizonte, in Anschauungen und ein ganzes Netz letztlich religiös verankerter Formen.

Die Magistrate waren nicht einfach mit einem Amt Betraute oder Beauftragte des Senats oder wessen auch immer, sondern fußten auf eigenem Recht, eigener Verantwortung. Das auspicium, also das Recht, den Himmel namens der Gemeinde auf Zeichen zu beobachten, ihr ursprünglich wohl bedeutendstes, auf dessen richtige Ausübung dieses eigentümliche Gemeinwesen sich angewiesen sah, war von solcher Qualität, daß es sich nur vom einen auf den andern weiterreichen ließ. Sobald (oder sofern) sie durch Wahl bestellt wurden, ging es lediglich darum, wer Obermagistrat sein sollte. Nicht jedoch konnte die Wahl Quelle seines Rechts, seiner Wirkensmöglichkeiten sein. So der ursprünglichen Auffassung nach, die sich wohl nie ganz verlor. ${ }^{23}$ Es war der Vorgänger, der den Nachfolger zum Obermagistrat „krëierte“ (creare

22 Meier, RPA (wie Anm. 2), 52; Wilfried Nippel, Aufruhr und „Polizei“ in der Römischen Republik. Stuttgart I988, I 3 ff.; Kunkel, Staatsordnung (wie Anm. I), I66ff.

23 Cicero sagt zwar (de lege agraria 2,I 7), alle imperia gingen vom ganzen Volk aus (ab universo populi Romani proficisci), aber er meint damit, daß eine kleinere Versammlung dafür nicht hinreichend sei. Natürlich ist die Wahl durch das Volk Voraussetzung für die Bekleidung des Obermagistrats, aber nicht die einzige. Die creatio durch den Vorgänger mußte hinzukommen (Kunkel, Staatsordnung [wie Anm. I], 36). Sie wird vollzogen durch den Akt der renuntiatio. Und sie betrifft speziell das auspicium (das im Fall der Vakanz an die patricischen Senatsmitglieder zurückfällt, also von ihnen ausgeht). Wie sich die lex curiata de imperio, 
war der Terminus technicus dafür). Nicht gegen die Abstimmung durch das Volk, aber gegen die renuntiatio, die öffentliche Ausrufung der neugewählten Consuln konnten Volkstribunen intercedieren. ${ }^{24}$ Sie war also ein eigenständiger Akt des die Wahl leitenden Magistrats. Ohne ihn kam die Wahl nicht zum Abschluß.

Wurde die Reihe einmal unterbrochen, mußte sie durch Zwischenschaltung der aus den ältesten, den patricischen Adelsfamilien stammenden Senatsmitglieder wiederhergestellt werden. Auspicia ad patres redeunt, hieß es dann: die Auspicien kehren zu den Vätern zurück. Anscheinend sind sie also ursprünglich - und bei Bedarf stets von neuem - von ihnen ausgegangen, somit ihnen zu eigen gewesen. ${ }^{25}$ Im Fall einer Vakanz konnten die Patricier aber nicht selber einen neuen Obermagistrat wählen lassen (wohl weil nur ein Obermagistrat die dazu notwendigen Auspicien einholen konnte), sondern sie mußten einen Interrex bestellen (wie es ihn in der Königszeit gegeben haben muß), für fünf Tage. Auch der konnte keine Wahl abhalten, wohl weil er ohne die notwendigen Auspicien eingesetzt werden mußte; aber der von ihm - und nun wohl, wie auch immer, mit den notwendigen Auspicien ernannte-Nachfolger (oder ein weiterer Interrex) konnte es. Wolfgang Kunkel spricht von „einer Mischung von Primitivität und juristischer Raffinesse“. ${ }^{26}$ Jedenfalls zeigt sich auch in diesem Detail, wie bedeutsam die Kette von Magistrat zu Magistrat war. Und es wird zugleich die in „primitiven“, aber offenbar lebhaften Vorstellungen beruhende außerordentliche Befähigung der Patricier sinnfällig. Eine lex de imperio ${ }^{27}$ scheint dem Obermagistrat zusätzlich zur renuntiatio seine militärischen Machtbefugnisse bestätigt - oder überhaupt erst verliehen? - zu haben. Dafür war eine besondere Volksversammlung notwendig, die ursprünglich vielleicht nur aus Patriciern bestanden hat. Während seines Amtsjahrs war der Magistrat unabsetzbar.

Das Widerspiel, das sich zwischen Senat und Obermagistraten herausbildete, kann nicht einfach gewesen sein. Dem Senat mußte daran gelegen sein, daß die

die ebenfalls zur Bestellung der Obermagistrate gehört, in diesen Reigen einfügt, ist nicht auszumachen (vgl. unten Anm. 27). Meiner Vermutung nach ist sie der zwar eigentlich erübrigte, aber konservierte Überrest des ursprünglichen Wahl- (oder Akklamations-Akts) der Versammlung der Gesamtheit (s. unten S. 654f.).

24 Kunkel, Staatsordnung (wie Anm. I), 2 I 3 Anm. 395.

25 Alfred Heuß, Gedanken und Vermutungen zur frühen römischen Regierungsgewalt (I983), in: ders., Schriften (wie Anm. 20), Bd. 2, 908-985, hier 950 ff.

26 Kunkel, Staatsordnung (wie Anm. I), 35.

27 Dazu André Magdelain, Recherches sur l'Imperium, la loi curiate et les auspices d'investiture. Paris I968. 
Obermagistrate dem Volk (zumal wenn Unzufriedenheit oder Unruhe aufkamen) mit Macht entgegentreten konnten. Andererseits konnten die Obermagistrate, wie die Geschichte der Republik zeigt, zu Eigenmächtigkeit neigen. ${ }^{28}$ Wohl erwies sich der Senat am Ende zumeist als der Stärkere. Doch hatte er die, gern betonte, fides, die Verantwortung des Magistrats zu respektieren. Die daraus sich ergebenden Reibungen und Konflikte mochten gelegentlich störend sein. Doch war die Ordnung der Republik nicht darauf angelegt, für irgendwen bequem zu sein. Im Endeffekt waren den Auseinandersetzungen klare Grenzen gesetzt.

Stärkere Auswirkungen auf die Ordnung hätten die Kollisionen zwischen Senat und Magistraten auf die Dauer nur zeitigen können, wenn die Politik durch Faktionen bestimmt worden wäre. Dann nämlich hätten die Magistrate längerfristig mit den einen Senatoren gegen die anderen agieren, oder die Faktionen hätten sie in ihren Dienst nehmen, eventuell hätte auch die Volksversammlung in die Konflikte einbezogen werden können. Doch scheint das ja eben nicht oder jedenfalls nicht über einzelne Situationen hinaus der Fall gewesen zu sein. Anders wäre es nicht möglich gewesen, daß der Senat, aufs Ganze gesehen, die Oberhand über die Republik bewahrte; daß er zum Beispiel auch die Verfügung über die Mittel, Finanzen und Armeen gewann, auf die die Magistrate angewiesen waren, wenn sie - nach außen - Größeres ins Werk setzen wollten (worin ja bald die wichtigste Bewährungsform bestand).

Senatoren und Magistrate wurden ursprünglich - und das sollte für die folgende Zeit jedenfalls von großer Bedeutung sein - von Patriciern gestellt, den Mitgliedern eines kleinen, mit großen Privilegien ausgestatteten Kreises alter Familien, welcher sich - spätestens in den Anfangsjahren der Republik - nach außen abgeschlossen hatte. Bis zu Caesars Zeiten wurde keiner mehr in ihn aufgenommen.

Diese Patricier standen insgesamt in einem besonderen Nahverhältnis zu Überirdischen Gewalten. Nicht aufgrund konstruierter Abstammung einzelner Geschlechter, schon gar nicht weil sie Götterlieblinge gewesen wären, sondern in der Nachfolge derer, die einst das Gemeinwesen mehr oder weniger ausgemacht und dabei diese besondere Verbindung begründet, wohl auch erfahren und dann befestigt hatten.

Mit ihrem über erstaunlich lange Zeit erfolgreich behaupteten Anspruch, allein

28 Mommsen, Staatsrecht (wie Anm. I6), Bd. I, 57. Ein krasses Beispiel: Hölkeskamp, Entstehung (wie Anm. I8), I87ff. 
befähigt zu sein, den Willen der Götter zu erkunden und zu interpretieren, war vermacht, daß sie über mehr als ein Jahrhundert hinweg das Monopol auf die Bekleidung der Magistrate behaupten konnten. Sie waren über noch längere Zeit auch die einzigen, die die für Rom charakteristischen einflußreichen hohen Priesterschaften besetzten, denen die Deutung verschiedenster Götterzeichen und damit wichtige, auch politische Aufsichtsfunktionen oblagen, die sie im Einklang mit dem Senat auszuüben hatten. Aufgrund der besonderen Mittlerstellung der Patricier zwischen überirdischen Gewalten und römischem Gemeinwesen war man weitgehend von ihnen abhängig. Zunächst und über viele Jahrzente hin bedurften Gesetzesbeschlüsse und Wahlen der auctoritas der patricischen Senatsmitglieder, um gültig zu sein. ${ }^{29}$

Nachdem Nichtpatricier zu den höchsten Ämtern zugelassen worden waren, blieb es noch für nahezu zwei Jahrhunderte dabei, daß zumindest einer der beiden Consuln Patricier war (obwohl deren Kreis mit der Zeit stark schrumpfte). Auch nach deren Zulassung hat man eine ganze Weile lang versucht, die plebejischen Consuln zumindest von der Wahlleitung fernzuhalten. ${ }^{30}$ Außerdem scheinen weiterhin auch innerhalb der Rangklassen des Senats Patricier als erste aufgerufen worden zu sein. ${ }^{3 \mathrm{I}}$ Von irgendeinem Zeitpunkt an, jedenfalls früher als zu den höheren Magistraten, konnten Nichtpatricier dem Senat als Mitglieder „zugeschrieben“ werden, als conscripti. An die sollte sich der zweite Teil der Anrede im Senat auch weiterhin richten: patres conscripti. Es scheint sehr viel leichter gewesen zu sein, sie in den Senat aufzunehmen als ihnen Ämter anzuvertrauen. Zu sehr verknüpfte sich die hochgetriebene, religiös gut verankerte Vorstellung des Amtes lange Zeit mit jenen Qualitäten, von denen die Patricier so gut, daß ihnen so leicht nicht zu widersprechen war, behaupten konnten, sie seien ihnen allein eigen.

Es gehört zu den geradezu unheimlich anmutenden Eigenheiten Roms, daß bei den beiden großen frühen Neuerungen, dem Sturz der Monarchie wie dem bald darauf folgenden Sich-Aufbäumen der Plebs, wesentliche Züge des Alten übernommen, vielleicht gar befestigt, jedenfalls modifiziert überlebensfähig gemacht wurden. So konnten viele zum guten Teil religiös begründete, die ganze Bürgerschaft durchwaltende Gebundenheiten bewahrt bleiben. Dank einer Disziplin, welche sie nie hätte hervorbringen können, sie aber zu hegen - und aus ihr Kraft zu beziehen - wußte.

29 Bleicken, Lex (wie Anm. I I), $294 \mathrm{ff}$.

30 Hölkeskamp, Entstehung (wie Anm. I 8), 62 ff.

3I Mommsen hat das wahrscheinlich gemacht: Staatsrecht (wie Anm. I6), Bd. 3, 967. 
Wobei freilich, und ebenso erstaunlicherweise, eine bemerkenswerte Elastizität (alias: Rücksichtnahme) sich ihr beigesellte.

IV.

I. Gleichgültig, wie es um Anlaß, Formen und Daten der bald nach Begründung der Republik einsetzenden „Ständekämpfe“ bestellt war, ihr Ansatz bezeugt, wie überlegen die Patricier weit über die Anfänge der Republik hinaus allen andern gegenüber gewesen sein müssen. Wir kennen für sie keine Parallele in der Weltgeschichte.

Schon in der Königszeit scheint Rom eine frühe Form der Versammlung der Gesamtgemeinde, die sogenannten comitia curiata gehabt zu haben. Vielleicht traten in ihr ursprünglich nur die Patricier, hier freilich in ihrer Gesamtheit, zusammen; wenn sie nämlich damals, was nicht auszuschließen ist, allein vollberechtigte Mitglieder des römischen Gemeinwesens waren.

Eine zweite Versammlung der Gesamtgemeinde, die comitia centuriata, muß von vornherein Patricier und zahlreiche andere umfaßt haben (von denen ein nicht genauer zu bestimmender Teil den Patriciern als Clienten anhing). Grob gesagt handelte es sich um die Heeresversammlung. Die Entstehung dieser Comitien gehört wohl in die ersten Jahrzehnte der Republik.

Ob es jedoch die Centuriatcomitien damals nun schon gab oder nicht, größere Teile der (inzwischen möglicherweise erweiterten) breiteren Bürgerschaft haben sich unseren Quellen zufolge in eben den ersten Jahrzehnten der Republik zu einer Art Sondergemeinde zusammengetan und das Recht ertrotzt, in eigenen Versammlungen, in einer dritten Form der Volksversammlung also zusammenzutreten. Sie wollten eigene Amtsträger, die tribuni plebis wählen und gemeinsam Resolutionen (auf Antrag von Tribunen) fassen, um Forderungen mit Nachdruck vorzubringen. Wer diese plebs eigentlich war - ungebundene Bauern, Handwerker, Tagelöhner? Freigewordene Clienten des Königs? Zugewanderte? Oder auch Adelsgeschlechter samt Anhang, die aus dem Kreis der Patricier ausgegrenzt worden waren? - ist offen. Jedenfalls waren sie ein Teil, während die Patricier für das Ganze standen.

Wie man weiß, verschworen sie sich zum Schutz der Volkstribunen: Die sollten sacrosanct, das heißt unverletzlich sein. Wer ihnen ein Haar krümmte oder sie in ihrer Amtsführung beeinträchtigte, sollte der Rache verfallen, und diese Rache soll- 
te straffrei sein. Den Tribunen wurde der Auftrag erteilt, einzelnen Plebejern gegen Willkürakte der Magistrate (oder was sie dafür hielten) beizustehen, woraus sich dann ein ius auxilii entwickelte. Sie praktizierten es so wirkungsvoll, daß aus ihrem „Dazwischentreten“ (intercedere) ein erfolgreich erhobener Anspruch wurde, der auf die Dauer weit über solche Hilfeleistung hinausging; das sogenannte Veto, das innerhalb der Stadt Rom bald gegenüber vielen Amtshandlungen eines Magistrats, später auch gegen Senatsbeschlüsse eingelegt werden konnte.

Es vollzog sich somit in den Anfangszeiten der Republik etwas höchst Erstaunliches. Da ist eine große Zahl von Bürgern unzufrieden, ja sie empört sich. Sie wollen zu Wort kommen, etwas ändern. Aber durch direkte Einwirkung auf die existierenden Institutionen, Magistrate, Senat oder Volksversammlung (sofern es die Centuriatcomitien schon gab) können sie das nicht erreichen. Vielleicht weil sie keine Mehrheit in den Comitien erzielen, vielleicht weil sie die patricischen Magistrate nicht dazu bewegen können, entsprechende Abstimmungen (für die ja die Einholung von Auspicien notwendig war) zuzulassen. Statt sich also in den alten Formen durchzusetzen oder auch: sie zu sprengen, gerinnt die Empörung in die neue Form einer Sondergemeinde innerhalb der Gesamtbürgerschaft. Man kann und/oder will die Macht des alten Adels und der von ihm dominierten Institutionen nicht zerstören, sondern man organisiert sich innerhalb der bestehenden Ordnung als Opposition. Und zwar nicht, indem man versucht, sich vermittels einer Vertretung - wie sie etwa die griechischen Volksräte darstellten - regelmäßig im Alltag des Gemeinwesens präsent zu machen, sondern man läßt dort andere für sich agieren (die man schützt, unterstützt und von denen man dann ein Stück weit abhängig wird). Sie übernehmen es, Rechtssicherheit für die einzelnen Bürger zu schaffen, teilweise durch Volksbeschlüsse, weithin in täglicher Praxis. ${ }^{32}$

Im Schwurverband der Plebs trafen - zumindest mit der Zeit ${ }^{33}$ - grob gesagt zwei verschiedene Tendenzen zusammen. Zum einen war da ein engerer Kreis von Familien, die an Vermögen kaum hinter so manchem Patriciergeschlecht zurückstanden. Ihnen ging es um das Recht, sich um die Magistrate der Gesamtgemeinde zu bewer-

32 Wolfgang Kunkel, Bericht über neuere Arbeiten zur römischen Verfassungsgeschichte II (I956), in: ders., Schriften (wie Anm. 2), 479-586, hier 582.

33 Vgl. Kurt A. Raaflaub, From Protection and Defense to Offense and Participation: Stages in the Conflict of the Orders, in: ders. (Ed.), Social Struggles in Archaic Rome. New Perspectives on the Conflict of the Orders. Expanded and updated Edition. Oxford 2005, I85-222. 
ben. Neben ihnen fand sich die breite Schicht derer, die Rechtssicherheit, etwa gegen magistratische Eigenmächtigkeiten bei Aushebungen zum Wehrdienst, bald aber auch die schriftliche Fassung des Rechts anstrebten. Zusätzlich hatten sie wirtschaftliche Beschwerden, aufgrund von Verschuldung, Mißernten und dergleichen, oder forderten die Verteilung eroberten Ackerlandes respektive einen gebührenden Anteil daran.

Wenn es, wie es doch wohl das Wahrscheinlichste ist, prominente Familien waren, die sich die Not breiter Schichten zunutze machten, die Plebs organisierten und die Volkstribunen stellten, so würde sich darin ein interessanter Unterschied zur griechischen Geschichte zeigen. Wo dort einzelne Adlige (mitsamt Faktionsgenossen) verschiedentlich zahlreiche Notleidende hinter sich scharten, um eine Tyrannis zu errichten (auch ihre Standesgenossen ihrer Herrschaft zu unterwerfen), hätten sich hier mehrere Familien vereint, um - bei wirtschaftlich vergleichbar verbreiteter Not - Gleichberechtigung mit den führenden Patriciern anzustreben. $\mathrm{Zu}$ diesem Zweck wäre hier eine Volksführerschaft im Wechsel zwischen mehreren geradezu institutionalisiert worden. Möglicherweise blieb gegenüber dem Patriciat gar nichts anderes übrig; statt daß es also jeweils für einen Einzigen auf einmal ums Ganze einer Herrschaft hätte gehen können, mußten in Rom mehrere mit der Zeit Verbesserungen im einzelnen zu erkämpfen versuchen. Es brauchte dazu einen langen Atem und vermutlich einige Disziplin. ${ }^{34}$

Jedenfalls war einerseits die Plebs stark genug, anfangs um ihre Sondergemeinde auf Dauer zu etablieren, danach um in einem, wenn man den Quellen insoweit trauen kann, mehr als hundertjährigen Kampf neben vielem andern schließlich (wie sich in den Consullisten zeigt) die Zulassung auch von Plebejern zum Consulat durchzusetzen.

Wenn damit auf der anderen Seite, wie immer die „Ständekämpfe“verlaufen sein mögen, der doch recht enge Kreis der Patricier über hinreichend Potential verfügte, um zumindest den Forderungen auf Zulassung von Plebejern zu den Ämtern über lange Zeit hinweg erfolgreich widerstehen zu können, so wurde das zum einen ermöglicht durch die großen Anhängerschaften, über die sie verfügten, die sogenannten Clienten. Die waren ihnen - denen waren in diesen patriarchalischen Verhältnissen aber auch sie - stark verpflichtet, und zwar aufgrund erblicher Bindung. Die

34 Und es scheint viel einfacher gewesen zu sein, die Forderungen der breiten Menge durchzusetzen, als diejenigen derer, die sie anführten (weil die nicht die mit Charisma versehenen Ämter betrafen). 
Herkunft des so bemerkenswerten römischen Clientelwesens - samt den in ihm wirkenden Zügen der Mentalität - ist uns unbekannt. Doch kann es ja wohl nicht erst angesichts der rebellischen Plebs entstanden sein. ${ }^{35}$ Gut möglich ist dagegen, daß es damals auf spezifische Weise befestigt und fortentwickelt wurde, da man die Clienten in hohem Maße brauchte; insofern also wiederum Bewahrung, vielleicht auch Befestigung, jedenfalls Fortbildung alter Institutionen angesichts angestrebter Neuerung.

Ob die Clienten neben Patriciern und Plebejern anfangs eine dritte Statusgruppe gebildet haben, kann hier offenbleiben. Jedenfalls hingen sie den Patriciern an, zumindest in ihrer großen Mehrzahl und regelmäßig. Auch wenn viele von ihnen in manchen Zielsetzungen mit der Kampfgenossenschaft Plebs übereingestimmt (und sich ihr hier und dort vielleicht auch einmal beigesellt) haben mögen. Nicht zuletzt mit ihrer Hilfe könnten die Patricier lange Zeit (wie auch immer) die Versammlungen der Gesamtgemeinde dominiert haben.

Doch kann die langanhaltende Behauptung der Vorrechte der Patricier kaum nur eine Frage von Mehrheiten in Volksversammlungen gewesen sein. Sie muß einen guten Grund vielmehr in ihrem als legitim geltenden Anspruch auf die Magistraturen gehabt haben. Er wurzelte in ihrem Standescharisma ${ }^{36}$, ihrem privilegierten Nahverhältnis zu den Göttern, ihrer besonderen Befähigung zum Achthaben auf Zeichen und Zeremonien wie in der überlegenen Statuskongruenz, zu der sich ihre Vorzüge vereinten, in all dem auch, was das Amtscharisma der Obermagistrate ausmachte. Es muß ihnen gelungen sein, großen Teilen der Bürgerschaft das als selbstverständlich zu vermitteln. Sie mögen auch die Ängste geschürt haben, die zu hegen sie beanspruchten - um auch in diesem Punkt archaische Befangenheiten zu perpetuieren.

Dies alles aber hätten die Patricier kaum bewahren können, wenn sie nicht zwei weitere Bedingungen erfüllt hätten: Zum einen mußten sie sich mit aller Sorgfalt

35 Meier, RPA (wie Anm. 2), 24ff. (am Ende im Sinne des Obigen zu modifizieren). Zu den daraus folgenden Ansprüchen Rolf Rilinger, Der Einfluß des Wahlleiters bei den römischen Konsulwahlen von 366 bis 50 v.Chr. (Vestigia, 24.) München I976, 43 ff., 5 off., I $70 f$.

36 Max Weberspricht (Wirtschaft und Gesellschaft. Grundriss der verstehenden Soziologie. 5., revidierte Auflage, besorgt v. Johannes Winckelmann. Studienausgabe. Tübingen I972, 775) von dem „der charismatischen Adelsbildung überall typischen politischen Merkmal: Abstammung aus einer Familie, in welcher Ämter und Würden bestimmter Art einmal bekleidet worden waren [...].“ Ebd. I 44 zum Amtscharisma; I43, I47 zu Rom; 672 zum Gentilcharisma. 
und Disziplin in engem Zusammenhalt darauf kaprizieren, das Überkommene genau in den rechten Formen zu praktizieren. Zum andern müssen sie damals jene Weisen „ritualisierter Politik“ (E. Flaig ${ }^{37}$ ), jene „zwingenden Gesten“, wenn nicht entwickelt, so doch eingeübt und fortgebildet haben, mit deren Hilfe künftig in Rom geherrscht wurde; alle Ungleichheit abfedernd durch Respekterweisungen gegenüber dem Volk, alle Konflikte elastisch, eventuell mit Jovialität ${ }^{38}$ auffangend (und sofern sie in der Aristokratie ausbrachen, sie eng begrenzend), nichts überspannend und gleichwohl das Wesentliche behauptend, so lange es ging. Nahezu wunderbarer Weise, wie es scheint.

Die Patricier hatten keine Polizei, und von ihren Clienten konnten sie wohl auch nicht gerade Gehorsam in inneren Kämpfen erwarten. Sie hätten sich, was immer sie gelegentlich versucht haben mögen, kaum behaupten können, wenn sich nicht unter ihnen stets neu die Einsicht durchgesetzt hätte, daß es besser war, hier und da nachzugeben als Gefechte zu riskieren, in denen alles auf dem Spiel stehen konnte. Es mag günstig für sie gewesen sein, daß sie für die Gesamtgemeinde stehen konnten, während die plebs nur einen Teil darstellte. Sofern die Einheit der Republik in Frage gezogen wurde - und das scheint ja etwa bei der secessio plebis der Fall gewesen zu sein - müssen schließlich Zugeständnisse dazu beigetragen haben, daß sie neu befestigt wurde. Dabei ist es besonders interessant, daß man in Phasen der Zuspitzung gelegentlich einen Dictator ernannte, jenen außerordentlichen Magistrat also, der (um von Sonderfällen abzusehen) in besonders kritischen Situationen, zumeist im Krieg, eingesetzt wurde, um unter Zusammenfassung aller Kräfte, unter Zurückdämmung aller möglichen Einsprüche, das Notwendige ins Werk zu setzen. Im Falle innerer Unruhen pflegten die Dictatoren interessanterweise gerade nicht mit Gewalt vorzugehen, vielmehr mit aller Macht auf Zugeständnisse und damit die Wiederherstellung der Concordia hinzuwirken. ${ }^{39}$

37 So der Titel seines 2003 in Göttingen erschienenen Buches (2.Aufl. 2004). Untertitel: Zeichen, Gesten und Herrschaft im Alten Rom. Anders als in Meier, RPA (wie Anm. 2), I 22 Anm. 357, ist doch wohl anzunehmen, daß die Patricier eine gewisse Elastizität im Umgang mit der Plebs schon im Laufe der „Ständekämpfe" einübten.

38 Martin Jehne, Jovialität und Freiheit. Zur Institutionalität der Beziehungen zwischen Ober- und Unterschichten in der römischen Republik, in: Bernhard Linke/ Michael Stemmler (Hrsg.), Mos maiorum. Untersuchungen zu den Formen der Identitätsstiftung und Stabilisierung in der römischen Republik. Stuttgart 2000, 207-235.

39 Giovanni Meloni, Dictatura popularis, in: François Hinard (Ed.), Dictatures. Actes de la table ronde réunie à Paris les 27 et 28 février I984. Paris I988, 73-86. Dazu unten S.687. 
Was immer man aber über die konkreten Machtverhältnisse annehmen will: Man wird festhalten können, daß in all den Kämpfen das Befangensein der Römer in der göttlich sanktionierten Ordnung nicht erschüttert worden ist. Die Plebs samt ihrer Führerschicht fügte sich ihr unter der Bedingung ein, daß sie ihre Rechte und Interessen verfechten konnte (ohne übrigens in ihren eigenen Aktivitäten religiöse Rücksichten üben zu müssen). Sie blieb Teil in einem übergreifenden Ganzen.

2. Irgendwie müssen sich Patricier und Plebejer lange die Waage gehalten haben. Beide waren sie mächtig, je auf verschiedene Weise. Im Endeffekt aber wollte oder konnte sich keiner aus dem Zusammenhang der gemeinsamen Ordnung ausklinken, im Gegenteil: dieser Zusammenhang scheint auf die Dauer dadurch gestärkt worden zu sein, daß sich die Minderberechtigten innerhalb seiner nur stärker zur Geltung bringen wollten und - konnten. Denn es blieb ja dabei, daß sich die Plebejer, abgesehen von der Gleichstellung ihrer Führer mit den Patriciern, nur Freiheitsrechte, Schutz sowie Möglichkeiten zu wirksamer Notwehr und zu einigen Verbesserungen ihrer Lage verschaffen wollten. Sollte irgendwer die Absicht gehegt haben, mitsamt der plebs eine größere Rolle in der Republik zu spielen, so wäre das steckengeblieben. Dabei wäre Rom zunächst noch klein genug gewesen, um stärkere, regelmäßige Mitwirkung breiterer Bürgerschichten an der Führung zu ermöglichen; etwa nach griechischem Vorbild. Die Volkstribunen blieben also in ihren Zielsetzungen, wenn nicht von selbst, so durch das Gegenüber der mächtigen, zusammenhaltenden Patricier beschränkt.

Innerhalb des Schwurverbandes der plebs werden sich mit der Zeit ähnliche Strukturen eingependelt haben wie in der übrigen Bürgerschaft. Ihre Vorkämpfer begründeten ihrerseits Anhängerschaften. Viele Plebejer waren ihnen zu Dank verpflichtet. Die Bindekraft solcher Dankbarkeit, die später bezeugt ist, aber kaum erst später aufgekommen sein kann, führte dazu, daß sich in der Plebs die Struktur des ganzen Gemeinwesens mit der deutlichen Überlegenheit der Höheren über die Niederen wiederholte; auch mit den Verpflichtungen, die jene gegenüber diesen (wie gegenüber der res publica) zu erfüllen hatten.

Der Weg zum Ausgleich zwischen Patriciern und Plebejern könnte durch militärische Mißerfolge unter patricischer Führung gebahnt worden sein. ${ }^{40}$ Heiratsverbindungen erleichterten den Übergang. ${ }^{4 \mathrm{I}}$ Jedenfalls gab es anscheinend keine Mög-

40 Hölkeskamp, Entstehung (wie Anm. I8), 39.

4I Münzer, Adelsparteien (wie Anm. I5), $8 \mathrm{ff}$. 
lichkeit (oder kein Bedürfnis), die Patricier abzuservieren. Die führenden Plebejer konnten (und wollten) folglich nur mit ihnen teilen. Leicht zu verstehen ist das nach all den Benachteiligungen, die sie erlitten hatten, nicht. Sind auch sie nicht so leicht von dem Bann losgekommen, in den die Patricier das Gemeinwesen geschlagen hatten? Jedenfalls wußten sie nichts Besseres, als mit ihnen gleichzuziehen. Die Patricier mögen ihnen zuletzt entgegengekommen sein.

366 wurde das patricische Monopol auf die Bekleidung der Obermagistrate aufgehoben. Nach kurzer Zeit spielte es sich ein, daß stets einer der Consuln Plebejer war. Die andere Stelle dagegen pflegte, wie schon erwähnt, noch sehr lange Zeit mit einem Patricier besetzt zu werden. 300 v.Chr. wurden auch die hohen Priesterämter den Plebejern zugänglich. Nach I 3 weiteren Jahren (287 v. Chr.) wurde beschlossen, daß die Resolutionen der plebs (plebiscita) Gesetzeskraft haben sollten. Man befürchtete, und mit gutem Grund, wohl kaum, daß die Volkstribunen die ihnen damit zuwachsende Macht mißbrauchen könnten; sei es (was wohl das wahrscheinlichste ist), weil keiner auf die Idee kam, sie könnten größere Vorhaben etwa im Sinne einer stärkeren Einwirkung des Volkes auf die Ordnung und die Politik der Republik verfolgen ${ }^{42}$; sei es, weil man sicher war, sie an der Durchsetzung solcher Pläne, falls sie sie denn wirklich entwickeln sollten, vermittels des Vetos von Collegen oder durch andere Mittel hindern zu können. Was sie dagegen sehr wohl künftig können sollten, war, bei Gelegenheit gegen größere Beeinträchtigungen der rechtlichen und wirtschaftlichen Lage der Plebs Abhilfe zu schaffen durch bindende Volksbeschlüsse. Der Ordnung wurde auf diese Weise ein Ventil eingebaut, dank dessen bei gewissen Spannungen Überdruck abgelassen werden konnte. Der Ausnahmefall konnte somit Ausnahme bleiben, so daß die Regel Regel blieb. Daher wurde durch die Reform von 287 zumal die Klaviatur der Republik erweitert.

3. Die „Ständekämpfe“ haben die Ausformung der klassischen römischen Ordnung entscheidend mitbestimmt. Die Konstituierung der Plebs, das Einfangen von Unzufriedenheit und Empörung in die geregelten Bahnen einer institutionalisierten, zu mancherlei bindenden Entscheidungen befähigten Opposition hat wesentlich zum Abbau von Spannungen und zur Integration der Bürgerschaft beigetra-

42 Unter den damaligen Voraussetzungen mag auch der Gedanke ferngelegen haben, an die concilia plebis könnten Anträge gestellt werden, die nicht im speziellen Sinne die Plebs betrafen (Jochen Bleicken, Das Volkstribunat der klassischen Republik. Studien zu seiner Entwicklung zwischen 287 und I33 v.Chr. [Zetemata, I3.] München I955, 25). 
gen. ${ }^{43}$ Die plebejischen Institutionen, zumal das Volkstribunat, haben die römische Ordnung um wichtige Möglichkeiten der Kontrolle (etwa von Magistraten), der Einschränkung von Willkür und der Herbeiführung von Beratung und Ausgleich bereichert. $^{44}$

Wenn der römische Bürgerbegriff künftig vornehmlich durch die starke Ausbildung von Freiheitsrechten (und viel weniger durch den Drang zur Mitsprache in politicis) charakterisiert war, so ist dies vor allem der spezifischen Form des plebejischen Aufbegehrens zu verdanken.

Zugleich ist der römische Adel dadurch gestärkt worden, daß sich in ihm mächtige plebejische Geschlechter mit den Patriciern verbanden. Neben der Herkunft wurde es jetzt die Bekleidung von Ämtern, also die Wahl durch die Volksversammlung sowie die Mitgliedschaft im Senat, die über die Zugehörigkeit entschied, übrigens - da manch einer zwar nicht die höchsten, aber doch niedere Ämter erreichen konnte - auch über den Rang innerhalb der Führungsschicht.

So entstand ein Senatsadel, aus dem sich der engere Kreis der patricisch-plebejischen Nobilität heraushob, welcher diejenigen umfaßte, die die höchsten Ämter bekleidet hatten ${ }^{45}$; samt deren Nachkommen. Was zuvor schon (aus ganz anderen Gründen) für die Patricier der Fall gewesen war, bürgerte sich jetzt in minderem Ausmaß auch unter den sich ihnen zugesellenden Plebejern ein, eine Art Exklusivität.

\footnotetext{
43 Flaig, Ritualisierte Politik (wie Anm.37), I6.

44 Vgl. unten S.674ff..

45 Das waren in der späten Republik die Consulare (ein Kreis, in den zuletzt nur mehr jeder vierte Praetor aufstieg): Gelzer, Kleine Schriften I (wie Anm. 2), 39f. Vorher mögen es schon diejenigen gewesen sein, die die curulische Aedilität bekleidet hatten; vgl. Adam Afzelius, Zur Definition der römischen Nobilität vor der Zeit Ciceros, in: CM I, I 938, 40-94 und CM 7, I 945, I 50-200. Was gegen Gelzers These (etwa von Jochen Bleicken, Die Nobilität der römischen Republik, in: Gymnasium 88, I 981, 236-253, und Peter A. Brunt, Nobilitas and Novitas, in: JRS 72, I982, I-I7) vorgebracht wurde, scheint mir nur dafür zu sprechen, daß das Wort nicht streng terminologisch, aber in der Regel eben doch auf die Consulare beschränkt, gebraucht wurde: vgl. Hermann Strasburger, Nobiles (I936), in: ders., Studien zur Alten Geschichte I. Hildesheim I982, I49I5I. Daß in den Kreis der consularischen Familien immer neue Geschlechter aufstiegen (und aufsteigen mußten angesichts nicht ausreichenden Nachwuchses), versteht sich von selbst; s. Meier, RPA (wie Anm. 2), 46 Anm. I22. Dazu in Auseinandersetzung mit der einschlägigen jüngeren Literatur Leonhard A. Burckhardt, The Political Elite of the Roman Republic: Comments on Recent Discussion of the Concepts Nobilitas and Homo Novus, in: Historia 39, I990, 77-99; Jürgen von Ungern-Sternberg, Rez. zu Keith Hopkins, Death and Renewal. Cambridge I983, in: Gnomon 62, I990, 424-428; auch Werner Dahlheim, in: HZ 242, I986, 653 f. Zur Bezogenheit der Nobilität auf Amt und Leistung s. Hölkeskamp, Entstehung (wie Anm. I8), 294ff. Zur „Exklusivität“ des Senatsadels insgesamt Hölkeskamp, Rekonstruktionen (wie Anm. I9), $78 \mathrm{ff}$.
} 
Senatsadel und Nobilität stellten zwar, da sie grundsätzlich für Aufsteiger offen waren, keine Stände im genauen Sinne des Wortes dar. Weil sich aber offenkundig in ihren Reihen sehr viel Macht vereinte und ein kräftiges Standesbewußtsein artikulierte, welches sich in einem bestimmten Stil der Lebensführung, des Auftretens, des Anspruchs und der Einflußnahme äußerte, blieb die Zahl der Aufsteiger, der homines novi gering. Wer von ihnen in die obersten Ränge vordrang, mußte außerordentliche Fähigkeiten besitzen oder viel Glück haben. Die meisten gelangten nur in die niederen Ämter, und erst ihren Nachkommen glückte, wenn überhaupt, die Aufnahme unter die Führenden. So konnten diese Familien samt den wenigen, die jeweils zu ihnen stießen, wie ein Stand fungieren (der zugleich die Vorzüge einer gewissen Offenheit genoß). Weil Rom in jener Zeit viele Kriege zu führen hatte und weil sich gerade auch Plebejer in ihnen bewährten, muß bei den Wahlen Leistung für die Republik künftig höher bewertet worden sein. Anders (oder doch in weit höherem Maße) als früher die Patricier war dieser Quasi-Stand darauf bezogen und dadurch legitimiert.

Insbesondere aber muß es auch die Weise, in der das Patriciat sich und sein Verhältnis zur übrigen Bürgerschaft sowohl behauptet wie modifiziert hat, gewesen sein, die die Ordnung der Republik künftig bestimmen sollte. Dazu zählt die unter den Umständen der Bedrängnis gestärkte Adelssolidarität, zählen jene Mechanismen, welche es bedingten, daß die Mehrheit des Standes eine gewisse Geschlossenheit entwickelte, der die Einzelnen sich einzufügen hatten. Es scheinen sich damals die Grundelemente jenes Habitus herausgebildet zu haben, der dem römischen Adel künftig eigen war. Er fand seinen Ausdruck unter anderm in der Bereitschaft, notfalls eher nachzugeben ${ }^{46}$, also in der Elastizität, wie sie die harten Kerne von Institutionen und Grundsätzen umgab, die nicht drangegeben wurden. Mit allem Adelsstolz verknüpfte sich - wohl damals schon - der Gedanke des notwendigen Dienstes an der res publica und des Respekts gegenüber dem Volk, wie ihn Cicero in de oratore $(\mathrm{I}, 226)$ formuliert hat: „Daß der Senat dem Volk dienen nicht nur könne, sondern müsse [...], der Senat, dem das Volk selbst die Macht, es im Zaum zu halten und zu lenken, wie eine Art Zügel übergeben hat“.

Indem das Patriciat in auspicium und anderem seine gleichsam archaische Ver-

46 Z.B. Livius 2,55,Io. Plutarch, Gracchi 20,I. Appian, Bellum Civile I, I; Flaig, Ritualisierte Politik (wie Anm.37); Christoph Lundgreen, Regelkonflikte in der römischen Republik. Geltung und Gewichtung von Normen in politischen Entscheidungsprozessen. (Historia Einzelschriften, 22 I.) Stuttgart 20I I, 282. 
mittlungskompetenz gegenüber den überirdischen Mächten entschieden und diszipliniert weiterpraktizierte, rettete es sie, wie schon angedeutet, in Zeiten hinein, in denen - wie die plebejischen Empörungen zeigen - manches am gleichsam naturwüchsigen Überkommenen durchaus schon infrage gestellt werden konnte.

So konnte sich, bei allen fortbestehenden Unterschieden, etwas vom patricischen Standescharisma auf den ganzen neuen Quasi-Stand übertragen. Je mehr man es brauchte (zumal im bangen Umgang mit überirdischen Gewalten), um so intensiver wird man es sich erglaubt haben. Schließlich war mit dem Obermagistrat das auspicium auch weiterhin verknüpft. Anderes verblieb ganz in der Hand der Patricier; vermutlich weil es sich auch für Plebejer so von selbst verstand. Der geheime Respekt vor den Patriciern, den auch die führenden Plebejer geteilt haben werden, kam zugleich dem Ansehen der Nobilität zugute, der sie nun angehörten.

Wenn die Patricier unter den Anforderungen der Selbstbehauptung die Beziehungen zu ihren Clienten mit besonderer Aufmerksamkeit gepflegt und entwickelt haben, so könnte sich daraus erklären, daß diese sich nicht mit der Zeit auflösten, sondern Formen annahmen, in denen sie auf lange Zeit überdauern, ja die ganze Bürgerschaft, die Formen ihrer Teilhabe am Gemeinwesen, Interessenvertretung und politische Gruppierung prägen konnten. Als Mittel nicht nur der Verpflichtung, sondern auch der dichten Kommunikation zwischen Hoch und Niedrig, und zwar zwischen einer Unzahl von Einzelnen, Familien sowie Städten mit der Zeit in ganz Italien und im Herrschaftsbereich. ${ }^{47}$ Denn da dieses Bindungswesen samt den mit ihm gegebenen patriarchalischen Denk- und Verhaltensweisen schon einmal von früher Zeit her existierte, intensiv gepflegt worden war und sich dadurch tiefer in die römische Mentalität eingelagert hatte, da es gebraucht wurde, ergab es sich von selbst, daß derartige Beziehungen nach außen, auch zu Verbündeten und Besiegten sowie zu den in die Bürgerschaft neu Aufgenommenen geknüpft und gepflegt wurden. So konnten sie - samt dem Senat, in dem sie zusammenliefen - immer weniger entbehrt werden. Was der Ausbildung horizontaler Solidarität (über die begrenzten

47 Meier, RPA (wie Anm. 2), 34 ff.; Hölkeskamp, Entstehung (wie Anm. I 8), I75ff. Man sollte nicht dagegen vorbringen, die römische Bürgerschaft sei bald zu groß gewesen, um von solchen Beziehungen durchdrungen werden zu können. Gerade durch die Aufnahmen ins Bürgerrecht (oder durch das Bündnis mit Rom) wuchs deren Notwendigkeit. Und warum sollten 300 Senatoren nicht zu einigen tausend domi nobiles Beziehungen unterhalten können, über die gegebenenfalls weitere Beziehungen von Anlaß zu Anlaß vermittelt werden konnten? Wo dergleichen in einer Bürgerschaft eine so große Rolle spielt, müssen entsprechende Fähigkeiten erwachsen sein. 
Interessen der Plebs hinaus) so sehr im Wege stand. Es bleibt Rätselhaftes genug am römischen Bindungswesen. Aber wenn sich Rätsel in der Häufung besser erschließen, so könnten sich das lange Überleben der patricischen Vorrangstellung und das des (sich modifizierenden) Bindungswesens gegenseitig erklären. ${ }^{48}$

Ähnliches gilt für den Stil des Umgangs mit dem Volk, wie es sich etwa auf dem Forum präsentierte; für jene eigentümlichen Formen der Rücksichtnahme, der Respekterweisung, des politischen Takts, der Mäßigung von Machtausübung und der Rituale, mit deren Hilfe man sich mitsamt dem Volk einer ganzen Reihe von Beschränkungen unterwarf und sich einer gemeinsamen Ordnung fügte, in der vielerlei Möglichkeiten des Denkens, des Handelns, des Gestaltens gar nicht erst ins Blickfeld kamen.

So ist die römische Ordnung, auch die Einheit der Republik offenkundig gestärkt aus den „Ständekämpfen“ hervorgegangen, als Adelsregime, das dem Volk wichtige Rechte beließ. Im Endeffekt haben sich Patricier und Plebejer aufs beste zusammengerauft. Es fragt sich jetzt, was genau in diesem Rahmen dem Volk zukam.

V.

I. Als „Volk“ begegnet uns in der römischen Republik, wie man weiß, einerseits die Gesamtbürgerschaft, der populus. In ihm war der Adel mit enthalten. Das wird besonders sinnfällig in den auf die alte Heeresversammlung zurückgehenden comitia centuriata, die bis zu ihrer Reform im dritten Jahrhundert unter dem demonstrativen Vorantritt (und Einfluß) der adligen Rittercenturien abstimmten. Andererseits firmierte als Volk von den „Ständekämpfen“ her die plebs, das heißt die Gesamtheit abzüglich der Patricier.

Versammeln konnte sich das Volk nur, wenn ein Magistrat es einberief, zu den formlosen contiones einerseits, zu wählenden oder über Anträge beschließenden comitia andererseits, welch letztere nach Stimmabteilungen gegliedert waren (um von Volksgerichtsverfahren hier abzusehen). Der Magistrat hatte die Verantwortung für

48 Die senatorische Existenz war dann auch ziemlich fordernd. Eindrucksvoll formuliert bei Lukrez, de rerum natura 2, I I ff. Nicht nur für Epikureer, sondern auch für sehr viele Ritter, also Angehörige der regimentsfähigen Schichten, könnte der Reiz gering gewesen sein, es mit den Senatoren um diesen Preis aufzunehmen. Vgl. Sallust, Historien I,55,9. 
den ordentlichen Ablauf der Versammlung; gegebenenfalls mußte er sie abbrechen. „Der Gemeindewille“, so Theodor Mommsen, „findet seinen Ausdruck [...] in dem Zusammenhandeln des Magistrats und der Bürgerschaft“. ${ }^{49}$

Der Volksversammlung oblag seit früher Zeit die Entscheidung über Krieg und Frieden, über Verträge, die Bestellung der Magistrate (zum Teil auch die Strafgerichtsbarkeit). Mit der Zeit kam sie dazu, auch normative sowie situationsbezogene Beschlüsse zu fassen, welche die Form von Gesetzen hatten.

Der Wirkensradius der Comitien, wie sie hießen, hielt sich in engen Grenzen. Die Rolle, die sie spielen konnten und spielten, war gleichwohl wichtig. Durch sie wurde das Senatsregime modifiziert, ergänzt und gestützt.

Wie das geschah, läßt sich nur auf der Basis der besonderen mentalen Ausprägung der römischen Bürgerschaft verstehen. Ihr Abstimmungsverhalten bei den Wahlen pflegte zum guten Teil dadurch bestimmt zu sein, daß sie zu weiten Teilen den Adligen aufgrund von Clientel- oder Freundschaftsbindungen verpflichtet waren. Es war damit zugleich vermacht, daß sich im Volk eine Zusammenballung von Interessen größerer Gruppen oder gar ein gemeinsamer, ein „Eigen-Wille“ gegen den Adel kaum ausbilden konnte. So gut wie gar nicht bei den Wahlen; gelegentlich bei Abstimmungen über Gesetze; am ehesten dort, wo es - aber immer nur aus gegebenem Anlaß - um die alten Forderungen der Plebs nach Rechtssicherheit ging oder wo - wiederum in alter Tradition - gravierende wirtschaftliche Notlagen nach gemeinsamer Abhilfe riefen. Kaum etwas reichte darüber hinaus. Da die vertikalen Solidaritäten vorherrschten, waren die horizontalen schwach (respektive auf die alten Reservate der Plebs eingeschränkt).

Anfangs mußten sowohl die Wahlen wie alle Gesetzesbeschlüsse durch die patricischen Senatsmitglieder abgesegnet werden, um gültig zu sein.

2. Die Contionen ${ }^{50}$ dienten zum einen dazu, Gesetzesanträge unmittelbar vor der Abstimmung zur Diskussion zu stellen. Man erwartete vom Leiter, also vom Antragsteller, daß er auch Kritiker zu Wort kommen ließ; insgesamt wohl prominente Senatoren. ${ }^{5 \mathrm{I}}$ Die übrigen, die meisten Contionen galten der öffentlichen Bekanntma-

49 Mommsen, Staatsrecht (wie Anm. I6), Bd. 3, 30I; Gelzer, Kleine Schriften I (wie Anm. 2), I 99.

50 Francisco Pina Polo, Las Contiones Civiles y Militares en Roma. Zaragoza I989.

5I Besonders markantes Beispiel: Dio 39,34. Plutarch, Cato minor 43,2. Falls der Antragsteller Gegner nicht zu Wort kommen ließ, konnten andere Tribunen ihnen die Gelegenheit dazu bieten. Auch deswegen war es praktischer, es selbst zu tun. 
chung von Nachrichten, Absichten, der Erklärung von Politik, aber auch der Agitation. Hier setzte sich das Publikum aus denen zusammen, die sich gerade auf dem Forum (wo sie zumeist stattfanden) oder in dessen Nähe aufhielten und Interesse daran hatten; einige eigens dazu Aufgebotene vermutlich inklusive. In heißen Phasen pflegten Volkstribune anzuordnen, daß die tabernarii ihre Stände im Zentrum schlossen, um ein größeres Publikum zusammentrommeln zu können. ${ }^{52}$ Speziell in Contionen stellte sich Kontakt zwischen Magistraten und „dem Volk“ her. Mehrfach hören wir, daß Streit vor dem Senat und dem Volk ausgetragen wurde. Rhetorische Fähigkeiten zählten zu den wichtigen Tugenden römischer Adliger. Sie mußten sich vor allem auch vor der contio beweisen. ${ }^{53}$

Hier tut sich ein sehr schwieriges Problem auf. Wer nämlich war „das Volk“, das sich auf dem Forum jeweils antreffen ließ und/oder das die Contionen besuchte? Es können ja kaum nur Gassensteher gewesen sein. War es ein eher zufälliges Gemisch von römischen Bürgern und anderen, heute die, morgen die? Unter Umständen je nach dem, was im Zentrum der Stadt gerade verhandelt wurde, etwa im Senat, vor Gerichten oder Magistraten? Oder gab es einen Kreis von Männern, die sich dort häufiger aufhielten, die, wenn nötig, leicht andere herbeiholen (und wiederum andere gegebenenfalls unterrichten) konnten? Vielleicht auch Geschäftsleute oder deren Agenten, die an öffentlichen Aufträgen interessiert waren? Zufällig Anwesende aus den Führungsschichten in fernen Bürgerstädten? Jüngere, die sich mit römischer Politik und römischem Recht vertraut machen wollten, die daran dachten, eine politische Laufbahn einzuschlagen? Männer, die sich auf die Organisation von Wahlen verstanden? Unzufriedene? Spendenjäger? Übliches Gefolge von Volkstribunen?

Livius spricht einmal von einer factio forensis, einem „Forumsklüngel“. Cicero bezeichnet als populus contionarius oder contionalis hirudo aerarii einen Kreis von Bürgern, auf den sich tribunicische Agitation stützen konnte. ${ }^{54}$ Er war für Unruhe gut

52 Christian Meier, Art. „Populares“, in: Paulys Realencyclopädie der classischen Altertumswissenschaft, Suppl. Io, I965, 549-6I5, hier 6I4.

53 Hölkeskamp, Senatus Populusque (wie Anm.6); ders., Entstehung (wie Anm. I8), XVIIf.

54 Livius 9,46,Io. I3. I4 (dort heißt es forensis turba); Cicero, ad Quintum fratrem 2,3,4; ad Atticum I, I6, I I. Vielleicht kann man, wie ich es (ich weiß nicht mehr, ob im Wissen, daß es so in den Quellen nirgends steht) getan habe, daher von plebs contionalis sprechen (Meier, Populares [wie Anm.52], 6I4). Weiter dazu: Martin Jehne, Politische Partizipation in der römischen Republik, in: Hansjörg Reinau/Jürgen von UngernSternberg (Hrsg.), Politische Partizipation. Idee und Wirklichkeit von der Antike bis in die Gegenwart. (Colloquia Raurica, I3.) Berlin 2013, I03-I44, hier I 2 If. 
und zehrte von den Früchten popularer Politik. Gehört das erst in die späte Republik (von der auch Livius' Gewährsmänner für die frühe ihr Anschauungsmaterial bezogen haben mögen)? In jene Zeit also der heftigen Agitation, der unter Umständen täglichen Contionen ${ }^{55}$, deren Teilnehmer von den Aristokraten als „Bodensatz“ angesehen werden konnten? Und handelte es sich vielleicht auch dann nur um eine bestimmte Art von Contionen, neben der andere standen, in denen die plebs contionalis nur gleichsam ein Substrat darstellte, dem sich andere zugesellten? Wäre also für die „klassische“ Republik damit zu rechnen, daß in den Contionen immer wieder ein Kreis von Männern, hoch und niedrig, versammelt war, die einiges von Politik und politischer Ordnung verstanden, denen das wichtig war, die ein Urteil darüber hatten, was sich gehörte, und entsprechend Beifall bekunden, murren, protestieren oder auch schon einmal handgreiflich werden konnten, wenn etwas sie dazu anstachelte? Sie hätten dann gleichsam eine Rolle gespielt, die Rolle einer gewissen Öffentlichkeit ${ }^{56}$, wären ein Organ der Kontrolle gewesen (an das vielleicht auch in Sachen der entfernter Wohnenden zu appellieren war), das etwa auf die Einhaltung überkommener Regeln gedrängt hätte. Aber vielleicht verstanden sich auch die, die sich gewohnheitsmäßig um die tabernae aufhielten, darauf? Immerhin hatten sie Gelegenheiten genug, um stets von neuem in die Dinge einbezogen zu werden und auch manches dabei zu lernen. Die einen wie die anderen hätten winzige Bruchteile der - durch Bürgerrechtsverleihungen weiter anwachsenden - Bürgerschaft gebildet.

Allemal bemerkenswert ist, daß Magistrate immer wieder eigene Vorhaben und Überlegungen oder die des Senats öffentlich zur Kenntnis gaben, die Öffentlichkeit also gleichsam ins Vertrauen zogen (um ihr zugleich zu zeigen, wie gut Rom regiert wurde). Sie scheinen die Teilnehmer an der contio vermutlich auch schon früh gern als Herren der Republik sowie ihres weiten Imperiums angesprochen zu haben. Später attestierte Cicero der contio einmal, ihre Macht reiche fast an die der unsterbli-

55 Cicero, pro Cluentio ro3; Tacitus, dialogus 36,3; Meier, Populares (wie Anm. 52), 6 2 ff. Da gab es dann eine gewisse Verfügungsmasse für domini contionum (oder moderatores): Cicero, pro Sestio I 25f.; vgl. Plutarch, Aemilius 38,4 (zu I42 v.Chr.). Vgl. Plutarch, Cato Minor 49.

56 Flaig, Ritualisierte Politik (wie Anm.37), I4f., ıogf. u.ö. hebt das stark hervor, ohne sich weiter den Kopf darüber zu zerbrechen, wer sich unter dem Etikett „Volk“ zu regen (und somit um die Einhaltung der Ordnung zu kümmern) pflegte. Immerhin war das „Volk“ in sehr vielen Streitfällen nicht so wie die Adligen mit seinen Interessen beteiligt. 
chen Götter heran. ${ }^{57}$ Schon für die frühe Republik wird von dem Brauch berichtet, daß der Consul die Liktoren ihre Rutenbündel vor der Volksversammlung senken ließ. Das waren schöne, wichtige, gleichwohl unverbindliche Gesten. Denn der Respekt vor dem Volk unterlag nicht dem Risiko, daß ernste Konsequenzen daraus erwuchsen. Anscheinend wurde der tatsächliche Vorrang von Senat und Magistraten gerade auch dadurch behauptet, daß sie sich symbolisch vor dem Volk verbeugten. Indem die Magistrate das Volk als Herren ansprachen, machten sie es sich dienstbar. Gegenseitiger Respekt war ein wesentliches Schmiermittel der römischen Ordnung. ${ }^{5}$ So wurde Ärger vermieden. Wie man ja auch Willkürakte, wenn sie einmal geschehen waren, durch eine gewisse Jovialität aufzuwiegen pflegte.

Nur in der Contio (sofern es nicht geradezu zu Aufruhr oder zur secessio plebis kam) war „das Volk“ in Rom zu spontanen Willenskundgebungen in der Lage. Wie weit allerdings die Magistrate aufgrund davon sei es ihre Anträge, sei es ihre Absicht, ein Veto einzulegen, fallen ließen, ist unklar. Bezeugt ist nur, daß das aufgrund der vorgebrachten Argumente geschehen konnte. ${ }^{59}$ Vielleicht lief das jedoch aufs gleiche hinaus.

Niemals aber kam es in Rom dazu, daß die Bürgerschaft, wie in der attischen Demokratie, wirklich Entscheidungen, und gar die wichtigsten, nach eingehender Beratung und angesichts von Alternativen getroffen hätte. Dort nämlich versammelte

57 Meier, Populares (wie Anm.52), 596f. Sehr schön: Cicero, de oratore I,225f.; vgl. Bleicken, Lex (wie Anm. I I), 290. Der Respekt schloß nicht aus, daß Senatoren gelegentlich das Volk auch kräftig zur Ordnung riefen. Dazu Martin Jehne, Blaming the People in Front of the People: Restraint and Outbursts of Orators in Roman Contiones, in: Ralph Covino/Christopher Smith (Eds.), Praise and Blame in Roman Republican Rhetoric. Swansea 20 I I, I I I-I26.

58 Sehr schön dazu die schon zitierte Stelle Cicero, de oratore I,226.

59 Livius 45,2 I,5. Flaig hat auszumalen versucht, wie in den Contionen der Wille des Volkes allmählich sich bildete, aufs feinste gleichsam ertastet und dann nach Möglichkeit gelenkt von den Antragstellern, die schließlich eventuell ihre Texte auf Einwände hin modifizierten (Ritualisierte Politik [wie Anm.37], I95 ff.). Dort (und nicht in den Abstimmungen) hätten im Volk „Entscheidungsprozesse“ stattgefunden. Bezeugt ist davon nichts, die angeführten Belege besagen eher das Gegenteil. Außerdem ist ganz offen, wer die Contionen jeweils besuchte und wie die, die das taten, mit weiteren Teilen der Bürgerschaft, die zur Abstimmung gingen, in Kontakt waren, etwa durch ein System kommunizierender Röhren. Interessant immerhin Cicero, pro Sestio I 26, wo die „Sitte der Griechlein“, mit Fragen Antworten im Sprechchor zu produzieren, dem entgegengestellt wird, was bei den eigenen Vorfahren üblich war, also offenbar eher Mitteilung und Debatte sowie spontane Reaktionen darauf. Insbesondere scheint es mir notwendig, die Contio vor der Abstimmung von den vorangegangenen, in denen unter Umständen heftig agitiert und Stimmung gemacht wurde, zu unterscheiden. Immerhin: Als Öffentlichkeit konnten die Contionen fungieren. 
sich das Volk ungegliedert, relativ häufig, und zwar unter einem Vorsitzenden, der - durch das Los bestimmt - aus seiner Mitte kam. Es beriet sitzend, bei allgemeinem Rederecht. Jeder konnte Vorschläge unterbreiten, die verschiedenen Tagesordnungspunkte wurden von dem aus der Gesamtheit des Volkes erlosten Rat der Fünfhundert vorbereitet. Dessen Vorlagen konnten in der Versammlung abgeändert werden. Und nach der Beratung wurde unmittelbar, für jeden sichtbar, durch Handaufheben entschieden. Da galt, und zwar in Hinsicht auf das Ganze, der Grundsatz one man one vote. Alle zusammen, wie sie da waren, arbeiteten die Bürger, jeweils wie sich Mehrheit gegen Minderheit ergab, die Materien ab.

Römische Volksversammlungen dagegen fanden allesamt im Stehen statt. Keine von ihnen hatte den Charakter einer Beratung, und es gab auch keinen Ausschuß zur Vorberatung. Beschließende Volksversammlungen waren eher selten. Der Leiter, also der Magistrat, hob sich deutlich vom Volk ab, auf erhobenem Podest auf seinem Amtssessel sitzend. Die Initiative lag bei ihm. Er handelte aus eigenem Recht. Der Senat konnte ihn allerdings bitten, bestimmte Vorlagen zur Abstimmung zu stellen. Und die Bürger wurden, wenn es galt, Beschlüsse zu fassen, nicht danach gefragt, was sie wollten. ${ }^{60}$ Vielmehr konnten sie nur das annehmen oder ablehnen, was sie vorgesetzt bekamen; das war jeweils ein einzelner Antrag. Und damit sie das konnten, mußten sie in die Unterabteilungen auseinandertreten, um sich einer längeren Abstimmungsprozedur zu unterziehen.

Läßt man die bald unbedeutend gewordenen Curiatcomitien beiseite, so wären als Versammlungen der Gesamtgemeinde neben den (ursprünglich nahezu wie das Heer nach Rang und Vermögensklassen aufgebauten und abstimmenden) comitia centuriata die comitia tributa zu nennen, in denen das Volk nach geographischen Bezirken abstimmte. Nach Tribus gegliedert waren auch die concilia der Plebs (an denen alle außer den Patriciern teilnehmen konnten). Versammlungsleiter der Gesamtgemeinde waren Obermagistrate, Volkstribunen die der Plebs.

Ein besonderes Charakteristikum all dieser Versammlungen war die Art, in der die Bürger dort zur Geltung kamen. Wir kennen keine Parallele dazu in andern Kulturen. ${ }^{6 \mathrm{I}}$ Die Einzelstimmen wurden nämlich in den Stimmkörpern nicht nur gezählt, sondern ausschließlich auch dort gewertet. Denn weiter gemeldet wurden

60 Indes kann man sich fragen, wie so komplexe Beschlüsse wie der (oder die) bei Cicero, Philippica I I,I 8 erwähnte(n) zustandekamen.

6I Ursula Hall, Voting Procedure in Roman Assemblies, in: Historia I3, I964, 267-306. 
nicht deren Summen (um am Ende zu einem Gesamtergebnis zusammengerechnet zu werden), sondern nur, wofür die Stimmkörper mit relativer Mehrheit ${ }^{62}$ votiert hatten: Ja oder nein respektive etwa A und B als Consuln. Wenn die Stimmkörper, was zumindest mit der Zeit der Fall war, verschieden groß waren, führte das dazu, daß die Einzelstimmen zum Teil sehr unterschiedlich wogen.

Da die Centuriatcomitien anfangs, als Heeresversammlung, nach Centurien angetreten sein werden, brauchte zunächst - solange sie nämlich nur einem Vorschlag des Wahlleiters akklamierten ${ }^{63}$ - wirklich nur das Gesamtergebnis weitergemeldet zu werden. Nimmt man an, daß dieses Verfahren beibehalten wurde, als Wahl an die Stelle der Akklamation trat (und man die Einzelstimmen, aber nur innerhalb der Centurien, zählte), so könnte dieses merkwürdige Verfahren (das für die Tributcomitien übernommen wurde) erklärlich werden - angesichts der römischen Eigenart, wenn schon irgendwo geneuert werden mußte, so wenig wie möglich zu verändern. Also: Man zählt, statt die Akklamation zu notifizieren, aber man ändert nichts daran, daß allein die Centurienstimmen, nicht die Wählerstimmen insgesamt zu Buche schlagen.

Die Freigabe der Wahl erfolgte, vielleicht erst im dritten Jahrhundert, vermutlich mehr auf Druck rivalisierender Adliger, die kandidierten, als auf den breiterer Kreise, die wählen wollten (sofern beides nicht auf das gleiche hinauslief).

3. Im weiteren Verlauf unterlag sowohl das passive wie das aktive Wahlrecht oder, allgemeiner gesagt: die Möglichkeit zu wählen oder gewählt zu werden - diversen Begrenzungen. Die bedeutsamste erfolgte durch die lex Villia annalis von I80 ${ }^{64}$,

62 Mommsen, Staatsrecht (wie Anm. I6), Bd. 3, 408. Andernfalls wäre der Wahlvorgang ja wohl auch unerträglich kompliziert geworden.

63 Christian Meier, Art. „Praerogativa centuria“, in: Paulys Realencyclopädie der classischen Altertumswissenschaft, Suppl. 8, I956, 567-598, hier 586. Ob die Akklamation (ursprünglich wohl durch Schlagen mit dem Schwert auf den Schild [suffragium]) in Rom wirklich, wie Martin Jehne, Konsensfiktionen in römischen Volksversammlungen. Überlegungen zur frührepublikanischen Curienversammlung und zu den kaiserzeitlichen Destinationscenturien, in: Egon Flaig (Hrsg.), Genesis und Dynamiken der Mehrheitsentscheidung. (Schriften des Historischen Kollegs, 85.) München 20I 3, I 29-I 52, hier I 30 ff., meint, nach spartanischem Muster und in räumlich gegeneinander abgeschirmten Versammlungen erfolgte, ist mir höchst fraglich. Nach meinem Urteil ging es bei der Akklamation nicht um eine andere Form der Wahl zwischen mehreren, sondern um Zustimmung um einen Vorschlag. Da brauchte man keine Gegenprobe zu machen. 64 Rögler, Lex Villia (wie Anm. 3); Hans Beck, Karriere und Hierarchie. Die römische Aristokratie und die Anfänge des cursus honorum in der mittleren Republik. (Klio, Beihefte, Io.) Berlin 2005. Zur damaligen Lage Lundgreen, Regelkonflikte (wie Anm.46), 286ff. 
welche (an schon vorher einsetzende Tendenzen anknüpfend) für die Kandidatur zu den einzelnen Ämtern Mindestalter festsetzte. Die Zahl der jeweiligen Kandidaten sollte verringert werden, offensichtlich weil sonst die Auseinandersetzungen und wohl auch die Mißbräuche bei der Werbung zu störend geworden wären. Daraufhin wetteiferten die aussichtsreichsten Kandidaten darum, im ersten möglichen, also in dem gleichsam ihnen bestimmten Jahr (suo anno) gewählt zu werden. Da außerdem die Möglichkeit der Wiederwahl damals schon länger eng begrenzt war, hatten die Wähler also nur eine Auswahl unter wenigen Männern zu treffen, weit eher im Rahmen von deren Laufbahn vorgegebene Kandidaten zu befördern als Wunschkandidaten je nach Situation (etwa aufgrund gemeinsamer politischer Interessen und Auffassungen) in ein Amt zu bringen. ${ }^{65}$

Daß für höhere Ämter Militärdienst und die Bekleidung von niederen Ämtern Voraussetzung war, hatte sich schon früher eingebürgert, ohne daß es aber unbedingt bindend festgelegt gewesen wäre. Das gleiche mag für ungefähre Altersgrenzen gelten.

Ob, und wenn ja, seit wann die Kandidaten sich beim Wahlleiter vorher zu melden hatten, um in eine Kandidatenliste aufgenommen zu werden, ist kaum zu entscheiden. Jedenfalls war es nicht ausgeschlossen, daß sich jemand kurzfristig mit zur Wahl stellte. Der Wahlleiter konnte allerdings erklären, er werde einen Kandidaten bei der Feststellung des Ergebnisses nicht berücksichtigen. Oder er werde ihn nicht renuntiieren. Er mochte es im Sinne des Senats tun. Dagegen konnten Volkstribunen Einspruch erheben. ${ }^{66}$ Es hieß dann gern, das Volk sollte wählen können, wen es wollte. Und von der Wählerschaft aus konnte Druck ausgeübt werden (wohl zumal, wenn ehrgeizige Adlige dahinter standen). Falls große Mehrheiten gegen den Willen des Wahlleiters einem Kandidaten ihre Stimmen gaben, ließ sich kaum etwas Durchschlagendes dagegen vorbringen, es sei denn, daß vielleicht Himmelszeichen

65 Abgesehen davon hätten die unteren Schichten allein mit solchen Wünschen, wenn sie sie denn gehabt hätten, kaum etwas ausgerichtet. Anders hätte es sich allenfalls verhalten, wenn unter den Wählern des Ritterstands und der ersten Classe viele gewesen wären, die etwas betrieben hätten, für das die Senatsmehrheit nichts übrig hatte; oder wenn sie sich über die Macht und vielleicht die Willkür führender Senatoren ärgerten. Dergleichen könnte in den Jahren vor dem 2. Punischen Krieg vorgekommen sein. Einige Gesetze der Zeit und die Wahlerfolge derer, die sie beantragten oder unterstützten, könnten dafür sprechen. Doch hätte sich das nicht wiederholt, respektive erst - und zwar nur streckenweise - in der späten Republik (Meier, RPA [wie Anm. 2], 77 ff.), und durchgesetzt hat es sich auch dann nicht.

66 Mommsen, Staatsrecht (wie Anm. I6), Bd. I, 47 I; Meier, RPA (wie Anm. 2), I 92 Anm. I82; Rilinger, Wahlleiter (wie Anm.35), $65 \mathrm{ff}$. 
den Abbruch der Wahl ermöglicht hätten (womit diese aber zunächst einmal nur aufgeschoben war). In einem Fall, es handelte sich um eine Nachwahl, hat man auf Senatsbeschluß lieber auf die Wahl verzichtet, als die Machtprobe mit der Volksversammlung durchzustehen. ${ }^{67}$ Immerhin erwies sich das Volk hier einmal als eigensinnig. Aber dergleichen Unregelmäßigkeiten waren die Ausnahme.

Bei allen Unklarheiten und möglichen Grenzfällen aber sind in aller Regel Bewerber aus Nobilität und Senatsadel oder Männer aus den wohlhabenden Schichten gewählt worden, die kaum anderes wollten, als in deren Reihen aufsteigen. Es bedurfte eines großen Anhangs innerhalb der Comitien und eines guten Namens (sowie bei Aufsteigern großerVorzüge oder Leistungen), damit man überhaupt eine Chance hatte, also ernsthaft zur Wahl antreten konnte. Insofern waren es ausgeprägte Vorgegebenheiten, die den Raum absteckten, innerhalb dessen man sich nur bewegen konnte.

Andererseits konnte der Wahlleiter nur sehr begrenzt positiv auf das Ergebnis einwirken. Er konnte etwa der zuerst stimmenden centuria praerogativa, nachdem ihr Ergebnis bekannt war, ins Gewissen reden und sie anschließend von neuem zur Wahl rufen. Bezeugt ist das nur für Kriegszeiten, wo es um geeignete Kommandeure ging. ${ }^{68}$ Die früher verbreitete Annahme, wonach in Rom der Wahlleiter die Volksversammlung weitgehend manipulieren konnte, ist inzwischen widerlegt. ${ }^{69}$ Wohl ist es sehr auffällig, daß verschiedentlich vier bis sechs Angehörige derselben untereinander verwandten Familien in den Consulaten aufeinander folgten. Aber die Wahlleiter hatten kaum die Macht, die Wahl ihrer Verwandten der Versammlung aufzunötigen. Allenfalls nahmen die Senatoren und ihnen folgend die Comitien von sich aus Rücksicht auf deren familiäre Verpflichtungen - um entsprechende Gegenleistungen von ihnen und ihren Nachfolgern zu erhalten. ${ }^{70}$ Und die Autorität des Consuls mag seinen Empfehlungen zusätzliches Gewicht verliehen haben.

Weit mehr aber als durch die Laufbahn-Vorschriften sowie durch die Rechte und Möglichkeiten des Wahlleiters war die Volksversammlung durch die Modalitäten der Abstimmung selbst sowie durch das Bindungswesen eingeschränkt.

67 Livius 39,39. Dazu Mommsen, Staatsrecht (wie Anm. I6), Bd. I, 5 I 3 Anm. 3. Schwer zu erklären ist der ganz ungewöhnliche Eifer, der im Volk entflammt wird, eventuell aufgrund besonderer Umstände der Auseinandersetzung.

68 Livius 24,7,I 2 ff.; 26,22 sowie im folgenden zur Wahl von I47.

69 Rilinger, Wahlleiter (wie Anm.35).

70 „Prinzip der vertagten Gegenleistung“: Egon Flaig, Konsensprinzip im homerischen Olymp: Überlegungen zum göttlichen Entscheidungsprozeß Ilias 4, I-72, in: Hermes I22, I 994, I3-3 I, hier I6. 
Die Wahlen erfolgten stets in der Stadt Rom (was, je mehr die Bürgerschaft vergrößert wurde, dazu führte, daß immer mehr Bürger gar nicht oder nur unter Schwierigkeiten teilhaben konnten). ${ }^{7 \mathrm{I}}$

Die Ungleichheiten des Stimmgewichts, die durch die Gliederung in Stimmkörper bedingt waren, schlugen zumal in den Centuriatcomitien, welche die Obermagistrate wählten, zu Buche. Die Centurien der Ritter und der ersten Censusklasse (zu denen auch ein Großteil der Oberschicht in den Römerstädten außerhalb Roms, die domi nobiles, gehört haben müssen) waren (und blieben) eher klein. ${ }^{72}$ Auch unter den Tribus behielten einige mehr oder weniger ihren Umfang, während in andere mit der Zeit immer mehr Neubürger eingetragen wurden. ${ }^{73}$

Dieser Effekt wurde in den Centuriatcomitien verstärkt durch den Grundsatz, daß die absolute Mehrheit das mindeste und zugleich das höchste Erfordernis war und daß die Wahl nach deren Erreichen abgebrochen wurde. ${ }^{74}$ Denn die stimmten in mehreren Wahlgängen, grob gesagt nach Censusclassen, beginnend mit der obersten. So kamen die Centurien der unteren Klassen vielfach gar nicht mehr zum Zuge. Mehrheiten, die mit ihrer Hilfe hätten zustandekommen können, wurden gar nicht festgestellt, geschweige denn, daß sie etwas ausgemacht hätten.

Bei den comitia tributa wurde ebenfalls nach Erreichen der absoluten Mehrheit abgebrochen. Dort aber war die Reihenfolge durch das Los bestimmt. Als die Stimmen der Tribus schließlich gleichzeitig abgegeben wurden (man vermied den Zeitaufwand der sukzessiven Abstimmung), wurden die Ergebnisse weiterhin Tribus nach Tribus verkündet, und man brach bei Erreichen der absoluten Mehrheit ab (obwohl die Resultate der übrigen vorgelegen hätten). ${ }^{75}$ Auch hier wiederum: Man veränderte so wenig wie möglich.

Die Abstimmung in den comitia centuriata war zusätzlich so organisiert, daß das

7I Bleicken, Lex (wie Anm. I I), 255.

72 Cicero, de re publica 2,39f.: „,ita [...] ut suffragia non in multitudinis sed in locupletium potestate essent. Ne plurimum valeant plurimi“; Livius I,43,IO: „sed gradus facti, ut neque exclusus quisquam suffragio videretur, et vis omnis penes primores civitatis esset“. Lily Ross Taylor, Roman Voting Assemblies from the Hannibalic War to the Dictatorship of Caesar. Ann Arbor I966, I49 Anm. 3.

73 Lily Ross Taylor, The Voting Districts of the Roman Republic. The 35 Urban and Rural Tribes. Rom I960. Eine weitere Ungleichheit ergab sich seit der Mitte des 3.Jahrhunderts daraus, daß man den seniores gleich viele Stimmen gab wie den vermutlich viel zahlreicheren iuniores.

74 E. Stuart Staveley, Greek and Roman Voting and Elections. London I972, I79f.

75 Staveley, Voting and Elections (wie Anm.74); Hall, Voting Procedures (wie Anm.6I), 276ff., $292 \mathrm{ff}$. Unwahrscheinlich ist für mich, daß auch die Centurien innerhalb der verschiedenen Rangklassen nach- 
Votum der später Aufgerufenen von dem der vorangegangenen suggestiv beeinflußt wurde. Denn die Centurien wurden nicht nur in mehreren Schüben zur Stimmabgabe gerufen, sondern es wurde jeweils das Ergebnis sofort ermittelt und verkündet, bevor die nächsten antraten. Daß sich der Vorgang damit verlängerte, spielte keine Rolle. Offensichtlich sollte davon eine Vorbildwirkung ausgehen. In der frühen Zeit war die Reihenfolge einfach nach Rang festgelegt: Erst stimmten die achtzehn Rittercenturien, also die Vornehmsten, dann das Fußvolk, eine Censusclasse nach der andern (sobald es nicht mehr nur eine einzige, die der Schwerbewaffneten gab, sondern fünf). Irgendwann zwischen 292 und 2 I 8 änderte man das. Als erste gab dann eine aus der ersten Classe erloste, die praerogativa centuria, ihre Stimme ab. Das Gros der ersten Classe samt zwölf Rittercenturien folgte. Danach wurde ein eigener Abstimmungsgang für jene sechs Rittercenturien eingerichtet, in denen die Männer der senatorischen Familien konzentriert waren. In der zweiten Classe konnte die absolute Mehrheit erreicht werden. ${ }^{76}$

Der Anlaß zu dieser Änderung kann nur darin gesucht werden, daß man die Voten stärker vereinheitlichen wollte. So hätte es dem in der römischen Ordnung verschiedentlich zum Ausdruck kommenden Wunsch nach Eingrenzung von Differenzen entsprochen (der wohl auch hinter dem Abbruch bei Erreichen der absoluten Mehrheit stand). ${ }^{77}$

Zuvor wäre das gelungen, wenn die Rittercenturien mehr oder weniger dieselben Kandidaten gewählt hätten. Möglich wäre das gewiß gewesen. Doch nur so lange,

einander abgestimmt hätten. Das war auf dem Marsfeld nicht nötig. Es hätte den Wahlvorgang unnütz verlängert und doch wohl auch (wenn die Ergebnisse immer gleich gezählt und mitgeteilt worden wären) dem Wunsch nach Konzentration der Stimmen widersprochen.

76 Ich setze dabei voraus, daß die Versetzung der sex suffragia erst nach der Einsetzung der praerogativa centuria erfolgt ist, vielleicht innerhalb einer Phase des Experimentierens. Vgl. Meier, Art. „Praerogativa centuria“" (wie Anm.63), 575; ders., RPA (wie Anm.2), 3 I I.

77 Jehne, Partizipation (wie Anm. 54), I34, meint, man habe „eine mögliche Zerrissenheit der Wählerschaft nicht stärker öffentlich machen“ wollen „als nötig“; ähnlich ders., Integrationsrituale in der römischen Republik. Zur einbindenden Wirkung der Volksversammlungen, in: Karl-Joachim Hölkeskamp u.a. (Hrsg.), Sinn (in) der Antike. Orientierungssysteme, Leitbilder und Wertkonzepte im Altertum. Mainz 2003, 279-297, hier 293. Nach meinem Urteil wäre die Zerrissenheit deutlich genug gewesen, wenn sie sich unter Rittern und den Angehörigen der ersten Classe zeigte. Und überhaupt würde es ausreichen, anzunehmen, daß man eben mehr als die absolute Mehrheit nicht brauchte. Das Motiv, es nicht dazu kommen zu lassen, daß in den unteren Classen die Entscheidung fiel (und die Kandidaten besonders um sie warben), wird hinzugekommen sein. 
wie der Wettstreit um die Ämter einigermaßen in Grenzen zu halten war (vielleicht überhaupt nur, solange gar nicht gewählt, sondern nur einem Vorschlag des Wahlleiters centurienweise akklamiert wurde). Sobald das nicht mehr der Fall war (und er muß sich mit der Zeit verschärft haben), war es viel praktischer, eine einzige Centurie als erste zu befragen. Das konnte auf andere Weise eine gewisse Vereinheitlichung bewirken, auch wenn es nun vom Zufall des Loses abhing, wer die ersten Stimmen abgab und zu wessen Gunsten das geschah. Da viele Wähler mit nur einer Stimme durch Nah- und Treuverhältnisse gebunden waren, konnten sie über die zweite frei verfügen. Das scheint nicht zuletzt dem als ersten ausgerufenen Kandidaten der vorwegstimmenden Centurie zugute gekommen zu sein. Denn Cicero stellt fest, derjenige, der dort die meisten Stimmen gewonnen hatte, sei stets gewählt worden. ${ }^{78}$

Daß sodann die sechs Centurien des Senatsadels einen eigenen Wahlgang, aber nach der ersten Classe erhielten, widersprach dem römischen Prinzip, wonach überall Rangverhältnisse nicht nur festgestellt, sondern auch öffentlich manifestiert zu werden pflegten. ${ }^{79}$ Hier muß folglich ein gewichtiger praktischer Grund vorgelegen haben, davon abzuweichen. Es kann kaum ein anderer gewesen sein als der, daß die Stimmen der ersten Classe sich immer wieder, trotz aller Vorbildwirkung der praerogativa centuria, auf mehrere Kandidaten verteilten. ${ }^{80}$ Die Vielzahl der Bindungen, die in der Oberschicht besonders groß war, kann es kaum anders zugelassen haben. Außerdem wurde ihr Votum besonders beachtet. Wenn sich nun diese Zersplitterung, befördert durch die Ergebnisverkündigung, in den folgenden Classen fortgesetzt hätte, hätte die Entscheidung unter Umständen erst in der untersten fallen können. Das wollte man offenkundig möglichst vermeiden. Den Adligen in den sechs Centurien konnte man - auch wenn viele gerade von ihnen andere Präferenzen hatten - um der Geschlossenheit willen vermutlich abverlangen, sich auf zwei Kandidaten zu einigen. ${ }^{8 \mathrm{r}}$ Sei es, daß sie einfach den beiden an Stimmen stärksten des vorangegangenen Wahlgangs den Zuschlag gaben (was wohl das Normale war), sei

78 Cicero, Pro Plancio 49.

79 RolfRilinger, Ordo und dignitas. Beiträge zur römischen Verfassungs- und Sozialgeschichte. Hrsg. v. Tassilo Schmitt u. Aloys Winterling. Stuttgart 2007, 95-I04 u. I66ff.

80 Meier, RPA (wie Anm. 2), 3 Iof.

8I Daß innerhalb von Stimmkörpern vor der Abstimmung beraten werden konnte (von wem auch immer), ist von einer anderen Gelegenheit her bekannt: Livius 26,22; Lundgreen, Regelkonflikte (wie Anm.46), 67. 
es, daß die Maßgebenden unter ihnen in Zweifelsfällen den ihnen Genehmsten durchsetzten. Jedenfalls muß von ihnen in der Regel auf die weiteren Centurien eine starke Vorbildwirkung ausgeübt worden sein. Noch eine Einengung also der Freiheit der Stimmabgabe für viele Bürger. Übrigens auch ein deutlicher Anhaltspunkt dafür, wie vielfältig der Einfluß des Adels auch innerhalb dieser Comitien war.

Zusätzliche große Einschränkungen der Freiheit der Wahl erfolgten dadurch, daß ein großer Teil der Wählerschaft, zumindest mit einer Stimme, durch „Nah- und Treuverhältnisse“, die modifizierte Fortsetzung der alten Clientelen, an Adlige gebunden war. Dadurch ergab es sich, daß solche Verpflichtungen für viele bei der Wahl den Ausschlag gaben. Und dies war möglich, ja es drängte sich auf, da es in aller Regel nicht dazu kam, daß größere Teile des Volkes bei der Wahl gemeinsame Interessen etwa gegenüber dem Senat oder dort vorherrschenden Kreisen verfolgt hätten. Sofern allgemeinere Gravamina vorlagen, führte der normale Weg, sie zu beheben, über Gesetzesanträge. Dafür sorgten vornehmlich die Versammlungen der Plebs.

Amici und existimatio gaben nach Cicero den Ausschlag unter den Motiven der Wähler. ${ }^{82}$ Neben den Bindungen also der Glanz adliger Namen, die Erinnerung an hervorragende Leistungen des Kandidaten oder seiner Vorfahren, an prächtige Spiele, Spenden, sein Auftreten etc. Nicht oder allenfalls ausnahmsweise kann die Erwartung besonderer Taten oder gar einer bestimmten Politik mitgesprochen haben. Das kann in der mittleren Republik kaum anders gewesen sein als in der späten. Die besondere Interessenlagerung in der römischen Bürgerschaft, negativ gesehen: die Tatsache, daß größere Teile der breiten Schichten sich nicht zusammenballten, um gemeinsam - oder im Wechsel der Mehrheiten - bestimmte politische Ziele zu erreichen, war die Voraussetzung für das Funktionieren der römischen Wahlcomitien.

Schließlich ist die Öffentlichkeit des Wahlvorgangs zu vermerken: Jeder gab seine Stimme mündlich ab, in den Centurien zunächst möglicherweise dem zuständigen Offizier ${ }^{83}$, später und im übrigen jedenfalls einem Beauftragten des Wahlleiters. Also hörbar für den Zähler wie für die Umstehenden, darunter vermutlich Beauf-

\footnotetext{
82 Cicero, ad Atticum I,I,2; Meier, RPA (wie Anm. 2), $8 \mathrm{ff}$.

83 Mommsen, Staatsrecht (wie Anm. I6), Bd. 3, 403 ff.; G. W. Botsford, The Roman Assemblies. From their Origin to the End of the Republic. New York I909, 2 I I. - Ein eklatanter Fall war die öffentliche Drohung eines Consulars, in diesem Fall bei den Tributcomitien, die ganze Abstimmung, Tribus für Tribus, genau zu beobachten, um zu sehen, wer (wie er meinte) die Schande auf sich nähme, den Antrag für den Triumph des Aemilius Paullus abzulehnen: Plutarch, Aemilius 3I, IO.
} 
tragte mächtiger Patrone, die darauf achteten, daß die Wähler ihre Verpflichtungen im Rahmen des Bindungswesens einhielten.

Insgesamt muß die Wählerschaft die verschiedenen Einengungen und Ungleichheiten der römischen Wahlverfassung als selbstverständlich hingenommen haben. Zwar wurde I39 durch ein Gesetz schriftliche Abstimmung für die Wahlen eingeführt, in der späten Republik wurden auch die Stege verengt, an deren Ende die Wähler ihre Stimme abgaben. Aber an der starken Position der Adligen bei den Wahlen hat das kaum etwas geändert. ${ }^{84}$

Darüber hinaus hat man selbst in der späten Republik nur in einem Punkt (der Reihenfolge des Aufrufs) an eine Änderung gedacht. ${ }^{85}$ Doch ist es auch dazu nicht gekommen. Und auf jeden Fall konnte die Politik der Republik bei den Wahlen in aller Regel weder direkt noch indirekt zur Debatte stehen. Denn es wurden ja nur Magistrate, nicht der Senat ausgewechselt.

Wir kennen allerdings einen Fall, in dem die Mehrheit der Wähler geradezu in einen Konflikt mit dem Senat geriet. Im Jahre I 47 hatte sich eine ganze Strömung herausgeschält, offenbar bis in die oberste Classe hinein. Man wollte unbedingt den jungen Scipio Aemilianus zum Consul machen. Er sei der richtige Feldherr, um den dritten Punischen Krieg siegreich zu beenden. Dabei kandidierte er gar nicht und hätte das auch nicht gedurft, denn er war zu jung dazu, hatte auch nicht alle notwendigen Vorstufen schon erklommen. Seine Wahl hätte daher gegen die lex Villia annalis verstoßen, die den Adelsehrgeiz kanalisieren sollte. Vielleicht fürchtete man gar, daß die Wahlen infolge davon politisiert, also etwa zum Gegenstand heftiger politischer Agitation hätten werden können.

Nach hartem Ringen mit den Volkstribunen, welche wieder behaupteten, die Versammlung könne wählen, wen sie wolle, gab der Senat nach. Jedoch verlangte er, die Tribunen sollten zunächst ein Gesetz beantragen, aufgrund dessen Scipio ausnahmsweise kandidieren dürfe. Eine Quelle schreibt gar, die Tribunen hätten zunächst beantragen sollen, die lex annalis aufzuheben, danach sollte sie wieder eingeführt werden. ${ }^{86}$ Aber wie auch immer: Es wurde alles getan (und konnte auch alles

\footnotetext{
84 Christoph Lundgreen, Geheim(nisvoll)e Abstimmung in Rom. Die leges tabellariae und ihre Konsequenzen für die Comitien und die res publica, in: Historia 58, 2009, 36-70.

85 [Sallust], ad Caesarem 2,8; Cicero, pro Murena $47 \mathrm{f}$.

86 Christian Meier, Das Kompromiss-Angebot an Caesar i. J. 59 v.Chr., ein Beispiel senatorischer „Verfassungspolitik“, in: Museum Helveticum 32, I975, I97-208, hier 206f.: Die Sache wurde konzediert, die Ordnung sollte unberührt bleiben.
} 
geschehen), um die Ausnahme als Ausnahme gleichsam einzukapseln. Das Beispiel sollte nicht Schule machen, die Volksversammlung in die Legalität eingebunden bleiben. Sie sollte eben nicht unbeschränkt wählen dürfen, wen sie wollte. ${ }^{87}$ Und das ließ sich durchsetzen, auch wenn es manch einen stören mochte.

Man könnte einwenden, daß gewisse Regulierungen des Wahlrechts in jeder Verfassung ihren Platz haben können. Doch war mit der lex Villia wirklich eine empfindliche Einschränkung für die Wähler verknüpft. Wenn sie denn mehr gewollt hätten als eine Auswahl zu treffen aus einem sehr begrenzten Kreis von Aristokraten samt solchen, die es ihnen gleichtaten. Aber genau das war ja nur in Ausnahmesituationen der Fall.

Irgendwie scheint die ganze Bürgerschaft bis ins Denken und Meinen präformiert gewesen zu sein durch die Ordnung, in die sie eingefangen war. Andere Weisen, Amtsträger zu bestellen, müssen nicht wenigen Römern bei ihren Kontakten zumal mit griechischen Poleis, auch durch griechische Theorie bekannt geworden sein. Aber daraus Folgerungen für Rom zu ziehen, verbot sich offenbar.

Der Sinn des römischen Wahlsystems erschließt sich, wenn dessen verschiedene Funktionen bedacht werden. Auch wenn es nur galt, die Auswahl aus einem sehr kleinen Kreis zumeist adliger Kandidaten zu treffen, wurden die Wähler doch um nichts weniger umworben. Sie hatten ja zu entscheiden, wer von denen das Rennen machte. Das Volk als Ganzes stellte insofern gleichsam den Schiedsrichter in einem großen Wettbewerb dar. Jeder konnte in diese Funktion mit hineinschlüpfen, auch wenn die Unteren am Ende gar nicht mehr zu Wort kamen. ${ }^{88}$ Man darf das nicht von außen, muß es vielmehr von innen sehen; als Teil einer Ordnung zwischen Oben und Unten, die sich von selbst verstand und die Unteren gerade dadurch aufwertete, daß sie unter den Oberen wählten.

Indem auf diese Weise nicht nur über Ämterbekleidung, sondern auch über den Rang im Senat entschieden wurde, trug die Wahl durch das Volk dazu bei, den Adel zu entlasten. Denn bei Personalentscheidungen hätten innerhalb dieses ehrwürdigen Standes leicht verletzende Rangstreitigkeiten und Parteiungen aufkommen können, wenn sie direkt unter den Interessierten getroffen worden wären; die Volks-

87 Grundsätzlich war auch der Senat dafür, aber nur, soweit es die Gesetze erlaubten (Livius 32,7,8). Und das bedeutete (zumal nachdem die lex Villia die Anforderungen verschärft hatte) eben doch eine starke Einschränkung.

88 Jehne, Integrationsrituale (wie Anm. 77), 284ff. 
versammlung war dagegen als Ganze neutral. Einflüsse auf sie wurden im Wettbewerb ausgeübt, ohne direkt aufeinanderzuprallen. ${ }^{89}$

Wenn nun aber das Volk als Gesamtheit oder zu größeren Teilen keinen Eigenwillen entwickelte, folglich auch nicht Adressat entsprechender Wahlwerbung war - auch öffentliche Wahlreden wurden kaum gehalten (vielleicht am ehesten noch außerhalb Roms?) -, so erfüllte das Wahlsystem doch insofern eine weitere wichtige Funktion, als Unsummen von einzelnen Bürgern respektive kleineren Gruppen vermittels der Nah- und Treuverhältnisse eine Art Vertretung im Senat erhielten.

Diese Bindungen verpflichteten in erster Linie die Wähler der Rittercenturien und der ersten Classe, aber zumindest indirekt auch andere. Clientel und Freundschaft werden vielfach - und mit der Zeit immer mehr, je mehr Männer aus weiter entfernten Städten das römische Bürgerrecht erhielten - auch den Ausschlag dafür gegeben haben, wer sich überhaupt zur Wahl in Rom einfand. Wohl gab es gerade für die Prominenteren verschiedene Gründe, die Stadt aufzusuchen; und die Zeit der Wahlen, in der sich viele dort versammelten, war besonders günstig dafür. ${ }^{90}$ Auch hatten gerade die, die dringend auf Unterstützung im Senat angewiesen waren, gute Gründe, sich ab und zu in Rom blicken zu lassen. Trotzdem - über viele, eventuell gar Hunderte von Meilen anzureisen, war beschwerlich. Insofern lag es nahe, dies nur dann zu tun, wenn man sich geradewegs dazu verpflichtet sah. Dank der Gegenseitigkeit der Verpflichtungen sowie der Dauer, auf die sie beide Seiten banden, konnte man sich, wenn man das einige Male innerhalb einer Generation tat, eine Reihe mächtiger Fürsprecher im Senat oder vor Magistraten und Gerichten sichern. Damit war normalerweise für die meisten der Sinn der Wahlen erfüllt.

89 Zu dieser Funktion der Comitien ist eine Bemerkung Georg Simmels aufschlußreich, auf die Hölkeskamp, Rekonstruktionen (wie Anm. I9), 86, hingewiesen hat. Es bemühen sich hier, vor dem Volk, Konkurrenten „um einen und denselben Kampfpreis“. Da der sich nicht in der Hand eines der Gegner befindet, ringen sie nicht „unmittelbar miteinander“, sondern „um den Erfolg ihrer Leistungen bei einer dritten Instanz“; s. Georg Simmel, Soziologie. (Gesamtausgabe, Bd. I I.) Frankfurt am Main I992, 323 ff.

90 Meier, RPA (wie Anm. 2), I93f. (auf die späte Republik bezüglich, in der die Wahlen zumeist im Juli stattfanden; aber einige der Zeugnisse können auch für die frühere Zeit beispielhaft in Anspruch genommen werden). Zu den Zweifeln von Jehne, Integrationsrituale (wie Anm.77), 284 Anm. 35, wäre zu bemerken, daß mit diesen Aussagen nicht ausgeschlossen ist, daß auch Bauern einmal zu dem (wie Jehne zeigt) Spektakel nach Rom kamen, die die Bewerber nicht kannten. Nur lernten sie eben durch die Praerogativa auch nicht die Bewerber kennen, vielmehr nur zwei von ihnen. Varros Deutung scheint mir nicht sonderlich sachkundig zu sein. Auch Festus, dem wir sie verdanken (ebd.Anm. 37), hat da ja seine Zweifel. Weitere Belege, außer den angeführten, finden sich bei Taylor, wie dort zitiert, sowie bei Jehne, Partizipation (wie Anm.54), I2I Anm.65. 
Mit großer Regelmäßigkeit werden sich natürlich die Senatoren, aber vermutlich auch wohlhabende Geschäftsleute, zumal die Pächter öffentlicher Aufträge zu den Comitien eingefunden haben - sowie vielleicht noch Teile der stadtrömischen Unterschicht, die mit einem gewissen Stolz an dem aufregenden Ereignis teilgenommen haben mögen (so wenig sie dabei auszurichten vermochten). Wochenlang jedoch war die Stadt davon erfüllt. So warb man auch um die plebs urbana, schon weil die Luft für oder gegen Kandidaten auch von ihr geregt wurde.

Daß die Einführung der Ämterlaufbahn wesentlich zur Sozialisierung der Adligen beitrug, weil sie sich mehrfach zur Wahl zu stellen hatten, mag am Rande erwähnt werden. Es machte sie insgesamt weniger vom Volk (da das gesammelt kaum zur Geltung kam) abhängig als von den führenden Adligen, welche großen Einfluß ausübten $^{9 \mathrm{r}}$, um deren Zustimmung ein Kandidat also werben sollte. Dies trug freilich zugleich dazu bei, daß sie sich um eine Unmenge Einzelner kümmerten (und dem Volk ihre Reverenz erwiesen).

Um insoweit zusammenzufassen: Indem amici und existimatio über die Wahlen entschieden, fungierte die Volksversammlung zum einen als Gefäß, innerhalb dessen eine große Zahl von Einzelnen (als Individuen oder als Bürger einzelner Städte oder Mitglieder von Steuerpachtgesellschaften, Vereinen etc.) aufgrund von vielerlei Verpflichtungen ihre Stimme abgaben. Zum andern wurden vielerlei Verdienste bis hin zur Ausgestaltung der öffentlichen Feste honoriert. Man respektierte obendrein die Namen der alten Geschlechter und das standeskonforme (dabei generöse) Auftreten der Kandidaten. Man wählte nicht Männer bestimmter politischer Couleur, sondern traf eine Auswahl unter denen, die dran waren, und allesamt können sie sich in ihrer Haltung eventuellen Interessen des Volkes gegenüber kaum voneinander unterschieden haben. Man war dazu nicht gezwungen, allenfalls vielleicht einmal genötigt, mit Sicherheit aber ist kaum je einer auf den Gedanken gekommen, die Wahlen als Hebel für spezielle Interessen „des Volkes“ zu nutzen.

4. Neben den Wahlen hatte die Volksversammlung von Fall zu Fall über die verschiedensten Gegenstände abzustimmen. Diese Beschlüsse rangierten unter dem Rubrum „Gesetze“ (leges). Die Beschlüsse der Plebs (plebiscita) waren ihnen seit 287 gleichgestellt.

Was die Volksversammlung beschloß, war bindend; entgegenstehende Senatsbe-

9I [Q. Cicero], Commentariolum Petitionis 4; Cicero, de legibus 3,39; ad Atticum I,2,2. 
schlüsse oder Anordnungen von Magistraten vermochten demgegenüber nicht zu bestehen. Übrigens konnte auch gegen die Abstimmung über Gesetze, sobald sie einmal begonnen hatte, kein Veto eingelegt werden. Höchstens konnten Zeichen der Götter zu deren Annullierung führen. ${ }^{92}$ Gegen Senatsbeschlüsse dagegen war Interzession möglich. Insoweit fungierte die Volksversammlung als höchste Instanz, freilich in der Gemengelage der gewachsenen, aristokratisch dominierten Verfassung (und mit der Möglichkeit, daß der Senat Ausnahmen von der bindenden Wirkung der Gesetze beschloß).

Jede Versammlung, die ein Magistrat ordentlich zu einer Abstimmung einberief, konnte Volksbeschlüsse fassen. Cicero berichtet von Versammlungen, in denen aus manchen der 35 Tribus nicht ein einziger Mann anwesend war. Man ließ dann je fünf aus andern Tribus in ihnen abstimmen. ${ }^{93}$ Wer und wie viele sich einzufinden pflegten, mußte stark variieren. Neben dem Inhalt des Antrags und seiner Dringlichkeit werden Ansehen, Beliebtheit und Engagement des Antragstellers zur Teilnahme bewogen haben. So wird die Zusammensetzung der Comitien wie bei den Wahlen von einem zum andern Mal gewechselt haben. Man sollte annehmen, daß vornehmlich solche Bürger kamen, die positiv an einer Sache interessiert waren. Denn selten nur ist ein Antrag, wenn er einmal die Hürde des möglichen Vetos hinter sich gelassen hatte, durchgefallen. ${ }^{94}$ In der breiteren Bürgerschaft waren vielfach nur wenige durch die Anträge negativ betroffen. Und sofern Aristokraten (oder gar die

\footnotetext{
92 Lundgreen, Regelkonflikte (wie Anm.46), $265 \mathrm{f}$.

93 Cicero, pro Sestio I04; Jehne, Partizipation (wie Anm.54), I34f.

94 Nach Nippel, Aufruhr (wie Anm. 22), 55, hat Egon Flaig in letzter Zeit unterstrichen, daß in Rom fast nie ein Antrag gescheitert ist (Flaig, Ritualisierte Politik [wie Anm.37], I75f., wo die zwei gleich zu erwähnenden fast gescheiterten Anträge vielleicht auch hätten aufgeführt werden sollen, da von den ursprünglichen Mehrheitsverhältnissen her die Abstimmung negativ ausgefallen wäre: Livius 43,I6; 45,36ff. Zu fragen ist, wie weit gescheiterte Anträge als überlieferungswürdig angesehen wurden. Von den letzten drei der zehn aufgeführten Fälle hören wir nur ganz zufällig. Zudem scheint mir der Wortlaut nicht nur bei der rogatio Papiria, sondern auch bei der Marcia [Cicero, de officiis 2,73: antiquari] deutlich auf eine Abstimmung zu verweisen, vgl. unten Anm. I I4). Übrigens auch Alfred Heuß, Zur Thematik republikanischer „Staatsrechtslehre“ (I978), in: ders., Schriften (wie Anm. 20), Bd. 2, I300-I3 I8, hier I303. Damit stellt sich auch die Frage, ob Flaig, Ritualisierte Politik (wie Anm. 37), I84ff., recht hat mit seiner Behauptung, die beschließende Volksversammlung sei kein Entscheidungsorgan gewesen. Ob ein Antrag Aussicht auf Erfolg hatte, habe sich vorher, etwa in Contionen herausgestellt; wenn nicht, habe man es gar nicht erst zur Abstimmung kommen lassen. Das wird für manche Fälle gewiß zutreffen (zur Problematik, wer in der Contio oder anderswo an der Willensbildung und -ermittlung teilhatte, oben S.622). Allein, war das wirklich stets so absehbar? Bei aller bemerkenswerten Fähigkeit, Kräfteverhältnisse einzuschätzen, mit der man in Rom
} 
Senatsmehrheit) politische Einwände hatten, könnte es schwierig für sie gewesen sein, Freunde und Clienten deswegen aufzubieten - anders als bei den Wahlen, wo ihre elementaren Rangansprüche (und indirekt die Interessen ihrer Freunde) auf dem Spiel standen. Doch gab es wohl Ausnahmefälle. ${ }^{95}$ Ob es darüber hinaus einen gewissen Stamm durchweg in der Politik engagierter Bürger gab, der mit einiger Regelmäßigkeit die Comitien besuchte, ist nicht zu ermitteln.

Für die Gesetzgebung waren vornehmlich die nach Tribus organisierten Comitien zuständig, seien es die der Gesamtgemeinde oder - seit 287 - vor allem die der Plebs. Das Abstimmungsverfahren war dort viel einfacher, also schneller abzuwickeln. In beiden Versammlungen waren die Stimmgewichte sehr viel weniger ungleich verteilt als in den Centuriatcomitien. Es gab in ihnen auch keine Vorbildwirkungen nach Rang und Classe. Antragsteller waren zumeist die Volkstribunen. Die hatten seit alters viel mit der Volksversammlung zu tun. Andererseits waren ihnen von Amts wegen viel weniger Geschäfte aufgetragen als etwa Consuln und Praetoren. Wenn sie sich dabei immer wieder als Werkzeuge der Senatsmehrheit erwiesen, so ist damit andererseits wohl nicht gesagt, daß sie Anträge nur hätten stellen können, wenn der Senat sie zuvor beraten und gebilligt hatte. ${ }^{96}$

Es gab eine Reihe von Agenden der Politik, für die ein Volksbeschluß - in aller Regel zur Bestätigung von Senatsbeschlüssen - notwendig war. Die Entscheidung über Krieg und Frieden etwa, über Bündnisse, Verlängerung von Kommanden, Verleihung von Triumphen. ${ }^{97}$

In aller Regel hat das Volk, soweit wir sehen können, die ihm zur Bestätigung vorgelegten Anträge beschlossen. Wir kennen nur zwei bedeutsamere Fälle, in denen das nicht geschah. Als der Senat es im Jahre 200 für richtig hielt, Makedonien den

rechnen muß (unten S.667f., 68I, 682), mußte nicht manch einer dazu neigen, es darauf ankommen zu lassen, was die Abstimmung schließlich ergab? Wenn Livius 42,2 I ausdrücklich erwähnt, daß ein Antrag magno consensu durchging, waren ja wohl auch knappe Mehrheiten gängig. Etwas anderes war es, daß die weitaus meisten Volksbeschlüsse im Sinne des Senats gefaßt wurden.

95 S. Anm. I 4 .

96 Das wird allerdings „üblich“ gewesen sein, auch ohne Gesetzesnorm (Kunkel, Staatsordnung [wie Anm. I], 32of.), nur schließt das verschiedene Ausnahmen keineswegs aus. Z. B. Livius 38,36,7f., wo offensichtlich der Antrag direkt dem Volk vorgelegt wurde. Daß es ihm zustand, das ius suffragii zu verleihen, schließt keineswegs aus, daß der Senat üblicherweise die Sache vorher beriet, was immer den Volkstribunen zur Rücknahme seines Vetos bewog.

97 Dazu Lundgreen, Regelkonflikte (wie Anm.46). 
Krieg zu erklären, wollte das keine Mehrheit finden. Man hatte nach dem langen verlustreichen zweiten Punischen Krieg (2 I 8/20I) genug vom Kriegsdienst. Und es waren offenbar viele Wehrpflichtige oder solche, die sich deren Sache zu eigen machten, anwesend. Darauf folgte eine höchst erregte Senatssitzung. Der Consul wurde beauftragt, die Comitien noch einmal einzuberufen. Er hielt eine eindrucksvolle Rede, worauf die Versammlung zustimmte. ${ }^{98}$ Im Jahre I67 wollte der Senat den glanzvollen Sieger über das makedonische Königreich mit einem Triumph auszeichnen. Der hatte sich aber bei seinen Soldaten (von denen viele sich nach der Heimkehr in Rom aufhielten) durch Strenge unbeliebt gemacht, speziell weil er sie zu wenig an der reichen Beute beteiligt hatte. Einer seiner Offiziere redete kräftig auf sie ein. Sie sollten ihren Unwillen deutlich manifestieren, indem sie die Volksversammlung besuchten und mit Nein stimmten. Was sie in großer Zahl taten. Livius schreibt, sie hätten zuvor wenig Interesse gehabt, überhaupt teilzunehmen. Wie wohl üblich, wären sonst also auch in diesem Falle vor allem diejenigen anwesend gewesen, denen an der Sache gelegen war (oder die jedenfalls bereit waren, dem Senat - oder den Betroffenen - zu Willen zu sein). Da nun aber die Tendenz zur Ablehnung des Antrags überwog, war der Senat alarmiert. Die Abstrafung eines bedeutenden, erfolgreichen Feldherrn konnte nicht in seinem Sinne sein. Als die ersten Tribus mit Nein stimmten, eilten darum die führenden Senatoren auf das Capitol, gaben ihrem Zorn lauten Ausdruck und verlangten, daß die Sache nach öffentlicher Diskussion erneut zur Abstimmung gestellt würde. Was den erhofften Erfolg brachte. Insofern hatten die Senatoren, wenn sie sich mit aller Macht für etwas einsetzten, beste Aussichten, von der Volksversammlung zu bekommen, was sie wollten. Das war äußerstenfalls eine Frage des Engagements, nicht der Wahrnehmung irgendeines Rechts. ${ }^{99}$ Vom Gegenteil findet sich in den Quellen keine Spur.

Darüber hinaus dienten die Comitien dem Senat dazu, durch Gesetze bestimmte Dinge wie die Bewerbung um die Magistrate bindend zu regeln - was, wie erwähnt, auf eine Einschränkung der Wahlfreiheit hinauslief. Hinzu kamen zahlreiche Anträge, vielfach auf Veranlassung des Senats, im übrigen auf Initiative von Consuln oder Volkstribunen, die etwa Einzelheiten des Privat- oder Strafrechts regeln sollten,

\footnotetext{
98 Livius 3I,6f.

99 Livius 45,35ff.; Plutarch, Aemilius 3off. Für einen ähnlichen Fall senatorischen Einsatzes, diesmal in der Form des Bittflehens s. unten S.677.
} 
Anordnungen zur Behebung von Notlagen breiterer Schichten, aber auch Eingriffe in die politischen Abläufe.

Übrigens konnte es auch sein, daß der Senat den Comitien eine Entscheidung zuwies, weil er sich aus irgendwelchen Gründen scheute, sie selbst zu treffen (obwohl er das durchaus hätte tun können). Er hatte offenbar keinen Anlaß zu der Befürchtung, dadurch würde die Volksversammlung zu mächtig. Er nahm vielmehr in Auseinandersetzung mit Magistraten einfach die gegebenen taktischen Möglichkeiten wahr. Oder er vermied den Ärger, der ihm bei riskanten Personalentscheidungen hätte erwachsen können. Vielfach war es, gerade in schwierigen Fragen, auch klug, sich nicht in bestimmte Richtungen zu exponieren. ${ }^{\text {100 }}$

Doch gab es natürlich auch die anderen Volksbeschlüsse, die gegen die Senatsmehrheit beantragt und zumeist auch beschlossen wurden, wie ja auch mit der Volksversammlung gedroht werden konnte, falls sich der Senat nicht dazu bereitfand, bestimmte Beschlüsse zu fassen.

Diese Volksbeschlüsse sind insofern von besonderem Interesse, als ihnen abzulesen ist, innerhalb welchen Radius’ sich diese Tätigkeit nach Abschluß der „Ständekämpfe“ zu bewegen pflegte. Denn wo die Grenzen der formal fast uneingeschränkten Vollmachten römischer Verfassungsorgane verliefen, ist ja nur aus der Beobachtung dessen zu ermitteln, was sie taten oder beschlossen respektive gerade nicht getan oder beschlossen haben. Am weitesten unter den Eingriffen in die Exekutive ging die lex agraria des C. Flaminius von 232, die eine Aufteilung von Äckern im Picenum an römische Bauern vorsah. Zu nennen ist weiter die Gleichstellung des magister equitum, grob gesagt: des Stellvertreters des Dictators mit seinem Vorgesetzten im Jahre 2 I 7. Diese Entscheidung richtete sich gegen den amtierenden Dictator, ohne daß damit für die weitere Zukunft etwas präjudiziert werden sollte. 204 war man drauf und dran, gegen den Willen des Senats das Kommando des jungen Scipio auf Africa zu erstrecken. ${ }^{\text {IOI }}$ Er hatte schon damit gedroht. Nur hat es der Senat schließlich selbst getan. I67, in einem vierten Fall, als nämlich ein Praetor einen Krieg gegen Rhodos zu beschließen beantragte, ohne vorher den Senat zu befragen,

Ioo Als der Senat darauf verzichtete, einen Beschluß zugunsten des Kriegs zu fassen, der dann der erste Punische werden sollte (Polybios I,I0,3.9 f.), könnte neben der Schwierigkeit der Sache auch der Brauch, im Zweifel keinen Beschluß zu fassen, mitgesprochen haben. Vgl. unten S.686.

IOI Livius 28,40,Iff. 
ist die Abstimmung, ja schon die üblicherweise vorangehende Debatte darüber, durch Veto vereitelt worden. ${ }^{\text {I02 }}$

Ganz selten und ziemlich unbeträchtlich waren auch solche gegen den Senat gefaßte Beschlüsse, welche direkt oder indirekt das Regelwerk der Republik betrafen. Es könnte zu ihnen der aus der ersten Hälfte des 3.Jahrhunderts gehören, den obersten Priester (pontifex maximus) unter Mitwirkung der Comitien bestellen zu lassen, nachdem zuvor das Priestercollegium selber dafür zuständig gewesen war. Wahrscheinlich ist das nicht unbedingt. Denn es könnte auch im Sinne der Entlastung des Adels (oder kleiner Kreise von Adligen) von schwierigen, für manch einen verletzenden, Personalentscheidungen erfolgt sein. Oder im Sinne eines ambitionierten Interessenten? Ohnehin blieb es dabei, daß die adligen Priester ihr Collegium durch Kooptation ergänzten.

Sicher gegen den Willen, ja gegen heftige Widerstände von seiten vieler Senatoren wurde die lex Claudia von 2 I 8 beschlossen. Sie schränkte die wirtschaftliche Tätigkeit der Senatoren ein. Politisch mochte das der Geschlossenheit des Hauses zugute kommen, es diente aber vor allem den wohlhabenden Nicht-Senatoren, die das dadurch entstehende Vakuum besetzen konnten. Nicht unbedingt auf Beifall beim Senat könnte der Antrag auf die lex Calpurnia von I49 gestoßen sein, durch den ein ständiger Gerichtshof für Fälle der Ausbeutung von Provinzialen eingerichtet wur-

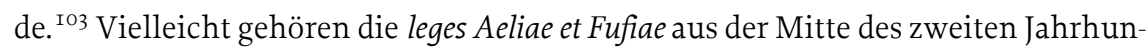
derts ebenfalls in diesen Zusammenhang, sofern sie die Möglichkeit einschränkten, aufgrund von Himmelsbeobachtung Gesetze nachträglich annullieren zu lassen. ${ }^{\text {I04 }}$ Schließlich fallen die ersten beiden leges tabellariae (I 39 und I37) noch in die Zeit vor Tiberius Gracchus: Es wurde die schriftliche Abstimmung zunächst für die Wahlen, dann für verschiedene Volksgerichtsverfahren beschlossen. Soweit wir aus den Consullisten schließen können, hat letzteres Gesetz nicht dazu geführt, daß andere Kandidaten gewählt wurden als üblich. Doch sollten bestimmte störende Praktiken zur Kontrolle der Wähler ausgeschlossen werden (soweit das möglich war). ${ }^{\text {I05 }}$

I02 Livius 45,2 I; Christian Meier, Die loca intercessionis bei Rogationen, in: Museum Helveticum 25, I968, 86-I00.

I03 Lily Ross Taylor, Forerunners of the Gracchi, in: JRS 52, I962, I9-27, hier $24 \mathrm{f}$.

I04 Meier, Populares (wie Anm. 52), 607. Die Sache ist natürlich umstritten; s. schon Taylor, Forerunners (wie Anm. I03), 22 u. 25.

I05 Meier, Art. „Populares“ (wie Anm.52), 602. Martin Jehne, Geheime Abstimmung und Bindungswesen in der Römischen Republik, in: HZ 257, I993, 593-6r 3; Lundgreen, Abstimmung (wie Anm. 84), $36 \mathrm{ff}$. 
Dieser Befund, wonach nur vergleichsweise wenige und kaum sehr weitreichende Anträge zugunsten breiterer Schichten - oder wenigstens zuungunsten des Senats - gestellt und verabschiedet worden sind, kann nicht dadurch bedingt gewesen sein, daß die Volksversammlung nur von Obermagistraten oder Volkstribunen einberufen werden konnte und daß nur sie berechtigt waren, einen Antrag zu stellen. Denn das kann nur begrenzt etwas ausgemacht haben.

Jeweils waren es mehrere, die dafür in Frage kamen. Wenn also größere Ärgernisse dringend nach Abhilfe gerufen, wenn sich in breiteren Schichten so etwas wie ein veritabler Druck zu politischer Aktion herauskristallisiert hätte ${ }^{\text {I06 }}$, hätte sich da nicht jemand finden müssen, der die Sache zum Gegenstand eines Antrags machte? Gewiß, es hätte Konflikte geben können zwischen den Forderungen „des Volkes“ (samt der Verantwortung, die den Volkstribunen von Amts wegen dem Volk gegenüber oblag) und den Bedenken führender Senatoren. Vieles war eine Frage der Courage. Und gerade die Couragierteren unter den Tribunen strebten oft nach einer Fortsetzung ihrer Laufbahn - konnten also so leicht nicht bereit sein, es sich mit den Häuptern der Republik zu verscherzen (die im Zweifelsfalle auch bei Wahlen weit mehr vermochten als „das Volk“ oder größere Teile von ihm). Andererseits mußte nicht jeder bei jeder Gelegenheit nur spätere Wahlchancen im Auge haben. Und es gab genügend Anreize für junge Männer, ihrem Ärger gegenüber den Standesgenossen (oder dem Senat) einmal Luft zu machen. Und vor allem: wenn wirklich im Volk akute Not oder größere Beschwerden für Ärger gesorgt, wenn Unruhen gedroht hätten, wäre es da nicht geradezu geboten gewesen, dem abzuhelfen? ${ }^{107}$ Wie man das getan, wie man einen Antrag formuliert hätte, eventuell unter Berücksichtigung von Bedenken, hätte beim Antragsteller gelegen. Gewiß, bei längerfristig störenden, aber kurzfristig nicht geradezu alarmierenden Mißständen konnte vieles unterbleiben, was eigentlich notwendig gewesen wäre. ${ }^{\text {I08 }}$ Aber für alle akuten Spannungen kann das kaum gegolten haben. Folglich wird man annehmen können, daß die Beschränkung des Rechts zur Antragstellung zwar eine gewisse Schwelle, aber keine höhere Barriere für die Wahrnehmung der gesetzgebenden Kompetenz der Volksversammlung dargestellt hat. Wenn so wenig weiterreichende Anträge gestellt wurden, spricht das dafür, daß keine stärkeren Kräfte darauf gedrängt haben.

Io6 Vgl. etwa Plutarch, Gracchi 8, I0; Lintott, Constitution (wie Anm. 2), 205.

I07 Cicero, de legibus 3, 23.

I08 Plutarch, Gracchi 8,5. 
Übrigens sollte man auch die Möglichkeiten, durch das Veto Volksbeschlüsse zu verhindern, nicht zu hoch veranschlagen. Wohl war das Recht des Einspruchs gegen einen Antrag (sei es des Collegen des Obermagistrats, sei es des Volkstribunen) formal kaum begrenzt. Aber wieweit sich das Veto am Ende durchhalten ließ, wäre eine Frage nicht nur der Courage, sondern auch der Unterstützung durch andere sowie vor allem der Kraft gewesen, mit der „das Volk“ einen Antrag trug. Die mußte sich unter den spezifischen Bedingungen römischer Öffentlichkeit gut bemerkbar machen. Immerhin hätte es sich, wenn es wirklich einen Willen gehegt hätte, gefallen lassen müssen, daß der interzedierende Tribun es an der Äußerung dieses Willens hinderte. ${ }^{\text {I09 }}$ Es wirkte somit vieles dahin, daß vom Veto kein absoluter, von den Bedingungen absehender Gebrauch gemacht wurde.

Es ist schwer zu sagen, wie weit sich der Radius möglicher Beschlüsse hier und dort problemlos hätte ausweiten lassen. Aber wenn man annimmt - und es bleibt doch wohl nichts anderes übrig -, daß in dieser Ordnung die verschiedensten Kräfte zumindest im Endeffekt ein einigermaßen ausgewogenes Verhältnis zueinander eingehalten haben, so müssen ihren formal großen, ja unbeschränkten Spielräumen Grenzen gesetzt gewesen sein, die nicht, wenigstens nicht ungestraft (oder - vielleicht besser: - ohne kräftige Korrekturen hervorzurufen) mißachtet werden konnten. Wo sie genau verliefen, wird vielleicht erst bewußt geworden sein, wenn sie überschritten zu werden drohten. Bei aller möglichen Elastizität mußte irgendwo harter Widerstand einsetzen. Dann mußte geleistet werden, wofür formale Regelungen nicht aufkamen.

Insgesamt ergibt sich: Es ist so gut wie nichts mit Hilfe der Volksversammlung an der bestehenden Ordnung geändert worden, und sofern doch, so oft im Sinne des Senats. Und man wird annehmen können, daß die Beschlüsse gegen den Senat primär auf Anträge zurückgingen, die im persönlichen Interesse einzelner Adliger lagen. ${ }^{\text {I } ~}$ Es wurde insofern durch die Volksversammlung nur der Instrumentenkasten der Politik bereichert. Der Befund korrespondiert der Bereitschaft der Volksversammlung, sich etwa bei den Magistratswahlen in ein enges Korsett einschnüren zu lassen. Auch das hätte ganz und gar nicht in ihrem Sinne sein können, wenn sie oder zumindest größere Teile von ihr in der Politik eigenen Willen hätten geltend machen wollen.

I09 Zum möglicherweise Empörenden solcher Interzession Cicero, pro Cornelio I,3 I. Im übrigen vgl. unten S.674f., 68 o.

I Io Bleicken, Volkstribunat (wie Anm.42), $64 \mathrm{ff}$. 
Der schon erwähnte Antrag, er stammte von Gaius Gracchus, die Reihenfolge der Centurien durch das Los bestimmen zu lassen, ist vermutlich gar nicht erst eingebracht worden. Auch zwei später versuchte Wiederaufnahmen sind gescheitert. ${ }^{\text {II }}$ Und mehr als das hat man an den Centuriatcomitien ohnehin nicht in Frage gestellt.

Auffällig ist auch, daß die mündliche Stimmabgabe nicht in einem Akt, also grundsätzlich abgeschafft wurde, sondern - zwischen I39 und Io6 - durch insgesamt vier Gesetze für die Abstimmungen über verschiedene Gegenstände. Je nach Anlaß also wurden hier die Anträge gestellt.

Am aufschlußreichsten sind die Versuche von Volkstribunen, eine unmittelbare Wiederwahl durchzusetzen. In der Zeit der „Ständekämpfe“ hatte es das gegeben. Danach scheint es sich eingebürgert zu haben, daß für die Tribunen wie für alle andern Magistrate Kontinuation des Amtes ausgeschlossen war. Keiner sollte ein Amt über Jahresfrist hinaus innehaben. Mit dieser Regel wollte Tiberius Gracchus im Jahre 133 brechen. Es schien ihm gut, auch im anschließenden Jahr den Schutz der sacrosanctitas zu genießen; er hatte aber zudem wahrscheinlich weitere Reformen vor. Da wurde es gefährlich. Der Senat war ohnehin schon aufs äußerste gereizt. Jetzt schien sich die Möglichkeit einer nachhaltig gegen ihn und wohl auch gegen die herkömmliche Ordnung sich richtenden Politik zu eröffnen. Wir wissen nicht, ob Gracchus sich einfach zur Wahl stellte oder zunächst ein Gesetz einbrachte, das ihm die Wiederwahl erlaubt hätte. ${ }^{\text {II2 }}$ Jedenfalls ist er, als die Volksversammlung darüber beschließen sollte, zum Opfer senatorischer Lynchjustiz geworden. Daß das Gros der Senatoren - ein Beschluß wurde nicht gefaßt - damit seinerseits die Linie des gewaltlosen Regiments und der Überparteilichkeit, eine sehr wesentliche Voraussetzung der Ordnung der Republik, aufgab, war die andere Seite der Medaille. ${ }^{\text {II3 }}$

Als zwei oder drei Jahre später ein anderer Tribun ein Gesetz zur Abstimmung bringen wollte, das die unmittelbare Wiederwahl von Volkstribunen erlaubte, erlitt er eine Abstimmungsniederlage. Scipio Aemilianus soll das durch eine höchst eindrucksvolle Rede bewirkt haben. A. E. Astin hat diese Erklärung nicht für zurei-

\footnotetext{
II I S. oben Anm. 85 .

I 2 Lily Ross Taylor, Was Tiberius Gracchus' Last Assembly Electoral or Legislative?, in: Athenaeum 4I, I963, 5 I-69; dies., Appian and Plutarch on Tiberius Gracchus' Last Assembly, in: Athenaeum 44, I966, 238250.

I 3 Wenn Cicero, de re publica I,3 I später formuliert: „Wie ihr seht, hat der Tod des Ti. Gracchus und schon vorher die ganze Weise seines Volkstribunats das eine Volk in zwei Teile geteilt" (divisit populum unum in duas partes), so war genau dies mit der überkommenen Ordnung unvereinbar.
} 
chend gehalten. Vielmehr müßten die Adligen ihre Clienten in großer Zahl gegen den Antrag aufgeboten haben. Dafür spricht, daß der Tribun im gleichen Jahr das Gesetz beantragt und durchgesetzt hat, wonach auch bei gesetzgebenden Versammlungen künftig schriftlich abgestimmt werden sollte. Dann hätte also der vereinte Einsatz des Adels mitsamt seinen Gefolgsleuten den Antrag zu Fall gebracht. Die Vermutung hat sehr viel für sich. ${ }^{{ }^{I} 4}$ Später ist es Gaius Gracchus mit Hilfe seiner großen Anhängerschaft einmal gelungen, wiedergewählt zu werden, ohne daß es ein Gesetz darüber gegeben hätte. Doch hat sich das nicht wiederholt. ${ }^{\text {II5 }}$ Bei den nächsten Wahlen scheint man massiv Clienten gegen den Tribunen aufgeboten, eventuell auch die Wahlen manipuliert zu haben.

5. Von kurzfristigen Ausschlägen vielleicht abgesehen, hat sich mithin im Volk kein Wille geregt, über das hinaus, was gleichsam plebejisches Grundrecht war, gemeinsame Interessen gegen den Adel zu verfechten. Zu schweigen davon, daß „das Volk“ - von den genannten Einzelheiten abgesehen - etwas zur grundlegenden Verbesserung der eigenen Position hätte ins Werk setzen wollen. Wohl könnte man einwenden, das sei überflüssig gewesen, da „das Volk“ doch alle Rechte schon gehabt habe, deren es bedurfte. Doch fehlte es ja daran, daß es sie nutzte und das heißt nutzen konnte, etwa zur Einrichtung regelmäßiger Rechenschaftsablage der Magistrate vor der Volksversammlung, zum Recht, sie abzusetzen, zur Änderung des Wahlsystems, der Wahlcomitien, des cursus honorum, zur Begründung eines Rechts, unabhängig von Magistraten Anträge vor das Volk zu bringen und/oder das Veto dagegen zu verhindern, ganz zu schweigen davon, daß man die Lebenslänglichkeit der Senatssitze abgeschafft und periodische Senatswahlen eingeführt (oder einen neuen Rat geschaffen und den Senat auf wenige ehrenvolle Funktionen beschränkt) hätte.

Anders hätte es sich wohl nur verhalten, wenn sich im Adel Gruppen gebildet hätten, die sich auf die Volksversammlung gegen die Senatsmehrheit zu stützen versucht, die entsprechend agitiert und bestimmte Teile der Bürgerschaft mobilisiert hätten, um sie zugleich aufzuwerten und vor den eigenen Wagen zu spannen. (Wo-

I 4 Cicero, Laelius 96; Alan E. Astin, Scipio Aemilianus. Oxford I967, 232 f. Angesichts der Tatsache, daß hier wirklich ein Nerv getroffen wurde und jede Gefahr in der aufgeheizten Atmosphäre kurz nach Tiberius Gracchus' Tribunat als bedrängend empfunden werden mußte, ist mit der Aufbietung zahlreicher Clienten bei dieser Gelegenheit doch wohl zu rechnen. Dafür daß der Antrag wirklich in der Abstimmung durchfiel, spricht ganz unverkennbar die Formulierung: lex popularis suffragiis populi repudiata est.

I 5 Ein weiterer Versuch immerhin, das Amt zu kontinuieren, erfolgte I Io: Sallust, Jugurtha 37,2. Hier ist kein besonderer Anlaß zu sehen. 
bei Antriebe von seiten Adliger wie von denen ganzer Teile des Volkes hätten einander entgegenkommen müssen). Genau das aber trat offenkundig nicht ein. Sonst müßten wir davon hören. ${ }^{\text {II } 6}$ Man kann sich fragen, ob eher adlige Disziplin oder eher die Schwäche der als Anhängerschaften denkbaren Teile des Volkes die Ursache dafür oder ob es schon im Rahmen des damaligen Wissens ausgeschlossen war, auf solche Gedanken überhaupt zu verfallen, sie jedenfalls ernsthaft zu erwägen und weiterzubringen in den politischen Raum. Vermutlich waren sowohl „das Volk“ als auch der Adel so sehr auf die seit alters bestehende Ordnung „eingestellt“, daß solche Fragen am Sinn der Sache vorbeigehen.

Hätte ein Grieche in der klassischen Republik einen Römer gefragt, worüber die römische Volksversammlung Beschluß fassen konnte, hätte er vermutlich zur Antwort bekommen: worüber sie will. Denn so war es; einerseits (jedenfalls soweit sich ein Magistrat fand, um den Antrag zu stellen). Hätte er aber nachgefragt, ob sie etwa einen Magistrat absetzen könne (wie die attische das konnte und nicht selten getan hat) oder gar die Zugehörigkeit zum Senat von immer neuen Wahlen abhängig machen, hätte der Römer vermutlich erwidert: Nein, das natürlich nicht. Es verstand sich eben, andererseits, eine ganze Reihe von Vorbedingungen (und Begrenzungen der Verfügungsmacht), und zwar gerade dort, wo es wichtig war, von selbst.

Freilich hat Tiberius Gracchus I33, um sein Ackergesetz durchzubringen, doch einen Tribunencollegen absetzen lassen können. Und sein Bruder Gaius hat I 23/22 vorgehabt, das Recht der Volksversammlung, so etwas zu beschließen, implizit bestätigen zu lassen. Er wollte einen Antrag stellen, wonach der, dem die Comitien ein Amt aberkannten, sich um weitere Ämter nicht mehr bewerben dürfe. Aber Tiberius Gracchus hat durch die Absetzung seines Collegen helle Empörung ausgelöst. ${ }^{\text {II7 }} \mathrm{Sie}$ war ihm keineswegs leichtgefallen, muß wesentlich zur Entstehung jener unver-

\footnotetext{
I 6 Vgl. oben Anm. I5. Anders könnte es sich in den Jahren vor dem zweiten Punischen Krieg (sowie zu dessen Anfang) verhalten haben, wenn sich nämlich um C. Flaminius ein Kreis von Senatoren gebildet hätte, der, auf einen Anhang bis in die erste Klasse der Wähler hinein gestützt, gemeinsam nach Machtpositionen gestrebt hätte. Abgesehen davon aber, daß das nicht recht klar wird: Es wäre die Ausnahme geblieben, eventuell abgeblockt durch den so großen, einschneidenden Krieg, der folgte.

I 7 Plutarch, Gracchi I I f.; Appian, Bellum Civile I, $48 \mathrm{ff}$. Gracchus ist sich offenbar im klaren darüber gewesen, wie einschneidend sie war. Das gilt unbeschadet der Tatsache, daß Octavius sein Interzessionsrecht verabsolutierte, also weit über das Angemessene hinaustrieb (Meier, Loca intercessionis [wie Anm. I02], 9of., 97 f.; Ernst Badian, Tiberius Gracchus and the Beginning of the Roman Revolution, in: Temporini [Hrsg.], Aufstieg [wie Anm. I8], Bd. I I. Berlin/New York I972, 668-73 I, hier 697f.).
} 
söhnlichen, feindlichen Atmosphäre beigetragen haben, der er schließlich zum Opfer fiel. Und Gaius hat seine Absicht fallengelassen.

Was also durfte die Volksversammlung, was durfte sie nicht? Oder ist es gar nicht angebracht, so zu fragen? Immerhin, als zahlreiche Senatoren gegen Tiberius Gracchus zur Gewalt greifen wollten und der Consul, ein prominenter Jurist, das ablehnte; man dürfe Bürger nicht töten, wenn sie nicht verurteilt seien; fügte er hinzu, wenn etwas, was gegen Recht und Sitte sei, beschlossen würde, werde er das nicht für gültig erachten. Da gab es also noch etwas anderes, was über der Volksversammlung war und woran diese nicht zu rühren hatte. ${ }^{\text {II8 }}$ Das kann nicht nur die unstrittige Überzeugung gewesen sein, daß sie zum Beispiel nicht in die Rechte der Götter eingreifen durfte. So hat der Consul sein Urteil auch nach Vollstreckung der Lynchjustiz korrigiert: Er hat mehrere Senatsbeschlüsse veranlaßt, in denen sie nicht nur verteidigt, sondern ausdrücklich gutgeheißen wurde. ${ }^{\text {II } 9}$ Wir kennen seine Argumente nicht, aber er muß doch wohl zu der Überzeugung gelangt sein, daß mit der Wiederwahl des Ti. Gracchus etwas geschehen wäre, was mit der überkommenen Ordnung nicht vereinbar war.

6. Daß die Volksversammlung an dieser Ordnung jahrhundertelang nichts Wesentliches veränderte, obwohl sie es (indes unter der Leitung ehrgeiziger oder willfähriger Magistrate) formal gekonnt hätte, zeigt, daß sie es in Wirklichkeit eben gerade nicht konnte, weil das gar nicht in Frage kam, gar nicht denkbar war. ${ }^{\text {I20 }}$

Aus den vielfältigen Beteuerungen der „Herrschaft des Volkes“ ableiten zu wollen, es hätte über wichtige Teile dieser Ordnung verfügen können, hieße also, die

I 8 Plutarch, Gracchi I9,4; Valerius Maximus 3,2,I 7; Nippel, Aufruhr (wie Anm. 22). Allgemein zum Problem: G. Nocera, Il Potere dei Comizi e i suoi Limiti. Mailand I940; Meier, RPA (wie Anm. 2), I I8f.; Bleicken, Lex (wie Anm. I I), 292 f., $339 \mathrm{ff}$.

I 9 Cicero, pro Plancio 88; de domo sua 9I.

I20 Die Volksversammlung hat auch in den folgenden Jahrzehnten der späten Republik an der Ordnung fast nichts direkt verändert. Das Senatsregime blieb, ebenso die Überzeugung, daß der Senat die Verantwortung für die Republik habe, Adlige besetzten weiterhin, wenn auch in einigen wenigen Jahren eingeschränkt, die Ämter, und die tägliche Routine setzte sich fort. Zu stark, zu alternativlos war das Herkömmliche in den Köpfen verankert. Allein, in wichtigen Fällen konnte der Senat sich nicht mehr durchsetzen außer durch blutige Gewalt (vgl. Christian Meier, Der Ernstfall im alten Rom, in: Der Ernstfall. [Schriften der Carl Friedrich von Siemens-Stiftung, Bd. 2.] Frankfurt am Main u.a. I979, 40-73, hier 5off.). Wenn es, wie sich gleich zeigen wird, zur römischen Ordnung gehörte, daß der Senat im Entscheidenden überparteilich blieb und sich ohne blutige Gewalt durchsetzen konnte, so erweist sich freilich gerade darin, daß die Republik eine andere geworden war. 
Rechte der Volksversammlung nicht „verfassungsgemäß“ interpretieren, nämlich die besonderen Bedingungen der gewachsenen Verfassung übersehen. Auch die Rechte der Volksversammlung verstanden sich im Rahmen des Gegebenen ${ }^{\mathrm{I2I}}$, unter den „Geschäftsbedingungen“, den ungeschriebenen, vermutlich nur zum Teil bewußten prerequisites der Republik.

Alle Komplimente an die Adresse des Volkes dienten nur dazu, es zu veranlassen, zu tun, was ihm abverlangt wurde; nicht zuletzt zur Stabilisierung des Adelsregimes durch Gesetze. Es war besser, mit seiner Einwilligung über es zu verfügen. Nur in Ausnahmesituationen konnte sich in ihm so etwas wie ein Eigenwille mehrheitsfähiger Gruppen regen, zwar zu Beschlüssen gegen den Senat führen, aber selten und um sich anschließend rasch wieder zu beruhigen.

Es ist charakteristisch, daß zwar für Magistrate und für Bewerber um die Ämter, aber nicht für Senat und Volksversammlung Einschränkungen durch Gesetze festgelegt wurden. Man neigte, man kam nicht dazu, gleichsam ein für allemal deren Spielräume zu normieren. Ja, man brauchte das nicht, weil die Ordnung selbst, zumindest alles Wesentliche an ihr, in allen und zwischen allen in der, wie immer gegliederten, jeweiligen Gegenwärtigkeit der Bürgerschaft lebendig war und dem Handeln Grenzen setzte.

Es gibt keinen Grund, die von heute her in antike Formeln - wie die vom Volk als Herrscher - hineinzudenkenden, aber eben durch Jahrhunderte hindurch überhaupt nicht wahrgenommenen Möglichkeiten (mit denen also praktisch nicht zu rechnen, die in Wirklichkeit gar nicht gegeben waren) innerhalb einer gewachsenen Verfassung einfach als Rechte zu verstehen und daraus etwa die Folgerung zu ziehen, die Volksversammlung sei in Rom souverän gewesen.

Der neuzeitliche Begriff der Souveränität scheint für das antike Rom weniger noch als mancher andere (etwa der des Staates) angebracht zu sein. Nie hat sich dort eine Frage gestellt, auf die dieser Begriff die Antwort hätte sein können. Es hätte Gestaltungsspielräume vorausgesetzt, die sich dort nicht eröffnet haben. Um es zu wiederholen: Nie hat sich „das Volk“ in Rom aus den Bindungen seiner Gesamtheit sowie seiner vielen Angehörigen an den führenden Adel emanzipiert, nie hat es Versuche gegeben, eine „politische“ gegen die „gesellschaftliche“ und die „mentale“ Ordnung zu setzen, Ordnung also sich verfügbar zu machen. Nie ist es - wie bei den

I2 I So auch Bleicken, Lex (wie Anm. I I), 297. 
Griechen - dazu gekommen, daß die selbstverständliche Geltung eines im ganzen vorgegebenen Rechts, also die „nomistische“122 Basis der Ordnung durchbrochen worden wäre, nicht einmal in der späten Republik, bevor die den Bürgerkriegen der 4oer und zoer Jahre anheimfiel. Die anschließend gegründete Monarchie konnte sich zwar in gewissem Umfang auf Volksbeschlüsse, aber kaum auf das Volk stützen. Sie beruhte wesentlich auf der Armee (und dem Friedensbegehr der gesamten Bürgerschaft und des Herrschaftsbereichs). Und - entscheidend für ihre Legitimation war der Senat, nicht die Volksversammlung.

Und schon gar nicht ist die römische Ordnung, auch nicht der Form nach, vom Volk ausgegangen. Senat, Patriciat und Magistrate waren vermutlich schon da, mit all ihrer Überlegenheit, ihren Qualitäten, ihrem Charisma, bevor „das Volk“ sich überhaupt zu Wort hat melden können. Weder ihre Existenz noch ihre Kompetenz sind (von Einzelheiten abgesehen) je einem Volksbeschluß unterworfen, ihr vorgegebenes Recht ist nie in Frage gestellt worden. Die einzige große Einwirkung auf die römische Ordnung, die vom „Volk“, in diesem Fall von jenem Teil davon, der sich als plebs konstituierte, ausging, hatte, wie gesagt, nur die Verbesserung der Rechte einer großen Zahl von Bürgern innerhalb der vorgegebenen Ordnung im Auge. Sie hat die aristokratische Struktur der Republik, abgesehen vom allmählichen Abbau der meisten patricischen Privilegien, allenfalls modifiziert. Letztlich ging diese Struktur erfolgreich und bestätigt, jetzt unter Führung der patricisch-plebejischen Nobilität sowie unter Hinzufügung von Freiheitsrechten, aus dem Ringen der „Stände“ hervor.

In Ciceros de re publica $(\mathrm{I}, 7)$ wird vom Gros der Bürger gesagt: Sie geben ihre Stimme ab, übertragen militärische Kommanden und Magistrate, werden umworben, gefragt, aber sie geben, was, auch wenn sie nicht wollten, gegeben werden muß und was sie selbst, von denen andere es begehren, nicht haben. Sie haben nämlich keinen Anteil am Oberbefehl, am Rat des Gemeinwesens, am Urteil ausgewählter Richter.

I 22 Die Unterscheidung zwischen „nomistischen“ und „kratistischen“ Verfassungen - Christian Meier, Drei Bemerkungen zur Vor- und Frühgeschichte des Begriffs Demokratie, in: Marc Sieber (Hrsg.), Discordia concors. Basel/Stuttgart I968, Bd. I, 3-29; überarb. in: Konrad H. Kinzl (Hrsg.), Demokratia. Der Weg zur Demokratie bei den Griechen. (Wege der Forschung, 657.) Darmstadt I995, I 25-I59, hier I4 I - erscheint mir nach wie vor als nützlich; vgl. Christian Meier, Entstehung des Begriffs „Demokratie“. Frankfurt am Main I970; ders., Die Entstehung des Politischen bei den Griechen. Frankfurt am Main I980, 244, 279ff., 427f. Freilich hat sie kaum Anklang gefunden. Ausnahme: Tonio Hölscher, Griechische Historienbilder des 5. und 4.Jahrhunderts v. Chr. Würzburg I973, 205f., sowie ders., Die Nike der Messenier und Naupaktier in Olympia. Kunst und Geschichte im späten 5.Jahrhundert, in: JbDAI 89, I974, 70-I I I: aufschlußreich für den Zusammenhang bei den Griechen, aber ohne die Begriffe zu gebrauchen. Vgl. jedoch IoI, I42. 
Denn die werden nach dem Alter der Familie oder nach Vermögen zugewogen. Er wird es gewußt haben.

VI.

I. Fragt man, wodurch es möglich war, daß sich die Volksversammlung bei Wahlen und Gesetzgebung in einem ganz engen Radius hielt, daß sich in ihr allenfalls einmal vorübergehend ein Eigenwille breiterer Schichten regte, daß in ihr also (über die Plebs und ihre spezifischen Angelegenheiten hinaus) keine horizontale Solidarität erwuchs, so könnte man sich, herkömmlich, auf einige allgemein anerkannte Eigenarten Roms verwiesen finden, die sich insgesamt als Grundbedingungen dieser Ordnung - Bagehots prerequisites - ansehen lassen. Sie müßten mit dieser Ordnung untrennbar verwoben, ihr nicht nur zugrundegelegen haben, sondern ihr Teil gewesen sein. Während sich in modernen Verfassungen, sofern sie demokratisch sind, Besonderheiten der Geschichte und der Mentalität der Nationen nur streckenweise oder schwach niederzuschlagen pflegen, müssen sie hier das Ganze tief geprägt und durchwaltet haben.

Diese Voraussetzungen sind schwer zu klassifizieren. Soll man (um einen Ausdruck Max Webers zu gebrauchen ${ }^{\mathrm{I} 23}$ ) von einer „Eingestelltheit auf das ,Regelmäßige“ als das ,Geltende“ “ sprechen? Von Präformierungen alles Denkens, soweit es die Ordnung betraf? Oder von alternativloser, übereinstimmender und insofern gleichsam unbewußt/bewußter Einfügung in diese Ordnung, die dann von allen so ausgemacht worden wäre, wie sie alle bestimmt hätte? Was dann doch wohl bedeutete, daß es sich nicht einfach um Festlegungen alles Denkens über die Ordnung, sondern um eine bestimmte Festlegung der ganzen Wirklichkeit gehandelt hätte, in die dieses Denken einrastete - bis tief in die Ausprägung des römischen Menschenschlags hinein.

Sie müßte es auch bedingt haben, daß sich irgend nennenswerte Teile der Bürgerschaft nicht derart aus dem Ganzen hätten ausklinken können, daß tiefer greifende Gegensätze, daß auch nur größere innere Distanzen innerhalb der Bürgerschaft, geschweige denn ein Bruch in deren „naturwüchsigem“ Zusammenhang sich hätten

I23 Weber, Wirtschaft und Gesellschaft (wie Anm. 36), I88. 
auftun können. Man scheint es mit einer weitgehenden Übereinstimmung der grundlegenden Kräfteverhältnisse mit dem, was man für die rechte Ordnung hielt, zu tun zu haben.

Jedenfalls muß die römische Ordnung recht tief in Praxis und Denken, ja Fühlen und damit in die Mentalität der ganzen Bürgerschaft eingelagert gewesen sein. Ihre

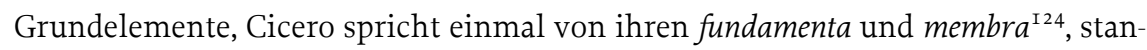
den nicht zur Disposition. Wer daran hätte zweifeln wollen, hätte kaum eine Chance gehabt, in einem irgend nennenswerten Kreis ein positives Echo zu finden. Solche Gedanken wären ins Leere gelaufen (statt daß sie irgendwo hätten aufgefangen und zurückgespielt werden, sich also irgend hätten verfestigen können). ${ }^{125}$ Sie wären einfach an der allgemeinen Übereinstimmung, an der Selbstverständlichkeit der überkommenen Ordnung, praktisch gesagt an der Geschlossenheit zumal (aber nicht nur) des Senats abgeprallt. Wenn es sich anders damit verhalten hätte, müßte es Auswirkungen gehabt haben, über die wir trotz im ganzen schlechter Quellenlage doch wohl informiert sein müßten.

Wo doch etwas geändert wurde, handelte es sich entweder um Einzelheiten, die irgendwem im Wege waren, oder es ging darum, Überkommenes unter neuen Umständen neu abzustützen: Prothesen sollten ersetzen, was nicht mehr von selber ging. Dabei war man in Rom für manche neuen Gedanken durchaus offen. Nur sollten sie nicht das Ganze, das Gemeinsame, das heißt die Ordnung der Republik in Frage stellen. Darin war man zu stark eingespannt. Das war gesichert durch die Einmütigkeit von Hoch und Niedrig.

So sind durch die ganze Geschichte der Republik hindurch die Überlegenheit und der Führungsanspruch des Adels, sein Standescharisma, überhaupt die Gliederung der Bürgerschaft nach Rängen, die große Autorität des Senats sowie die durch sella curulis, Kleidung und Liktoren stark markierte Herausgehobenheit der Magistrate (in geringerem Maße auch der Senatoren) unangefochten geblieben. Einzelne Handlungen mochte man kritisieren (oder bekämpfen) ${ }^{\mathrm{I2} 6}$, einzelne Einrichtungen mochte man - vorsichtig, auf das Nötigste beschränkt - schaffen (oder verändern), die

\footnotetext{
I24 Cicero, pro Sestio 98.

I25 Vielleicht darf man hier die Überlegungen zitieren, die James Madison im Federalist am 5.2.I 788 anstellte: „The reason of man, like man himself, is timid and cautious when left alone, and acquires firmness and confidence in proportion to the number with which it is associated.“

I26 Meier, Art.„Populares“ (wie Anm.52), $594 \mathrm{f}$.
} 
Ordnung selbst und ihre wesentlichen Elemente blieben davon unberührt. Die Selbstverständlichkeit des Überkommenen saß aller Vorstellungskraft zu dicht auf. Man muß sich all dessen vergewissern, um die Ordnung begreifen zu können.

2. Unter den fundamenta wäre wohl zuvörderst die dichte Bezogenheit des römischen Gemeinwesens auf überirdische Instanzen zu nennen, die aufs engste verknüpft war mit dem zunächst von den Patriciern, dann aber auch - in schwer zu bestimmendem, doch durchaus beachtlichem Ausmaß - von der Nobilität erfolgreich beanspruchten Monopol auf den Zugang zur Deutung des Götterwillens sowie zur Gewährleistung des rechten Umgangs damit. Dafür war nicht nur das Auspicium der Magistrate, sondern es waren auch jene merkwürdigen römischen Priestercollegien ${ }^{127}$ bezeichnend, deren Aufgabe zum guten Teil darin bestand, ungewöhnliche Vorkommnisse auf mögliche Zeichen von Götterwillen hin zu prüfen und darauf hinzuwirken, daß ihm nicht entgegengehandelt wurde. Sie hatten die Rechte der Götter, zum Beispiel ihre Feste, im Jahreslauf zu sichern, mithin den Kalender zu kontrollieren; übrigens zunächst auch die der Rechtsprechung zugrundeliegenden Formeln zu bewahren. Buchführung über ungewöhnliche Zeichen verschaffte ihnen überlegenes Wissen von großer Bedeutung. Mit der Vollziehung von Kult, Opfern etc. hatten sie nichts zu tun. Die Ersten des Senats legten Wert darauf, den Collegien der Pontifices oder der Auguren anzugehören. Im Senat hatten sie über deren Gutachten zu urteilen, gegebenenfalls Konsequenzen daraus zu ziehen, etwa Volksbeschlüsse zu kassieren, gegen welche Himmelszeichen ins Feld geführt wurden. Die Götter, interpretiert durch irdische Instanzen, standen insofern über der Volksversammlung wie über dem ganzen Gemeinwesen. ${ }^{\mathrm{I} 28}$ Deisidaimonia, bis zum Aberglauben gesteigerte Götterfurcht, berichtet Polybios $(6,56,6)$, habe die römischen Verhältnisse zusammengehalten. Das Bewußtsein, die Formen des Verkehrs mit den Göttern besonders gut zu beachten, wird mit der Zeit durch die enormen Erfolge der Stadt bekräftigt worden sein. Das Unheimliche, das außerordentlichen Erfolgen anhaftet, so lange man sich einen wachen Sinn für Realität bewahrt, mag dazu beigetragen haben.

Man weist gern darauf hin, daß die römische Eigenart, vielerlei Handlungen von Auspicien abhängig zu machen, praktisch nur erträglich war, wenn deren Ergebnisse

I27 John North, Religion in Republican Rome, in: Frank Walbank u.a. (Eds.), The Cambridge Ancient History. Second Edition. Vol.7/2: The Rise of Rome to 220 B.C. Cambridge I989, 573-624, hier $582 \mathrm{ff}$. I28 Mommsen, Staatsrecht (wie Anm. I6), Bd. 3, 335f.; Heuß, Thematik (wie Anm. 94), I 3 I 4. 
manipuliert wurden. Die Tatsache, daß etwa „den Himmel beobachten“ schon bedeutete, „einen Blitz gesehen zu haben“ “29, spricht ebenso Bände wie des alten Cato Bemerkung über das Lächeln, mit dem die Haruspices ihre Riten vollzogen; wir kennen es als „Augurenlächeln“. ${ }^{130}$ Aber das änderte nichts daran, daß man die Formen strikt einhielt; man machte sie nur praktikabel. Wie immer es um die Begründung der religiösen Rücksichten bestellt war - da war ja wohl Zynismus nicht ausgeschlossen -, man bestand allgemein darauf, daß sie eingehalten wurden. So hatte es sich eingefleischt (oder einversinnt). Nebenbei gesagt mochte dabei auch das religionsstabilisierende Argument des „Man-kann-nie-Wissen“ Sukkurs geleistet haben.

In dieser Götterfurcht drückte sich eine auffällig lähmende Bangigkeit aus, nur ja nichts falsch zu machen. Man hatte alle Zeremonien genauestens zu vollziehen, alle Formeln exakt zu sprechen, auch wenn sie nicht mehr verständlich waren, wie für die Lieder bezeugt ist, welche die Priesterschaft der Salier zu ihren kultischen Tänzen zu singen hatte. ${ }^{\mathrm{I}}{ }^{\mathrm{I}}$ Wenn etwas unkorrekt gesprochen war, mußte es wiederholt werden. Wenn irgendein Formfehler bei den Comitien (angeblich?) unterlaufen war, wurden Wahlen annulliert und neue anberaumt.

Als man dem - durch Kooptation sich ergänzenden - Collegium der Pontifices das Recht nehmen wollte, den Pontifex maximus zu bestimmen, verfügte man, I7 der 35 Tribus sollten darüber abstimmen, wen das Collegium zu ernennen hatte (denn dabei, daß das dessen Sache war, blieb es). Zu einer regelrechten Volkswahl hätten alle 35 antreten und ein Kandidat hätte eine absolute Mehrheit, also I 8 Tribus erreichen müssen. Folglich sollte zwar „das Volk“ die Auswahl haben, es sollte eine bindende Entscheidung treffen (woran sich die geständigen Priesterschaften auch hielten), aber man traute sich nicht, es eine Wahl sein zu lassen. Man scheute sich, die Gemeinde der Form nach in das im Collegium angelegte Nahverhältnis zu den Göttern eindringen zu lassen.

3. Wie an den Götterwillen sah sich die Republik weit über das Sakrale hinaus, freilich weniger starr, auch sonst an die Bewahrung überkommener Formen gebun-

I29 Mommsen, Staatsrecht (wie Anm. I6), Bd. I, 82 f. mit Bd. 3, I058 Anm. 2.

I30 Cicero, de divinatione 2,5 I. Heuß, Gedanken (wie Anm. 25), 939 f.

I3 I Varro, de lingua Latina 7,2 f.; Quintilian, institutio oratoria I,6,40f.; Georg Wissowa, Religion und Kultus der Römer. München I9I2, 538f. Latte, Religionsgeschichte (wie Anm. I6), I98, spricht vom „Glauben an die magische Kraft des gesprochenen Worts“; s. ebd.6I ff. zum „Formalismus“; Heinrich Honsell, Das Gesetzesverständnis in der römischen Antike, in: Norbert Horn (Hrsg.), Europäisches Rechtsdenken in Geschichte und Gegenwart. Fschr. für Helmut Coing zum 70. Geburtstag. München I982, I29-I48, hier I38f. 
den. Wie man sich ja auch - ganz anders als die Griechen - weit lieber an Erfahrung als an Erwartung hielt und möglichst wenig der Willkür oder dem Glück überließ. ${ }^{132}$ Obzwar im Politischen praktische Erwägungen und Notwendigkeiten, selten genug, zu Veränderungen Anlaß geben konnten.

Ein besonders schönes Beispiel bieten die leges Aelia et Fufia aus der Mitte des zweiten Jahrhunderts v.Chr. Es ging um die Himmelsbeobachtung, welche Magistrate vorzunehmen pflegten, um für ein Vorhaben Vorzeichen einzuholen. Besonders günstig für vieles war die Wahrnehmung eines Blitzes, die andererseits ungünstig war für Volksversammlungen. Die nämlich mußten aufgelöst werden, wenn sich, profan gesprochen, ein Gewitter ankündigte. Es hatte sich, wie eben erwähnt, eingespielt, daß sich die Magistrate den erwünschten Blitz von einem Amtsdiener melden ließen. Regelmäßig. Womit dann aber gleichzeitig gefaßte Volksbeschlüsse infragegestellt waren. Aelius und Fufius nun stellten keineswegs die Wirkung der Himmelsbeobachtung in Frage. Sie ließen nur beschließen, daß Magistrate, falls sie sie vornahmen, dies vor Beginn der Volksversammlung melden mußten. Gab es etwa, so ist das doch wohl zu deuten, eine starke Strömung, die auf einen Beschluß drängte, so sollten sie sich ihr coram publico aussetzen; ihr vermeintlicher Blitz konnte nicht erst nachträglich, in beruhigter Lage, geltend gemacht werden. Der Spielraum der Magistrate wurde insofern eingeschränkt - durch ein Gesetz, das sich im übrigen der herkömmlichen Übung anschmiegte. ${ }^{\text {I33 }}$

Auch wo man neue Institutionen an die Stelle von alten setzte, ließ man die alten nach Möglichkeit bestehen. Wie wenn man Angst gehabt hätte, Bewährtes aufzugeben, auch wenn man es praktisch nicht mehr brauchte. Nachdem die comitia curiata in der wichtigen Funktion der Bestellung der Magistrate längst von den Centuriatcomitien abgelöst waren (diese Änderung hatte sich offenbar aufgedrängt), ja als man längst aufgehört hatte, die Bürger überhaupt in Curien einzuteilen, hielt man es immer noch für unentbehrlich, daß das auspicium und damit der Oberbefehl der Magistrate durch eine lex curiata verliehen oder - besser wohl - bestätigt wurde. ${ }^{\text {I34 Man }}$ ließ dann 30 dazu abgeordnete Amtsdiener, einen für jede Curie, den fälligen Beschluß fassen. In der Regel jedenfalls. Wenn das, etwa durch Interzession, vereitelt

I32 Latte, Religionsgeschichte (wie Anm. I6), 40f., I79. Vgl. 6I.

I33 Meier, Art. „Populares“ (wie Anm.52), 607. Vgl. oben Anm. I04.

I34 Cicero, de lege agraria 2,27. Magdelain, Recherches (wie Anm. 27); Heuß, Gedanken (wie Anm. 25), 972 f., 976 . 
wurde, fehlte den betreffenden Magistraten irgendetwas, was sie vermißten, auch wenn sie ihr Amt und ihr Kommando weiter ausüben konnten.

Und warum hielt man die ganze Republik hindurch daran fest, daß die Wahl der Obermagistrate in den umständlichen Centuriatcomitien, und zwar in I93 Centurien zu vollziehen war? Dabei war, aufgrund einer Reform, die Zahl der Centurien höher, und es mußten in der zweiten bis fünften Classe jeweils zwei oder drei von ihnen zu Stimmabteilungen zusammengefaßt werden, damit sich am Ende die Zahl I93 ergab. ${ }^{\text {I35 }}$

Oder die Fahne auf dem Janiculum: Ein Kommando war dort in früher Zeit während der Volksversammlung postiert worden, für den Fall, daß Feinde die Gelegenheit dazu nutzten, die Stadt zu überfallen. Zum Zeichen dafür, daß von außen keine Gefahr drohte, ließ man eine Fahne wehen. Sie wurde noch in der späten Republik aufgezogen, als der nächste potentielle Feind viele hunderte von Meilen entfernt war. So konnte ein Praetor noch im Jahre 63, als eine Abstimmung nicht in seinem Sinne auszufallen drohte, die Fahne einholen lassen, damit die Volksversammlung, bevor das Ergebnis erzielt war, aufgelöst werden mußte. ${ }^{\text {136 }}$

Daß die Römer von Dingen, die seit alters gegeben, und von Verfahren, die seit alters zu vollziehen waren, nicht so leicht loskamen, war mehr als nur Niederschlag konservativer Gesinnung. Es bezeugte sich darin ein geradezu unwahrscheinlich angst- (oder: vorsichts-) besetztes Rundum-Verhaftetsein an das Überkommene, das zugleich das Bestehende war. ${ }^{137}$ So sehr es von den Anfängen her religiös mitbestimmt war, so sehr scheint es mit der Zeit in sich geruht zu haben. Wie ja wohl auch in der Gloriole der patricischen Adligen die ursprünglich religiösen Momente nicht immer durchscheinen mußten. Das alles hatte sich längst in die gewohnte, verpflichtende Wirklichkeit eingelagert. Es war gleichsam die Geschäftsgrundlage, auf der die verschiedenen Organe operierten.

Soweit einer - abgesehen von Veränderungen, die sich einfach aufdrängten über das Gegebene hinauszielte, tat er es, wie schon gesagt, am ehesten, weil er etwas für sich erreichen, und am wenigsten, weil er an der Ordnung der Republik grundsätzlich etwas hätte ändern wollen (was mit Einschränkungen über weite Strecken

I35 Gianfranco Tibiletti, Il funziamento dei comizi centuriati alla luce della tavola Hebana, in: Athenaeum 27, I949, 2 I0-245, hier 23I ff.

I36 Cassius Dio 37,27,3.

I37 Antiquitas proxume accedit ad deos, Cicero, de legibus 2,27. Vgl. Heuß, Thematik (wie Anm. 94), I3I 4 f. 
selbst noch der späten Republik gilt). Und schon gar nicht war es möglich, die wesentlichen membra oder gar die fundamenta des Adelsregimes anzutasten, nicht einmal die Ungleichheit der Aufteilung in Centurien oder auch nur deren Reihenfolge bei der Abstimmung (von der im Sinne des Senats erfolgten Reform des dritten Jahrhunderts abgesehen). Gewiß waren da auch Interessen am Werk, aber sie hatten eben leichtes Spiel.

Mit dem Verhaftetsein an das Herkommen verband sich die Bedeutung des mos maiorum, der Gepflogenheiten der Väter, die sich unter anderm in zahlreichen exempla niedergeschlagen hatten. Man hielt sich gern daran. Es scheint dem keinen Abbruch getan zu haben, daß es exempla für vielerlei gab, daß sie sich auch widersprechen konnten. Sie galten dann zumindest als Argumente, auf die man sich immer wieder berief, auch wenn man damit nicht unbedingt durchkam. Und jedenfalls sollte man nicht der Versuchung erliegen, in ihnen funktionale Äquivalente zu unseren Gesetzen zu sehen. Das konnten sie allenfalls in begrenztem Umfang sein. ${ }^{\text {I38 }}$

Die römische Bürgerschaft verharrte insofern auf einer archaischen Stufe, wenn denn zu deren Überwindung die Ablösung von starkem religiösen Befangensein, von nahezu lückenloser mentaler Einbindung in das Bestehende, das Aufkommen von Alternativen in Hinsicht auf die Ordnung, mithin eine gewisse Distanz zum einfach Gegebenen und damit größere Möglichkeiten der Neuorganisation gehören. So blieb alles Denken, soweit es die Ordnung betraf, in engen Bahnen. Darin wuchs man auf, dahinein wurde die ganze Bürgerschaft gebannt und dabei blieb es. Erstaunlicherweise ließ das Festhalten am Überkommenen das notwendige Maß an Elastizität zu, wie sich im Funktionieren der Ordnung sowie im Handeln der Römer überhaupt zeigte. Aber vielleicht setzte unter diesen Umständen eins das andere voraus?

Es war mit alldem jedenfalls vermacht, daß in Hinsicht auf die Ordnung zwischen Denkbarem und Gegebenem, zwischen Möglichkeit und Wirklichkeit kaum ein Spalt sich auftat. Eric Hobsbawm hat dergleichen für das „alte traditionelle England“ formuliert: „Man tat nicht das, was getan ,werden sollte‘, sondern was getan wurde, so wie ,es sich gehörte “ “. ${ }^{\text {339 }}$

I38 Nippel, Regel (wie Anm. I), I 2 I ff.; Lundgreen, Regelkonflikte (wie Anm. 46), bes. 273 ff.

I39 Eric Hobsbawm, Wieviel Geschichte braucht die Zukunft? München I 998, 33 I. Vgl. Heuß, Römische Geschichte (wie Anm. Io), 38: „Auf dem lebendigen Bewußtsein, was man von selbst zu tun hatte, beruhte die Ordnung des römischen Lebens.“ 
4. Als ein weiteres prerequisite der römischen Ordnung kann man das große Ausmaß ansehen, in dem man in Rom auf seine Rolle, also die Position, die man gerade innehatte, verpflichtet war. Manfred Fuhrmann und an ihn anknüpfend Jochen Martin haben das mit Recht stark herausgestrichen. ${ }^{\text {I4O }}$ Man fühlt sich wie in eine Vorgeschichte des Repräsentationsbegriffs versetzt, wenn man bei Cicero liest: est igitur proprium munus magistratus intellegere et gerere personam civitatis: daß eben der Magistrat sich bewußt sein soll, daß er die Rolle der Bürgerschaft spielt oder genauer: in der Rolle der Bürgerschaft handelt (de officiis I,I 24). In einzelnem konnte man sich an exempla orientieren. Aber in irgendeinem Ausmaß muß dahinter das Wissen vom Sinn des Amtes gestanden haben. Da war für jeden etwas vorgesehen, sei er Magistrat, Priester, Senator, Teilnehmer an der Volksversammlung oder Soldat. Die ganze Ordnung bestand darin, daß jeder an seiner Stelle tat, was zu tun war. Internalisierung und Erwartungsdruck griffen ineinander. Und die Erwartungen waren mächtig und ziemlich eindeutig, schließlich scheinen sich Hoch und Niedrig darin einig gewesen zu sein, sie ruhten in altem, sicherem Herkommen; die relativierende Wirkung, die von der Zeit ausgehen kann, war minimal. Alle waren ungewöhnlich stark aufeinander bezogen. Vielerlei Pflichten waren zu erfüllen. Überhaupt war Pflicht (officium) in Rom großgeschrieben.

Ein nicht geringer Teil des öffentlichen Lebens vollzog sich, wie neuerdings herausgearbeitet worden ist ${ }^{\mathrm{I} 4 \mathrm{I}}$, in Riten, nicht nur der Amtsausübung, sondern auch des respekterfüllten Umgangs mit Ungleichen, also etwa der Unterrichtung, des Ernstnehmens der contio, wie solchen der Jovialität (mit denen vorangegangene Härten ausgeglichen wurden), um von Triumphen und adligen Leichenzügen $\mathrm{zu}$ schweigen. Auch das umständliche Verfahren speziell der Wahlen in den Centuriatcomitien hatte rituelle Komponenten. Vielleicht kann man geradezu feststellen: So wenig die Bürger der Unterschichten mit ihren Stimmen dort für sich etwas auszurichten vermochten, so mächtig konnten sie sich dabei als Teil der großen römi-

I40 Manfred Fuhrmann, Persona. Ein römischer Rollenbegriff. In: Odo Marquard/Karlheinz Stierle (Hrsg.), Identität. (Poetik \& Hermeneutik, 8.) München I979, 83-I06; Jochen Martin, Zwei Alte Geschichten. Vergleichende historisch-anthropologische Betrachtungen zu Griechenland und Rom (I997), in: ders., Bedingungen menschlichen Handelns in der Antike. Gesammelte Beiträge zur Historischen Anthropologie. Stuttgart 2009, 29I-3I0, hier 302 f.; ders., Familie, Verwandtschaft und Staat in der römischen Republik (2002), in: ebd. 363-374, hier 365 .

I4 I Flaig, Ritualisierte Politik (wie Anm.37). Man tut nur vielleicht nicht immer gut daran, einmal Bezeugtes schon als Ritus anzusehen. Jehne, Jovialität (wie Anm.38). 
schen Bürgerschaft fühlen. ${ }^{\text {I42 }}$ Manche Züge hatte das öffentliche Leben in Rom mit der Aufführung eines Stücks gemein.

Daß man wußte, was jeweils zu tun war (und es weithin auch tat), muß mangels eines Erzwingungsstabs auch die Voraussetzung für die Aufrechterhaltung öffentlicher Ordnung gewesen sein. Denn die Bürgerschaft mußte in ihrer Gesamtheit respektive je gegenwärtige Teile davon jeweils das Nötige zu tun vermögen. Nichts zeigt so gut wie dies, welche Bedeutung eingeübten Erwartungen und Rollenvollzügen in Rom zugekommen sein muß.

Zu der Klarheit über die Rollen gesellte sich die über die Ränge, wie sie sich außer im Militär - in den Centuriatcomitien für alle sowie in Ämterlaufbahn und Gliederung des Senats für die Adligen ausprägten. Es wurden damit zugleich der Ehrgeiz der Adligen kanalisiert und Rangstreitigkeiten eingegrenzt. Denn die Ränge waren dann ja klar. Man mußte ihrer auch in seiner Lebensführung würdig sein.

Die auffällig starke Einbindung in Rollen und Zusammenhänge, was zugleich heißt: die Ausrichtung darauf, begann in der Familie. Die unterstand dem pater familias. Er verfügte, solange er lebte, über das Vermögen, ja potentiell über Leben und Tod von Kindern, Enkeln, oft auch von eingeheirateten Frauen. Von diesem wohl seit ältesten Zeiten überkommenen Recht muß sinngemäßer, also sehr begrenzter Gebrauch gemacht worden sein. Denn alle Erwartung drängte darauf, daß vor einschneidenden Beschlüssen der Rat eines Consilium einzuholen sei. ${ }^{\mathrm{I} 43}$ Es ging nicht zuletzt darum, die eigenen Söhne politisch zu disziplinieren.

Das Aufwachsen wie das Leben in derart anspruchsvollen Familien bedeutete Einübung in enge, zum Teil komplizierte Beziehungen. In irgendeiner, schwer genauer zu fassenden Weise setzte sich das fort in den Geschlechtern (deren Bedeutung sich auch darin manifestierte, daß die Römer als einzige im ganzen Mittelmeerraum nicht nur den eigenen samt dem Vatersnamen, sondern zugleich den Namen ihres Geschlechts und eventuell den einer bestimmten Linie dieses Geschlechts führten). Die daraus resultierenden Pflichten waren genau nach den verschiedenen Rollen innerhalb dieses Systems festgelegt. Für bestimmte Aufgaben war zum Beispiel der Mutterbruder zuständig. Übrigens zielten höchst merkwürdige, woher immer zu er-

I42 Jehne, Partizipation (wie Anm. 54), i 8 ff.

I43 Yan Thomas, Remarques sur la juridiction domestique à Rome, in: Jean Andreau/Hinnerk Bruhns (Eds.), Parenté et stratégies familiales dans l'antiquité romaine. (Collection de l'École française de Rome, I29.) Paris I990, 449-474. 
klärende Heiratsregeln darauf, die Zahl der Bindungen zu vermehren: Man durfte in Rom - bis gegen 200 v.Chr. - Verwandte nur vom sechsten Grade an heiraten. ${ }^{\text {I44 }}$

Rolleneinhaltung, Verpflichtung, Rang - dieser ganze Komplex reichte über die Generationen hinweg. Denn von den Angehörigen des Senatorenstands, zumal denen der Nobilität wurde erwartet, daß sie die politische Laufbahn einschlugen. Mehr oder weniger galt: Wer von Adel war, machte Politik, und wer Politik machte, war von Adel.

5. Wie stark Verpflichtungen die römische Bürgerschaft bestimmten, welche (gegenseitigen) Anforderungen, welche Indienstnahmen damit verknüpft waren, zeigt sich besonders im römischen Bindungswesen, einem ganz zentralen Bestandteil der römischen Ordnung. ${ }^{\text {I45 }}$

In ihm hatten sich ursprünglich patriarchalische Bindungen zwischen Patronen und Clienten fortgesetzt und - unter den Herausforderungen der „Ständekämpfe“ weiterentwickelt, vertieft und ausgedehnt. Man brauchte die Clienten, hatte sich um sie zu kümmern. Es trug wesentlich zum Ansehen des Adligen bei, wer alles ihm seine Aufwartung machte und sich seinem Gefolge einreihte. ${ }^{\mathrm{I} 6}$ Also hatte man die Bindungen zu mehren. Folglich spielte sich die Tendenz ein, aus allen möglichen Kontakten Verpflichtungen abzuleiten. Günstige Bescheide, die man etwa von seiten eines Magistrats erhielt, wurden als beneficia aufgefaßt und verpflichteten in $\mathrm{Zu}$ kunft sowohl den Begünstigten wie auch den Begünstiger zu gegenseitiger Unterstützung. Aber auch gemeinsame Bekleidung eines Amtes oder Zugehörigkeit zu einem Collegium hatten dauerhafte Beziehungen zur Folge. ${ }^{147}$ Matthias Gelzer hat deswegen von „Nah- und Treuverhältnissen“ gesprochen. Es ist, wie wenn bei vielerlei Berührungen ein Klebstoff abgesondert worden wäre, um die Beteiligten auch künftig einander nahe zu halten. Wie schon die alten Clientelverhältnisse waren auch die neuen Bindungen nicht nur dauerhaft, sondern auch erblich.

Wenn zunächst ein deutliches Gefälle zwischen Hoch und Niedrig vorgeherrscht hatte, vielleicht auch einzelne Geschlechter über klar abgegrenzte Gefolgschaften verfügten, so rückte mit der Zeit etwas anderes in den Vordergrund: Die Verpflich-

I44 Maurizio Bettini, Familie und Verwandtschaft im antiken Rom. Frankfurt am Main I992, I53 ff.; Martin, Familie (wie Anm. I40).

I45 Meier, RPA (wie Anm. 2), $24 \mathrm{ff}$.

I46 Fabian Goldbeck, Salutationes. Die Morgenbegrüßungen in Rom in der Republik und der frühen Kaiserzeit. (Klio, Beihefte, I6.) Berlin 20 Io.

I47 Meier, RPA (wie Anm. 2), 307. 
tungsverhältnisse zwischen den Angehörigen des Senatsadels und denen der gleich unterhalb von ihnen rangierenden wohlhabenden Schicht in Rom sowie - zunehmend - in andern Städten. Das waren etwa diejenigen, die in die Mehrzahl der Rittercenturien oder in die der ersten Classe eingeteilt waren. Sie verfügten im Zweifelsfall ihrerseits über zahlreiche Clienten. Sie selbst rangierten nicht als clientes, sondern als Freunde, amici. ${ }^{\mathrm{I} 8}$ Sie hatten es im Laufe der Zeit zumeist mit vielen Adligen zu tun, wechselnden Magistraten und Statthaltern zum Beispiel. So kamen sie dazu, je prominenter sie waren, um so mehr Beziehungen zu knüpfen. Folglich entstand eine ungeheure Zahl von oft sich überschneidenden Bindungen, die von Fall zu Fall, je nachdem, was gerade anstand, zu mobilisieren waren. Es verbreitete sich damit in Rom sehr viel Freundschaft und das Bedürfnis nach Freundschaft; weit mehr als Feindschaften.

Daraus ergab sich ein weit verzweigtes Netz dichter Kommunikation, ein Netz aber auch gegenseitiger Abhängigkeit, das direkt und indirekt weite Teile der Bürgerschaft durchzog. Ungemein viel wurde auf die Dauer über diese Bindungen erledigt. Mit ihrer Hilfe konnten im Senat sowie vor Magistraten und Gerichten Interessen vertreten, konnte auch für Schutz und Rechtssicherheit der Einzelnen aufgekommen werden. So blieb das System vertikaler Solidaritäten aufrechterhalten; die Interessen konnten - und das war sehr wichtig - vereinzelt bleiben. ${ }^{{ }^{4} 49}$ Es konnten sich kaum nennenswerte Gefolgschaften bilden.

Voraussetzung bei alldem war, daß mehr oder weniger jeder seinen Verpflichtungen nachkam. Dankbarkeit (gratia) wurde groß geschrieben. Gegenseitige Diensterweisung (pietas) wurde als göttliche Macht verehrt. Ebenso fides, wobei das Element

\footnotetext{
I48 Cicero, de officiis 2,69. Meier, RPA (wie Anm. 2), 3 I f. Vgl. oben Anm. 47.

I49 Meier, RPA (wie Anm. 2), 330, Register C. II d für die späte Republik. In der früheren kann es sich im wesentlichen kaum anders verhalten haben. Interessant ist eine Äußerung, die Livius (34,2,I f.) den alten Cato tun läßt (im Zusammenhang der weite Kreise ziehenden erregten öffentlichen Proteste römischer Frauen, welche sich dagegen wehrten, daß ihnen im zweiten Punischen Krieg auferlegte Beschränkungen von Kleidung und Schmuck nach dessen Ende beibehalten werden sollten): „si in sua quisque nostrum matre familiae, Quirites, ius et maiestatem viri retinere instituisset, minus cum universis feminis negotii haberemus [...] quia singulas sustinere non potuimus, universas horremus“. Man mußte eben vieles im kleinen (in diesem Falle im Hause) erledigen, damit es nicht zu einem größeren öffentlichen Problem wurde. Man wird das verallgemeinern können: Ungemein vieles wurde von vielen (zumal durch das Bindungswesen) singulatim, im Rahmen einer Vereinzelung der Interessen erledigt, so daß es universe nicht zum Problem werden konnte.
} 
der Verläßlichkeit und Treue hier besonders einschlägig war. ${ }^{150}$ Das ganze Gemeinwesen wurde durch eine kräftige Erwiderungsmoral durchdrungen.

Übrigens beobachten wir, was im Innern galt, auch in den Beziehungen nach außen. Nach Kriegen war es für Rom mit bloßen Friedensschlüssen selten getan. Zumindest tendierte man dazu, aus feindlicher Berührung Bündnisse abzuleiten. Überhaupt waren den Römern schutzbedürftige Verbündete lieb. Die Republik war gern bereit, für sie Krieg zu führen. Sie waren dann abhängig, kamen andererseits in den Genuß vielfältiger Unterstützung. Sie hatten dafür ihren Patronen dankbar zu sein. Man war in diesem Rom nicht nur bindungsreich, sondern geradezu bindungssüchtig.

Ein besonders schönes Beispiel bietet das Verhältnis zwischen Feldherrn und von ihnen eroberten Städten (speziell einigen prominenten Familien darin). Daß der Feldherr, wenn im Senat etwa über das Geschick einer dieser Städte verhandelt wurde, in besonderer Weise dafür zuständig war, leuchtet ohne weiteres ein. Aber dabei blieb es ja nicht. Es pflegte daraus more maiorum ein dauerhaftes, erbliches Patronat zu resultieren. ${ }^{\text {I5I }}$ Auf diesen und ähnlichen Wegen sammelte sich im Senat Wissen über die vielen Städte und Zugang zu den dort maßgebenden Kreisen in einem solchen Ausmaß, daß er für die Verwaltung des Herrschaftsbereichs unentbehrlich wurde. ${ }^{\text {I52 }}$

Vermittels des Bindungswesens waren die römischen Adligen tief in ihre Bürgerschaft (direkt zumal in deren obere Kreise) eingebettet, wurden sie von vielen Seiten in Anspruch genommen, hautnah an ihre Verpflichtungen erinnert, welche sich dadurch reproduzierten, möglichst auch vermehrten. Sie leisteten auf diese Weise Dienst an ihrer Macht. Macht bedarf ja, wenn sie stabil sein soll, der Pflege. Man darf sie nicht nur genießen wollen, sondern man muß auch einiges um ihretwillen auf sich nehmen; zumal dann, wenn man keine Apparate hat, die das für einen besorgen können (und dann selbst einen Teil der Macht in die Hand bekommen). Diese Adligen unterwarfen sich also dem „Zwang, womit man Zwang zu kaufen sich beque-

I50 Latte, Religionsgeschichte (wie Anm. I6), 40, 24I. Fritz Schulz schreibt (Prinzipien des römischen Rechts. 2.Aufl. Berlin I 954, I 58): „Die römischen Freunde nehmen sich wechselseitig in einem Maße in Anspruch, das den modernen ,Freund' gemeiniglich zum sofortigen Abbruch des Freundschaftsverhältnisses veranlassen würde.“

I5 I Cicero, de officiis I,35.

I52 Meier, RPA (wie Anm. 2), 34ff., 42 ff. Das römische Senatsregime ist seinerseits ohne das Bindungswesen nicht denkbar. Inzwischen auch: Raimund Schulz, Herrschaft und Regierung. Roms Regiment in den Provinzen in der Zeit der Republik. Paderborn u.a. I997, 26f., I 27 ff., 20 If. 
men muß“ (Schiller). Das gehörte zum Habitus des Standes, zumindest seit den Stän-

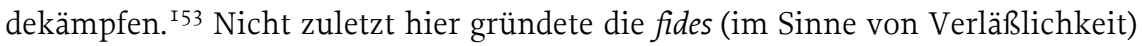
des Senators.

Das Bindungswesen war somit nicht einfach eine der Ursachen des Adelsregimes, sondern zugleich eine seiner Konsequenzen (wenn anders die Angehörigen der breiteren Bürgerschaft vor Senat und Magistraten - und vermittels der nur in Rom stattfindenden Wahlen - vertreten sein sollten). Nur so konnten die ursprünglich an die kleine überschaubare Gemeinde am Tiber gebundenen Institutionen mit wenigen Veränderungen angesichts des sich ausweitenden Weltreichs fortbestehen und ihren Aufgaben gerecht werden.

Es war eine eigenartige mentale Disposition, die hier wirkte und erzeugt wurde. Man war darauf geeicht, die verschiedensten Vorgänge und Gegebenheiten unter dem Gesichtspunkt der Bindung und der Erkenntlichkeit zu verstehen. Indem man dauerhaft, ja erblich in Anspruch genommen war, blieb man stark in seine Herkunft und seine eigene Biographie eingespannt. Ständig war man genötigt, auf andere hin zu leben und zu agieren. Die große Bedeutung der memoria in Rom ${ }^{154}$ hatte auch damit zu tun. Das war ganz anders als bei den Griechen, die so großen Wert auf Eigenständigkeit der Einzelnen legten. Und wo die Adligen dort über die Gemeinden hinaus auf eine gemeingriechische Öffentlichkeit bezogen waren, an der alle teilhatten, kreiste hier alles um das eine Gemeinwesen (und seinen Herrschaftsbereich) und im engeren Sinne um die von allen andern sich abhebenden Senatoren. Wo die griechischen Persönlichkeiten sich möglichst vielseitig ausbilden (und leben) wollten, hatten sich die römischen nicht nur auf das Politische und Militärische, sondern innerhalb dessen auf Rang, Rolle und Bindung zu konzentrieren. Darauf wurde man erzogen und immer wieder gestoßen, wenn man vorankommen wollte.

Es gehörte schon ein besonderes Schicksal, eine besondere ambitiöse Empfindlichkeit und das Aufkommen großer Probleme dazu, damit sich ein Mann wie Tiberius Gracchus veranlaßt sehen konnte, daraus auszubrechen.

I53 Mommsen spricht einmal (allerdings nicht in Hinblick auf Rom) von der „sittlichen Energie, welche die Welt beherrscht, weil sie sich selber zu beherrschen weiß“. Sie wurde erzeugt nicht nur dadurch, daß sie u.a. durch die Notwendigkeit der Laufbahn (und damit durch die besondere Art der Einbindung in die Bürgerschaft) dem Einzelnen abverlangt wurde, sondern sie war zugleich Teil des Habitus des herrschenden Standes. Übrigens das Schillerzitat: Don Carlos 2. Akt, Io. Auftritt.

I54 Uwe Walter, Memoria und res publica. Zur Geschichtskultur der römischen Republik. (Studien zur Alten Geschichte, I.) Frankfurt am Main 2004; Flaig, Ritualisierte Politik (wie Anm.37), 69ff. 
6. Nur - wie ist es zu erklären, wie ist es denkbar, daß eine ganze zu hohen Leistungen befähigte, ungemein erfolgreiche, klug geführte, schließlich auch mit griechischem Denken in Berührung kommende Bürgerschaft derart alternativlos und dicht in ihre Ordnung eingebunden war und blieb (mit einigen Einbußen selbst noch in der krisengeschüttelten späten Republik)?

Gewiß, struktureller Wandel pflegte sich damals langsam zu vollziehen, zumal Rom kaum auf äußere Einflüsse zu reagieren hatte. Immerhin aber gewann die Stadt zwischen der Mitte des vierten und der des zweiten Jahrhunderts die Herrschaft nicht nur über Italien, sondern auch über Sizilien, Sardinien, Korsika, Spanien und Griechenland, schließlich auch Teile Nordafrikas. Ihre Bürgerschaft wuchs relativ sehr rasch - und dann sollte das Angewiesensein auf bestimmte Formen des Umgangs mit überirdischen Mächten, die enge Bindung an die „Heiligkeit der Tradition“ (Max Weber), die dichte Verpflichtung auf die diversen officia sowie auf eine wachsende Zahl vielfältiger Bindungen sich fortsetzen?

Bestimmte Präformierungen des Vorstellens, Denkens und Wollens zugegeben: Wie konnte sich die gerade auch mentale Einschnürung in lauter Korsette so lange halten? Es mag ja manches darauf gedrängt haben, im Gewohnten und mit dem Gewohnten fortzufahren. Wenn es sich einmal eingebürgert hat, vielerlei Interessen, angefangen bei dem an der Gewährleistung eigenen Rechts, kulminierend bei dem an den höchsten Ämtern, über Verpflichtungsverhältnisse zu verfolgen, legte es sich nahe, diesen Weg weiterzugehen und auszubauen. Und warum sollten sich nicht auch Götterfurcht und Festhalten am Herkömmlichen von Generation zu Generation fortpflanzen? Gewohnheit kann ja ihrerseits eine Macht darstellen. Die Frage ist eben nur, warum kein Anlaß erwuchs, daran etwas zu ändern. Wären etwa stärkere Bedürfnisse unbefriedigt geblieben, hätten sich größere Ärgernisse aufgetan, hätten sich energische Persönlichkeiten deren angenommen, hätten sich angesichts heftiger Widerstände tiefere Gegensätze aufgetan, so hätten sich doch wohl die einen oder anderen gegen das Bestehende aufbäumen können. Manches davon wäre in Frage geraten, man hätte recht unterschiedlich darüber zu denken lernen können. Die Homogenität der Bürgerschaft hätte vielleicht auf dem Spiel gestanden. Aber eben das geschah ja nicht.

Auch mag man fragen, ob die breiteren Schichten in Rom wirklich zu beschränkt waren, um nicht zu merken, daß etwa die Beachtung der Auspicien, der Rechte der Auguren nur ad opinionem vulgi et ad magnas utilitates rei publicae aufrechterhalten wurden (Cicero, de divinatione 2,70; vgl. Cato I I). War die Vorsicht des „man kann 
nie wissen“ groß genug, um die Römer insgesamt über jeden möglichen Zweifel hinwegzutragen?

Und weiter: War das ganze Theater nicht durchsichtig, in dem das Volk als Herr der Republik respektiert wurde, um dann doch - und doch wohl gerade auch deswegen - nur sehr begrenzt oder ausnahmsweise etwas zu sagen zu haben? Setzte man die Reihe dieser Fragen fort, könnte man noch vieles vorbringen, was uns höchst auffällig erscheinen muß, was aber keineswegs unglaubwürdig ist.

Allein, indem im allgemeinen Denken und Auffassen das Überkommene und das Gegenwärtige weithin in eins fielen, kräftigte und reproduzierte sich die römische Ordnung stets neu in den allgemeinen Erwartungen an das Handeln zahlreicher Bürger, von Hoch und Niedrig, je nach den verschiedenen Rollen, die sie zu erfüllen hatten. Und diese Erwartungen waren kräftig, da sie ziemlich eindeutig waren, da und so daß - man in Rom stark von Akzeptanz, und zwar gerade auch der bei der Allgemeinheit abhängig war (weil es Parteiungen nicht gab, die sie auf sich hätten ziehen können), was zugleich einen gemeinsamen Grundbestand homogenen Wissens voraussetzte.

Freilich, ganz selbsttätig wird die Reproduktion der prerequisites der römischen Ordnung nicht gelaufen sein. Sie hatte insbesondere eine empfindliche Stelle: Im Adel, dessen Mitglieder am ehesten einerseits vieles zu durchschauen imstande, andererseits durch ihren Ehrgeiz leicht angetrieben gewesen sein könnten, Neues zu versuchen, zu ihrem Vorteil. Wenn die ihnen zu Recht immer wieder attestierte Disziplin also gehalten hat, so wird man nach den Gründen dafür im Funktionieren dieser Ordnung zu suchen haben.

7. Anzufügen wäre an dieser Stelle aber noch der Hinweis auf zwei weitere mögliche Voraussetzungen römischer Ordnung, die nicht Teil von ihr waren, die sie aber von außen abstützten und modifizierten: Die starke Verwicklung Roms in eine lange Reihe von Kriegen, anfangs vielleicht auch besondere Bedrohung von außen, könnte gerade in früher Zeit sehr auf den Zusammenhalt im Innern sowie die Bereitschaft zu Gehorsam, zu genauer Einfügung in das Ganze (samt Zugeständnissen an die Plebs) hingewirkt haben. Je weiter Rom und der Radius seiner Kriegführung ausgriffen, um so bedeutsamer wurde dann der Anteil der Führenden, der Strategen also, am Erfolg, mithin das Ansehen der Aristokratie.

Beute und Landgewinn (etwa in den von Rom gegründeten Colonien) trugen dazu bei, daß materielle Ursachen möglicher Spannungen zwischen Hoch und Niedrig vermindert wurden. Gewinne aus dem Herrschaftsbereich mußten überhaupt 
vielerlei Entlastung bringen. Als dagegen größere wirtschaftliche und soziale (und bald auch militärische) Probleme auftauchten, wurden jedenfalls Konflikte möglich, und es stellte sich heraus, daß die Ordnung der Republik nicht mehr recht im Gleis zu halten war - was freilich nichts daran änderte, daß man noch lange an ihr festhielt. Zu gut und tief war sie in die Bürgerschaft verankert.

\section{VII.}

I. Wie diese Ordnung funktionierte, ist nicht leicht zu bestimmen. Wenn Alfred Heuß ganz allgemein von einem der ,römischen Gesellschaft [...] innewohnenden Regulationsvermögen“ sprach, ist zu fragen, ob man das nicht genauer fassen kann, auch ob man diesen Befund nicht vielleicht besser modifizieren sollte. Wenigstens in Umrissen soll hier darauf eine Antwort versucht werden. Daß es an manchen Stellen mit Vermutungen genug sein muß, ergibt sich aus der Quellenlage.

Eine Ordnung muß ein einigermaßen friedliches Zusammenleben auf der Basis von Recht gewährleisten. Sie muß Mittel und Wege bereitstellen, damit alle wichtigen gemeinsamen Aufgaben angepackt, Rechte gewahrt, Interessen verfochten und kollidierende Ansprüche ausgeglichen, alle möglichen Streitigkeiten ausgetragen, ausgehalten und schließlich ordentlich zu Ende gebracht werden können; gewiß nicht zu jedermanns Befriedigung, aber doch insgesamt so, daß an der Ordnung selbst keine Zweifel aufkommen; daß sie, zumindest weithin, als selbstverständlich anerkannt werden kann. Nicht zuletzt müssen ihre politischen Organe für sich oder im Zusammenwirken mit anderen einerseits wissen, was sie zu tun haben und handlungsfähig sein, andererseits kontrolliert werden, und es muß sich zwischen ihnen ein erträgliches, vielleicht gar gedeihliches Verhältnis herstellen lassen. Immer neu.

2. Im Hinblick auf das Funktionieren der Ordnung ist für Rom zunächst zu bemerken, daß sehr vieles, was die Staaten weit über ihre paternalistische Fürsorglichkeit hinaus zu leisten haben, den politischen Organen dort kaum aufgegeben war. Sie hatten fast nichts mit Fragen der Wirtschaft, der Arbeit, des Steuersystems, der Währung, der Gesellschaft (Umverteilung), des Sozialstaats, der Alters- und der Gesundheitsvorsorge, von Erziehungswesen und Wissenschaft zu tun. Es gab kaum strukturellen Wandel, also keine Notwendigkeit, auf ihn durch Reformen stets neu zu reagieren. Die ganze Problematik öffentlicher Daseinsvorsorge war unbekannt, der Regelungsbedarf denkbar gering. Allenfalls war angesichts akuter Schwierigkei- 
ten punktuell Abhilfe zu schaffen, etwa durch Umlagen, vielleicht auch indem man diesen oder jenen Mißstand zum Anlaß nahm, eine begrenzte Materie für die $\mathrm{Zu}$ kunft besser zu ordnen. Selten genug.

Die Bürger brauchten - und man hatte - weder eine Bürokratie noch Staatsanwalt, Kriminalpolizei oder gar Geheimdienst, auch keine Post. Sie brauchten und hatten keine Erzwingungsstäbe. Vielmehr kamen sie für all das, was heute mehr oder weniger vom Staat besorgt wird, sehr weitgehend selbst (mit Hilfe von Freunden, Verwandten, Nachbarn, Patronen oder Clienten, zum Teil auch Sklaven) auf. Sie waren keine Spezialisten in arbeitsteiliger Gesellschaft. Sie kannten es nicht und hatten es nicht nötig, daß ihnen spezielle Instanzen alles mögliche abnahmen ${ }^{155}$ (und sie bei der Gelegenheit von sich abhängig machten). Sie waren eher Herren ihrer selbst, freilich in sehr ungleichem Ausmaß, mit vielerlei Abhängigkeiten untereinander. Verwaltung blieb auf ein Minimum beschränkt. Es wurde „weit mehr Recht gesprochen“(respektive über Ansprüche von Magistraten und Senat entschieden) als ,verwaltet“. ${ }^{156}$

Die brennendsten Probleme ergaben sich in Hinsicht auf Eröffnung und Abschluß von Kriegen, speziell bei den Aushebungen, andere aus dem Bedürfnis nach Land und akuten Notlagen der Versorgung - für die zumal die Volkstribunen Abhilfe schaffen sollten.

Gewisse „polizeiliche“ Funktionen mußten von Magistraten wie den Ädilen ausgeübt werden, etwa Marktaufsicht, Sorge für die Sauberkeit von Straßen, für Wasserzufuhr und Brandschutz, auch für die Einhaltung von Bauvorschriften sowie für die Überwachung der Getreidepreise etc. Eine Reihe von niederen Magistraten sorgten für Teile der Gerichtsbarkeit, Vollstreckung von Strafen, das Münzwesen und anderes. ${ }^{157}$ Das meiste davon ergänzte nur, was die Bürger selbst zu besorgen hatten.

Für Rechtsstreitigkeiten waren zumal Zivil- und zunehmend auch Strafgerichtsbarkeit zuständig. Anklage hatten in der Regel die Geschädigten oder deren Verwandte, aber auch irgendwelche Bürger zu erheben, die sich aus freien Stücken der

I55 Das moderne Gegenbild zeichnet Weber, Wirtschaft und Gesellschaft (wie Anm.36), 56I, wenn er vom „steigenden Bedürfnis einer an feste absolute Befriedung gewöhnten Gesellschaft nach Ordnung und Schutz (,Polizei') auf allen Gebieten“ spricht. Vgl. Christian Meier, Rezension zu A. W. Lintott, Violence in Republican Rome. Oxford I968, in: HZ 213, I97I, 395-400.

I56 Kunkel, Staatsordnung (wie Anm. I), 582.

I57 Hans Schaefer, Art. „Vigintiviri“, in: Paulys Realencyclopädie der classischen Altertumswissenschaft, Bd. 8 A, I958, 2570-2587. 
Sachen annahmen. Wenige Gesetze, zumeist sehr speziellen Charakters, haben einzelne Rechtsmaterien genauer geregelt. Die wichtigste (und umfassendste) Arbeit an der Interpretation und Fortentwicklung des Rechts leisteten Juristen, Männer, die sich privatim damit beschäftigten, zumeist Senatoren, darunter auch einige der Ersten des Senats ${ }^{158}$, unter sich und in öffentlich erstatteten Gutachten sowie in der Beratung des Praetors.

Sehr viele Aufgaben waren von den Häusern zumal der Adligen zu erledigen. Der pater familias war dafür verantwortlich, daß die Angehörigen seines Hauses sich ordentlich benahmen (und konnte sie gegebenenfalls bestrafen). ${ }^{159}$ Entsprechend besorgten die Adligen auch die Erziehung ihrer Söhne weitgehend selber, indem sie sie auf die Güter, auf das Forum und in den Senat mitnahmen und sie vertraut machten mit vielen Problemen und Weisen, ihnen beizukommen, sowie mit ihren Freunden und Clienten. Mit der Zeit kam privater Unterricht dazu. ${ }^{\mathrm{I} 0}$ Alles weitere erfolgte dann vielleicht im Anschluß an Juristen, jedenfalls im Militärdienst sowie in der Praxis der Wahrnehmung unendlich vieler Verpflichtungen.

Macht und Rang hatten sie sodann insbesondere dadurch zu erwerben, daß sie sich in vielfältigsten Diensterweisungen (und Anpassungen) bewährten. Daraus, daß sie, wenn sie in die obersten Ränge des Senats aufsteigen wollten, mehrere Wahlen bestehen, sich also immer neu gerade auch bei den führenden Senatoren annehmbar oder gar beliebt machen mußten, ergab sich ein langgestreckter handfester Sozialisationsprozeß; mit reichlich Gelegenheiten, um durch Erfahrung, durch Ausbildung von Erwartungserwartungen einen Sinn für das Angebrachte zu erzeugen im Umgang mit vielen anderen, in der Öffentlichkeit.

Die zahlreichen Gemeinden in Italien sowie im weiteren Herrschaftsbereich kamen für ihre Angelegenheiten im wesentlichen selbst auf. Nur gelegentlich hatten Magistrate oder Statthalter dort einzugreifen. Hilfsweise konnten die Patrone tätig werden (und über sie pflegte der Senat über vieles orientiert zu sein, auf Verschiedenes aber auch Einfluß zu nehmen). ${ }^{\text {I6I }}$

So vollzog sich auch ein Teil der Außenpolitik wie der „Verwaltung“ des Herr-

I58 Wolfgang Kunkel, Herkunft und soziale Stellung der römischen Juristen. Weimar I952; Wieacker, Rechtsgeschichte (wie Anm. I2), $528 \mathrm{ff}$.

I59 Jochen Martin, Formen sozialer Kontrolle im republikanischen Rom (2002), in: ders., Bedingungen (wie Anm. I40), 345-362, hier 348ff.; ders., Familie (wie Anm. I40).

I6o Vgl. Christian Meier, Caesar. Berlin I982, $76 \mathrm{ff}$.

I6 I Meier, RPA (wie Anm. 2), 35 f., r64. Dazu Livius 33,45,6. 
schaftsbereichs in den Häusern der Adligen, welche dorthin Beziehungen unterhielten, vielfach aufgrund früherer Statthalterschaften, eventuell von ihren Vorfahren her. In diesen Häusern wurden die Gesandtschaften empfangen, oft gewiß auch untergebracht, weitere Beziehungen geknüpft, Ratschläge und Empfehlungen ausgesprochen - bis die Gesandten dann im Senat vorgelassen wurden. Dort trafen sie auf andere Senatoren, die sich dank ihrer Tätigkeit als Statthalter sowie ihrer Beziehungen ebenfalls in ihrem Teil der Welt auskannten. Daher war es ja eben, daß der Senat den Magistraten vieles bot, wozu heute ganze Ministerien dienen müssen.

Natürlich stellten sich, was immer Bürger und Gemeinden selber besorgten, eine Menge Streitigkeiten ein. Ansprüche überschnitten sich, und es waren stets verschiedene Adlige durch ihre Clientelverhältnisse darin einbezogen. Die Dinge mochten, wenn nicht Gerichte, so Magistrate und/oder Senat, vielleicht auch die Volksversammlung beschäftigen. Dabei traf man, je nach den Bindungen, in immer neuen Gruppierungen aufeinander. Zu allermeist ging es um begrenzte Interessen begrenzter Subjekte. ${ }^{\text {I62 }}$ Lediglich wenn einmal größere Ärgernisse sich zusammenbrauten, konnten sich weitere Teile der Bürgerschaft zu Interessenblöcken vereinen und vermittels der Volksversammlung Abhilfe schaffen (womit die Sache dann erledigt war, ohne weitere Folgen für die Ordnung nach sich zu ziehen).

Nur weil so vieles unter den je Beteiligten sowie ihren Patronen und, wenn überhaupt, so erst in letzter Instanz mit Hilfe von Magistraten, Senat oder Volksversammlung erledigt wurde, war es möglich, daß Rom von den Anfängen bis zum Ende der Republik von einem sehr kleinen Kreis jährlich wechselnder Magistrate regiert und „verwaltet“ wurde. Ihre Zahl wurde zwar mit der Zeit vergrößert, aber doch nur um relativ wenige, während Rom selbst von der kleinen Gemeinde am Tiber zur Herrin über den ganzen Mittelmeerraum aufstieg. Und es waren relativ wenige Hilfskräfte, die ihnen zu Diensten waren.

Man muß anfügen, daß die Stadt, wo es um Effizienz ging, zumal in Kriegsnot, fähig war, rasch die nötigen Kräfte zu organisieren, unter regulären Magistraten oder (bis in den zweiten Punischen Krieg hinein) durch Ernennung eines Dictators mit nahezu unbegrenzten Vollmachten auf kurze Zeit. Offenbar brauchte man nicht zu befürchten, daß er sie mißbrauchte oder so leicht nicht wieder hergab. Auch diese Männer wußten (und/oder bekamen zu spüren), worin ihr officium bestand.

I62 Meier, RPA (wie Anm. 2), I63ff. 
Die kleine Zahl der Magistrate samt dem jährlichen Wechsel ihrer Inhaber bedingte es, daß die Führung weithin beim 3ooköpfigen Senat liegen konnte, in dem zumal Männer saßen, die diverse Magistrate innegehabt hatten. Die Zugehörigkeit war lebenslänglich, es sei denn, daß ein Censor einen Senator wegen Unwürdigkeit ausschloß. Im Senat versammelten sich Macht, Verantwortung, Erfahrungen, Kenntnisse sowie eben eine Unzahl von Verbindungen in alle Teile der Welt. Er allein konnte die Kontinuität der römischen Politik gewährleisten. Wo sonst hätte längerfristig angelegtes, durchhaltendes Denken und Planen, hätten die Bemühungen, die Republik im Lot zu halten, ihr Zentrum finden können?

Im Senat fielen in der Regel die Entscheidungen über Roms Außenpolitik, über Krieg und Frieden, Bündnisse, Kommanden, Aussendung von Colonien, Bürgerrechtsverleihungen, Einrichtung von Provinzen etc. (auch wenn die Volksversammlung anschließend vieles davon absegnen mußte). Er legte jährlich die Provinzen, also Amtsbereiche (oder Kommanden) der Consuln fest, verfügte über die finanziellen und militärischen Mittel der Republik. Bei ihm lag aber auch die Aufsicht über das Gemeinwesen insgesamt, was gelegentlich die Notwendigkeit, größere Ärgernisse zu beheben, einschloß. Nicht zuletzt wurden in ihm aber auch unzählige kleinere Streitigkeiten verhandelt und entschieden. Die Magistrate pflegten weitgehend dem Senat zu Willen zu sein, so daß es berechtigt ist, von einem Senatsregime zu sprechen (Cicero, pro Sestio I37). Die Frage ist, wie es funktionierte.

Dabei bildete der römische Adel das eigentliche Problem. Ob es um die Vertretung von Clienten und Freunden, um Entscheidungen oder um die Ausführung notwendiger Maßnahmen ging, überall waren seine Mitglieder beteiligt, lag auch die Initiative bei ihnen. Und vor allem: Überall ging es nicht zuletzt um deren Ansehen und Einfluß, oft genug um den Austrag von Rivalitäten, vielleicht auch um Rang und - etwa bei militärischen Kommanden - um die Gewinnung von Ruhm. Anlaß genug zu Eifer und Streit. Irgendwie mußten die sich entfalten.

Da andererseits die Ordnung daran hing, daß die Herren - um es mit der gebräuchlichen Formel zu sagen - Disziplin einhielten, durften ihre Auseinandersetzungen über bestimmte Grenzen nicht hinauslangen. So stellt sich insbesondere die Frage, wie dies zu gewährleisten war. Nach Montesquieu fällt es Aristokratien leichter, das Volk als sich selbst zu regieren. ${ }^{163}$

I63 De l'Esprit des Lois. Paris o.J., I,26: „Mais autant qu'il est aisé à ce corps de réprimer les autres, autant est-il difficile qu'il se réprime lui-même.“ 
Das Problem muß in Rom glänzend gelöst worden sein. Aber wie? Bei einem Adel, dessen Senat ein Gesandter des griechischen Königs Pyrrhos schon im frühen dritten Jahrhundert eine „Versammlung von Königen“ genannt hatte ${ }^{164}$; dessen Mitglieder als Befehlshaber römischer Legionen sowie als Statthalter in den Provinzen große Macht auszuüben gewohnt waren, über viel Anhang verfügten, einem Adel, dem aus glorioser (und immer wieder zelebrierter) Vergangenheit der eigenen Geschlechter hohe Ansprüche erwuchsen. Wie konnten diese Herren zur Einhaltung der Regeln, auch zu den notwendigen Respektbezeugungen gegenüber dem Volk, zur Einfügung in den Stand - und damit zum Verzicht auf so manche Vorteile, so manchen Ehrgeiz (auch so manche Ranküne) - genötigt werden, damit diese schwierige Ordnung gehörig zu handhaben und zu bewahren war? Wie konnten seine Mitglieder andererseits davon abgehalten werden, gegen die Senatsmehrheit an die Volksversammlung zu appellieren? Und wie konnte es sein, daß ihre jungen Söhne nicht, oder doch nur in geringem Ausmaß, über die Stränge schlugen oder aus dem Gegebenen ausbrachen?

3. Es gehörte zur gewachsenen Verfassung, daß die Befugnisse von Magistraten, Senat und Volksversammlung formal kaum eingegrenzt waren. Wohl waren die regulären Aufgaben der verschiedenen Organe ungefähr klar. Den Consuln etwa oblag zusammen mit dem Senat die Aufsicht über die Republik, die Festlegung ihrer Politik, der offizielle Verkehr mit den Gemeinden im Herrschaftsbereich und mit auswärtigen Mächten. Sie hatten den militärischen Oberbefehl und waren für die Abhaltung der Wahlen zuständig; den Praetoren war vornehmlich, aber nicht nur die Gerichtsbarkeit aufgegeben; den Tribunen die Erledigung von Beschwerden vieler Art, ein Gutteil der Gesetzgebung (vielfach im Sinne des Senats) sowie eine gewissermaßen kritische Begleitung der Politik; sie mochten auch, freilich selten, Magistrate nach ihrem Amtsjahr vor der Volksversammlung zur Rechenschaft ziehen. Einen besonderen Hinweis verdient die Censur, zu der alle fünf Jahre zwei Männer aus dem obersten Rang des Senats gewählt wurden. Sie hatten gleichsam für die Sicherung der Infrastruktur der Republik zu sorgen, zunächst für die Führung der Bürgerverzeichnisse, die Einteilung in Tribus und Centurien, auch für die Aufstellung der Senatsliste. Weil es dabei um die Gliederung in verschiedene Ränge ging und deren Inhaber sich ihres Ranges würdig erweisen sollten, waren damit, zumin-

I64 Plutarch, Pyrrhos I9,6. 
dest exemplarisch, Urteile über deren Lebensführung sowie Degradierungen verknüpft. Außerdem waren die Censoren zuständig dafür, die Einziehung von Steuern und Zöllen, die Ausbeutung von Bergwerken etc., den Bau von Straßen und öffentlichen Gebäuden zu verpachten, teilweise auch zu initiieren. Kurz, diesen eigentümlichen Magistraten war die römische Infrastruktur bis in die Moral hinein aufgegeben. Sie handelten weitgehend in eigener Verantwortung; soviel man sieht, waren ihre Entscheidungen nicht unbedingt unparteiisch. ${ }^{165}$ Doch dachte man offenkundig nicht daran, andere Wege zu finden, um ihre Aufgaben zu erledigen. Es wäre auch kaum möglich gewesen, zumal angesichts der Größe der Bürgerschaft.

Die Weisen, auf die die Magistrate zu verfahren hatten, waren in den Regelfällen weitgehend vorgegeben. Manches war genau festgelegt und mußte penibel beachtet werden, etwa Zeremonien von Gebet und Opfer und vor allem die Einholung göttlicher Zeichen. Vereinzelt gaben Gesetze vor, was zu tun oder zu lassen war. Es gab üblicher-, aber nicht unbedingt bindenderweise geltende Bräuche (mores) und Beispiele (exempla) der Amtsführung. Immer wieder aber waren die Magistrate auf das eigene Urteil und die eigene Entschlußkraft angewiesen. Manches wurde ihnen durch Erwartung oder Protest abgenötigt. Der Sinn ihres Amtes muß ihnen (und allen andern) ungefähr klar gewesen sein. So wurde es von ihnen erwartet, und daran werden sie sich im Zweifelsfall gehalten haben. Vielfach erteilte der Senat ihnen Aufträge. In schwierigeren Fällen pflegten die Magistrate kleine Kreise von Senatoren als consilia zu Rate zu ziehen, Männer, welche sachverständig und/oder dem Magistrat besonders verbunden waren, möglichst auch mächtig (so daß sie die zu treffenden Entscheidungen decken konnten). ${ }^{166}$ Als höchstes Consilium fungierte der Senat, dessen Funktion und Einfluß ja aber weit über die des Ratgebers hinausgingen. Wie gut all dies funktionierte, ist eine andere Frage. Sofern es das nicht tat, mochten die Nachfolger im Amt korrigieren, eventuell nachholen, was die Vorgänger versäumt oder falsch gemacht hatten.

Auch die Aufgaben der Volksversammlung wurden weithin routinemäßig erledigt. Vieles hatte sie einfach abzusegnen, anderes, wie die Wahlen, innerhalb enger Spielräume zu erledigen. Eine offene Frage ist, wie weit das in den Contionen sich versammelnde Volk durch Beifall oder Protest Einfluß auf die Politik nehmen, even-

I65 Kunkel, Staatsordnung (wie Anm. I), 4I 7 f.

I66 Mommsen, Staatsrecht (wie Anm. I6), Bd. I, 307 ff. u. Bd. 3, I028; Schulz, Prinzipien (wie Anm. I50), I6I. 
tuell auch als Resonanzboden für tribunicische Agitation dienen konnte. Davon war schon die Rede. Jedenfalls sollte nochmal unterstrichen werden, daß die Magistrate es für geboten hielten, vor der Contio über vieles offen zu berichten, diese also ins Bild zu setzen über Geschehnisse und Absichten, sie insofern ganz ernst zu nehmen (was immer sie am Ende, aber vielleicht nicht ohne gewisse Rücksichten zu nehmen, taten). Gerade auch indem sie sich vor den Contionen auseinandersetzten, zogen sie sie in die Politik hinein.

4. Immer wieder aber mußte es zu Streit kommen; aus verschiedenen Gründen; denn die Ansprüche der verschiedenen Organe überschnitten sich vielfach. Wir finden uns hier vor einer der besonderen Eigentümlichkeiten der römischen Ordnung. Sie war zum geringeren Teil mit der Doppelbesetzung des Obermagistrats, der Collegialität, zum größeren mit den Aufgaben des ursprünglich nahezu revolutionären Volkstribunats gegeben: Die Weite der Behinderungsmöglichkeiten korrespondierte der Weite der Vollmachten der Obermagistrate sowie der Verfügungsgewalt des Senats. Schließlich waren - außer in Hinsicht auf gewisse religiöse Materien und Hinderungsgründe - der Volksversammlung formale Begrenzungen kaum auferlegt. Daß sie nur auf Antrag eines Magistrats etwas beschließen konnte, stellte, um es zu wiederholen, nur eine Schwelle, keine Barriere dar.

Man kann sich fragen, warum die Römer an der Weite der Vollmachten angesichts so vieler möglicher Überschneidungen nichts änderten; etwa das Veto dadurch beschränkten, daß es nur aufschiebende Wirkung gehabt hätte oder daß mehrere Volkstribunen es hätten gemeinsam einbringen müssen ${ }^{167}$; oder auch daß der Senat einen Vorsitzenden aus den eigenen Reihen bekommen hätte, der ihn hätte einberufen und die Tagesordnung hätte bestimmen können. Erst aus der späten Republik sind uns zwei Gesetze bekannt, durch die wenigstens für bestimmte Fälle der Spielraum willkürlicher Senatsentscheidungen eingegrenzt und im Gegenzug die Einlegung eines tribunicischen Vetos verboten wurde. ${ }^{\text {I68 }}$ Doch hat das auch damals kaum Schule gemacht. Auch die genauere Regelung in Sachen Himmelsbeobach-

I67 Das wäre durchaus denkbar gewesen. In der Tabula Bantina, Kap. I wird zum Beispiel die Interzession (das inhibere) von einem Eid abhängig gemacht, in dem unter anderm zu beschwören ist, daß sie de senatus maximae partis sententia erfolge (s. Hartmut Galsterer, Die lex Osca Tabulae Bantinae - Eine Bestandsaufnahme, in: Chiron I, I97 I, I9I-2 I4, hier I95). Vgl. auch Livius 9,46,7.

I68 Lex Sempronia I23; Lex Cornelia 67. Weiteres bei Bleicken, Lex (wie Anm. I I), 450 Anm. 247. 
tung, wie die leges Aelia et Fufia sie in der Mitte des zweiten Jahrhunderts trafen, blieb ein ganz vereinzelter Eingriff.

Die allgemeine Zurückhaltung, was präzisere Regelungen angeht, unterscheidet sich, nebenbei gesagt, auffällig von der Bereitschaft zu gesetzlichen Festlegungen in Hinsicht auf Ämterbewerbung und Laufbahn, von der lex Villia annalis etwa, aber auch von den schon im vierten Jahrhundert erfolgten, später wiederholten gesetzlichen Einschränkungen der Iteration des Consulats. Da sollte der Ehrgeiz gerade prominenter Adliger eingedämmt oder kanalisiert werden. Dahinter stand auch das ungeschriebene Gebot, daß die grundsätzliche Gleichheit der Senatoren zwar durch Rangordnung abgestuft, aber nicht durch Begründung herausragender Macht bedroht werden durfte. Im Fall akuter Kriegsnot konnte man Ausnahmen machen. Für die Regel aber band man sich in diesem Punkt lieber die Hände, als daß man es auf das Spiel der Kräfte und Einflüsse hätte ankommen lassen. Der Stimmenzersplitterung hatte man ja schon im dritten Jahrhundert durch eine Reform entgegenzuwirken versucht, indem man sogar das Prinzip der Rangordnung bei der Reihenfolge der Abstimmung hintanzusetzen bereit war.

Im übrigen aber nahm man alle Schwierigkeiten in Kauf, die sich mit der Unausgeglichenheit zwischen den verschiedenen Organen auftaten. Hätte man sonst vielleicht gar mit Grundbedingungen der römischen Ordnung brechen müssen? Denn es fragt sich doch, ob das nur dem durchweg zu beobachtenden Bestreben zuwidergelaufen wäre, möglichst alles beim Alten zu lassen. Könnte das nicht auch gleichsam mit der zu respektierenden Statur der Verfassungsorgane gegeben gewesen sein? Daß nämlich den Obermagistraten - und entsprechend den Volkstribunen ein weiter Raum eigenständiger Verantwortlichkeit zugebilligt werden mußte (den sie möglichst mit dem von ihnen auszubildenden Sinn für das Angebrachte nutzen sollten) - Wie weit sie damit kamen, mußte sich im Zusammen- und Widerspiel mit anderen Organen erweisen; oft im Streit, im Messen der Kräfte. Denn die Ordnung beruhte ja auf weitgehender Macht sowohl der Magistrate wie des Senats. Was zugleich hieß, daß die damit gegebene Unausgeglichenheit zu immer neuem Ausgleich nötigte, folglich eine Bereitschaft zum Nachgeben teils voraussetzte, teils erzeugte, unter Umständen vermittels Kompromissen, und seien sie scheinbar. Die Frage ist nur, wie viel dabei zu erreichen war; anders gesagt, wie sehr es dabei eines Vermittlers bedurfte und wie das funktionieren konnte. Darauf wird gleich zurückzukommen sein. Anders hätte es, vermute ich, dem Charakter der römischen Ordnung widersprochen, insofern diese gleichsam in der - teils direkten, teils vermittel- 
ten-Gegenwärtigkeit und dem immer wieder neuen Austrag der Kräfteverhältnisse innerhalb (und vor) der Öffentlichkeit der Stadt bestand, ja geradezu lebte.

Es hatte ja seinen guten Sinn, wenn diese Bürgerschaft eben nicht eine Ordnung aus sich herausstellte, um sich dann danach zu richten, sondern sich faktisch darauf verließ, im Rahmen des Herkommens und des Gegebenen mit allem fertig zu werden. Entsprechend mußte sie doch nicht nur Fähigkeiten entwickeln, mit allen möglichen Konflikten umzugehen, sondern an dieser politischen Lebensform auch hängen.

So erfolgte die Eingrenzung, die Kontrolle der magistratischen Wirkensmöglichkeiten (sofern nicht durch den anerzogenen Sinn für das Angebrachte) vielfach durch Gegenkräfte; zumal die Volkstribunen machten Ärgernisse zum Gegenstand von Agitation und eventuell von Gesetzgebung; in Einzelfällen konnten sie damit auch die im allgemeinen maßgebende Senatspolitik vereiteln; eben dadurch wurden - gewiß unvollkommen, aber welche Ordnung ist schon vollkommen? - die Kräfteverhältnisse in stets neuem Zusammenraufen ermittelt. Insgesamt hielten sie sich in engem Rahmen; es konnten durchaus auch Auffassungen von der Berechtigung von Handlungen (im Sinne von Herkommen und Usus) in sie eingehen; sie konnten aber auch von Fall zu Fall variieren. Es hing auf diese Weise immer wieder einmal vom Ausmaß, in dem sich die verschiedenen Kräfte einsetzten und andere für oder gegen sich hatten, ab, was zu geschehen und zu gelten hatte.

Wenn hier von Kräften die Rede ist, so ist das ziemlich buchstäblich zu verstehen. Wenn die Volksversammlung in für wichtig erachteten Angelegenheiten dem Senat nicht zu Willen war, gab es kein anderes Mittel, als daß der senatus universus geschlossen und energisch herbeieilte und sie inständig um Zustimmung bat respektive unter Druck setzte; was genügte, aber eben keine Sache irgendwelchen Rechts war, gleichwohl im Instrumentenkasten der Ordnung seinen Platz hatte. Ähnlich war zwar nicht das Einlegen, aber das Durchhalten der Interzession Sache weniger des Rechts als des Temperaments und der Durchsetzungskraft des Tribunen respektive der Akzeptanz, auf die sein Veto stieß. Und falls es mißachtet wurde, war es wiederum eine Sache des Kampfes, ob sich das ahnden ließ. Was also mit den an sich gegebenen Befugnissen auszurichten war, bestimmte sich von Situation zu Situation. ${ }^{169}$

I69 Ein gutes Beispiel bietet auch das Filibustern: Der jüngere Cato wurde dabei nicht unterbrochen: Mommsen, Staatsrecht (wie Anm. I6), Bd. 3, 939f. Clodius mußte nach knapp drei Stunden odio et strepitu senatus coactus aufgeben (Cicero, ad Atticum 4,2,4). 
Je nachdem, was alles in die Kräfteverhältnisse einging, wer alles dafür und wer dagegen war, aber auch wie etwas allgemein aufgenommen wurde. In der Öffentlichkeit, in der sich die Auseinandersetzungen vollzogen, pflegte die Zahl der nicht direkt speziell Interessierten relativ groß zu sein (es gab ja auch kaum situationsübergreifende Parteiungen). Sie mochten durch Beifall, reserviert oder ablehnend Einfluß nehmen. Die Bürgerschaft selbst, wie sie in der römischen Öffentlichkeit vermittelt/ unvermittelt gegenwärtig war, stellte gleichsam den Boden dar, auf dem sich entschied, was mit den formal kaum eingegrenzten Rechten jeweils zu machen war.

5. Die Kollisionen, zu denen es zwischen den verschiedenen Organen immer wieder kam, und der Umgang mit ihnen sind hier von besonderem Interesse. Sie bewegten sich vielfach im Problemfeld dessen, was die politischen Organe in Rom - jenseits der Erfüllung ihrer Routineaufgaben - stark beschäftigen mußte: des Ehrgeizes der Adligen und der Rivalität zwischen ihnen und gegebenenfalls auch ihren Familien. Dazu zunächst einige Beispiele.

Im Jahre $20 \mathrm{I}^{170}$ etwa wollte sich ein Consul ein bestimmtes, sehr reizvolles Kommando vom Senat ertrotzen. Er erklärte, er werde keine Senatsverhandlungen über andere Gegenstände zulassen, bevor das Haus nicht darüber - in seinem Sinne - entschieden hätte. Zwei Tribunen setzten sich zur Wehr. Es wurde im Senat und vor dem Volk gestritten, schließlich einigte man sich darauf, dem Senat die Entscheidung zu überlassen, und zwar unter der Bedingung, daß die Senatoren zuvor einen Eid ablegten. Der Senat bestimmte darauf die von den Consuln zu übernehmenden Amtsbereiche. Sie sollten entweder durch Abmachung oder durch Los darüber entscheiden, wer welchen übernehme.

Im gleichen Jahr ${ }^{17 \mathrm{I}}$ intervenierte der gleiche Consul gegen einen Senatsbeschluß, der - weitverbreiteten Wünschen gemäß - einen Frieden mit Karthago herbeiführen wollte. Daraufhin wandten sich zwei Volkstribune an die Volksversammlung, um sie beschließen zu lassen, der Senat möge dies tun. Was dann auch geschah. Alle Tribus stimmten dafür und legten zugleich fest, wer die Bedingungen aushandeln und das Heer zurückführen sollte. Aufgrund davon beschloß der Senat zusätzliche Einzelheiten. Also: Was der Senat normalerweise zu tun (und das Volk abzusegnen) hatte, tun hier die Comitien allein und offenbar in seinem Sinne. Dabei hätten, wenn der Consul dagegen war, die Tribunen damals auch selbst den Senat einberufen und

I70 Livius 30,40.

I7 I Livius 30,43. 
beschließen lassen können. ${ }^{172}$ Wenn sie trotzdem den Weg über die Volksversammlung wählten, war das keine Frage von Recht und Zuständigkeit. (Wenn man jedenfalls davon absieht, daß ihnen als Beauftragten der Plebs dieser Weg nahegelegen haben könnte.) Vielmehr wollten sie entweder zusätzliche Kräfte ins Spiel bringen oder überhaupt das Volk in einer Sache zu Wort kommen lassen, an der sehr vielen dringend gelegen sein mußte. Zumindest hatten zahlreiche Soldaten nach eineinhalb Jahrzehnten zum Teil äußerst verlustreicher Kämpfe und Anstrengungen vom Krieg zunächst einmal gründlich genug.

Im Jahre $189^{173}$ erhob der Pontifex Maximus Einspruch dagegen, daß ein Praetor, der zugleich das Priestertum des Flamen Quirinalis innehatte, eine Provinzialstatthalterschaft antrat. Er dürfe die Stadt nicht verlassen. Daraufhin entbrannte ein Streit, der, wie es heißt, im Senat und vor dem Volk mit höchster Anspannung ausgefochten wurde. Beiderseits wurden die Ausführung von Befehlen verhindert, Pfänder genommen, Strafen verhängt, es wurde an Volkstribune wie an die Volksversammlung appelliert - bis „die Religion“ siegte. Der Praetor mußte dem Oberpriester gehorchen. Er erhielt einen städtischen Amtsbereich, wobei der Senat vermittelnd eingriff. Die verhängten Strafen allerdings wurden durch Volksbeschluß erlassen.

Im Jahre $172^{174}$ weigern sich die Consuln, obwohl der Senat sie dazu aufgefordert hatte, ein bestimmtes Thema auf die Tagesordnung zu setzen. Der Senat trat darauf in Streik: Über keinen anderen Gegenstand solle Beschluß gefaßt werden, bevor dies geschehen sei. Die Consuln wurden im Senat angegriffen. Durch die Einmütigkeit der Väter (consensu patrum) sahen sich, wie Livius schreibt, zwei Tribunen angefeuert, den Consuln mit Bestrafung zu drohen. Sie trugen dem Senat im weiteren Zusammenhang der Affäre einen Antrag vor, über den sie dann mit seiner Zustimmung die Volksversammlung abstimmen ließen: Es solle eine Untersuchung stattfinden, und der Senat, in eidbekräftigter Verhandlung, bestimmen, wer sie zu führen habe. Hier also soll der Senat über eine Personalie befinden. Die Plebs stimmte magno consensu zu. Was aber nichts daran änderte, daß der Beauftragte die Sache so lange hinzog, daß sie ausging wie das Hornberger Schießen.

I72 Mommsen, Staatsrecht (wie Anm. I6), Bd. 2, 3I 3 ff. Oder war das, weil es bei auswärtigen Angelegenheiten nicht üblich war, in diesem Fall nicht gewollt?

I73 Livius 37,5I.

I74 Livius 42,2I. 
Im Jahre $169^{175}$ entbrannte ein Konflikt zwischen einem Volkstribunen und den Censoren. Er begann damit, daß ein Client die Tribunen um Hilfe anging, weil die Censoren ihm befohlen hatten, eine Mauer einzureißen, die er auf öffentlichem Grund errichtet hatte. Weil nur einer der zehn interzedierte - so Livius -, scherten sich die Censoren nicht um das Veto. Darauf hatten sich einige wohlhabende Ritter mit Klagen über die Censoren (denen der Senat nicht stattgegeben hatte) an den Tribunen gewandt. Sie waren von der Versteigerung öffentlicher Aufträge ausgeschlossen worden. Jetzt beantragte der Tribun ein Gesetz, wonach die Versteigerung wiederholt werden sollte, ohne Beschränkung der Teilnahme. Als der eine der Censoren in der der Abstimmung voraufgehenden Contio durch Lärm von seiten der Anwesenden daran gehindert wurde, sich Gehör zu verschaffen, beauftragte er eigenmächtig einen Amtsdiener, für Ruhe zu sorgen. Aufgrund dieses Eingriffs in seine Rechte als Versammlungsleiter erhob der Tribun Anklage bei der Volksversammlung gegen ihn, wegen der vorangegangenen Mißachtung seiner Interzession gegen dessen Collegen. Er warf ihnen perduellio vor (Hochverrat respektive Verletzung der Rechte eines Magistrats). Eins also gab das andere. Keiner wollte nachgeben. Dann kam es zur Entscheidung: In den Centuriatcomitien stimmten zunächst acht der zwölf Rittercenturien und zahlreiche aus der ersten Klasse für die Verurteilung. Darauf legten die principes civitatis Trauerkleidung an, nachdem sie demonstrativ (in conspectu populi) ihre goldenen Senatorenringe abgezogen hatten, und gingen hilfeflehend im Volk herum. Es wurde erreicht, daß eine knappe Mehrheit den Censor freisprach, worauf der Volkstribun endlich klein beigab.

Eine halbe Generation später, I 5 I, und dann noch einmal I 38 kam es zu Streitigkeiten zwischen Consuln und Volkstribunen wegen Aushebungen. ${ }^{176}$ Da sich die Tribunen nicht durchsetzen konnten (von einer Interzession verlautet nichts, sie muß aber eingelegt und von den Consuln übergangen worden sein) warfen die Tribunen die Consuln ins Gefängnis (die Lictoren konnten sie nicht schützen, wohl wegen der Unverletzlichkeit der Tribunen). Wir wissen nicht, ob die Wärter dort ihrer Verfügungsgewalt unterstanden; aber sie haben ihre Weisungen ausgeführt. In einem ähnlichen Fall im Jahre 60 wollte der Consul den Senat ins Gefängnis berufen.

I75 Livius 43,I6.

I76 Livius, Periochae 48; Helmut Simon, Roms Kriege in Spanien I54-I33. Frankfurt am Main I962, $42 \mathrm{f}$.

- Livius, Periochae 55; Cicero, de legibus 3,20; Taylor, Forerunners (wie Anm. I03), I9 - Cicero, ad Atticum 2,I,9; Cassius Dio 37,50. 
Als der Tribun daraufhin seine Tribunenbank vor den Eingang stellen ließ und darauf Platz nahm, ließ er die Wand des Gefängnisses aufbrechen.

I93 ${ }^{\text {I77 }}$ erklärte der Senat angesichts schwieriger Aushebungen den tumultus, also Gefahr im Verzuge. Das hieß nach herkömmlicher Auffassung, beschleunigte Aushebung sei notwendig, wie es bei Kriegen in der unmittelbaren Nachbarschaft angebracht sein konnte, aber eigentlich nicht mehr war. Doch fügten sich die Tribunen.

Aber auch die für die Frühzeit bezeugten Drohungen, einen unliebsamen Magistrat vom Tarpejischen Felsen zu stürzen, waren noch nicht aus der Mode gekommen. Soweit wir sehen, blieb es aber bei der Drohung, da andere Volkstribunen dagegen einschritten. Immerhin zeigt sich hier das Maß möglicher Handgreiflichkeit.

Im Jahre $167^{178}$ versuchte ein Praetor - wider allen (in diesem Falle auch sachlich nur allzu gut begründeten) Brauch ohne Befragung des Senats -, die Volksversammlung zu veranlassen, Krieg gegen Rhodos zu beschließen. Hier ist das Interessante, daß das tribunicische Veto seinerseits in Abweichung von wohlbegründeter Üblichkeit gleich zu Beginn eingelegt wurde. Der Antrag durfte also nicht einmal diskutiert werden. Was zur Kollision hätte werden können, wurde sogleich abgewürgt. Eine Regelverletzung wird gegen die andere gesetzt, um deutlich zu machen, daß solche Abweichungen gleich im Keime erstickt werden müssen.

Gegen das Veto respektive das drohende Veto konnte auch ein Gegenveto ins Feld geführt werden, indem etwa ein Tribun erklärte, falls ein anderer gegen sein Vorhaben ein Veto einlegte oder aufrechterhielte, würde er seinerseits alle weiteren Verhandlungen des Senats blockieren. Im Senat konnten Tribunen ins Gebet genommen werden, in aller Regel mit Erfolg. ${ }^{179}$ Jedenfalls sah man sich immer neuen Kraftproben ausgesetzt.

Es konnte aber auch geschehen, daß der Senat sich scheute, eine Entscheidung zu fällen. Er pflegte dann zu beschließen, daß die Comitien sie treffen sollten. Das diente der Streitentlastung (und es war offenbar nicht zu befürchten, daß Volkstribunen aus der Befassung mit solchen Beschlüssen weitere Ansprüche für die Volksversammlung ableiteten).

Zu welch schweren Konflikten es kommen konnte, wenn einmal im Volk stark darauf gedrängt wurde, einen Mann zum Consul zu wählen, der die gesetzlich dafür

I77 Livius 34,56,9ff.

I78 Meier, Loca intercessionis (wie Anm. I02).

I79 Z.B. Livius 3I,20. 36, 39f. 
vorgesehenen Erfordernisse nicht erfüllte, ist schon gesagt worden. Hier war aber für den Senat auch ein besonders neuralgischer Punkt berührt. Es hätte ein gefährliches Präzedenz geschaffen werden können (weil man nämlich damit zu rechnen hatte, daß viele Mächtige, Ehrgeizige da waren, die es nutzten). Folglich leistete man erbitterten Widerstand, mußte dann aber doch nachgeben, indem man die Sache konzedierte, aber die gesetzlichen Bestimmungen noch einmal einschärfen ließ, was ein beliebtes Rezept war. ${ }^{180}$ Der Vorfall hat sich dann auch nicht wiederholt.

Von Fällen, in denen die Volksversammlung bestimmte Beschlüsse nicht fassen wollte, die den Senatoren dringlich erschienen, dies dann aber doch tat, als vom Senat aus fühlbar Druck ausgeübt wurde, war ebenfalls schon die Rede.

Es braucht keine weiteren Beispiele: Immer wieder versuchte ein Magistrat, für sich etwas Besonderes herauszuschlagen oder sich dem Willen des Senats zu entziehen. Volkstribunen erhoben Einspruch. Der Senat konnte in Streik treten. Die Volksversammlung konnte ins Spiel gebracht werden, zumeist im Sinne des Senats. Und dies war überhaupt in der Regel der Fall, wenn es um Personalangelegenheiten ging, in denen der Senat die Entscheidung gern an das Volk delegierte. Hätte er nämlich darüber entschieden, hätten sich die Senatoren dazu äußern müssen, einzeln, vor den Augen des ganzen Hauses. Es hätte sich buchstabieren lassen, wie die Entscheidung zustandekam. Das konnte peinlich sein und fortwirkend Streit generieren. Wenn dagegen die Volksversammlung (wie ja auch bei den Wahlen) sie traf, tauchten die Voten in der Menge unter, so sehr Einzelne darauf Einfluß nehmen konnten. Ohnehin bewegten sich die Personalentscheidungen innerhalb eines ganz begrenzten Kreises von Männern.

Interessant ist der Umgang mit dem Veto im Jahre I69. An sich hören wir bei Cicero $^{\text {I8I }}$, daß jeder einzelne Tribun es wirksam einlegen (und damit jeden Antrag verhindern) kann. Aber vielleicht nicht gegen alles und jeden? Oder dann nicht, wenn ein Privatmann das ganze Collegium darum bat und neun der zehn sich dem verweigerten? Oder wenn es sich um ganz persönliche Gründe handelte? ${ }^{182}$ Gab es da einen Grenzbereich, in dem Mißbrauch offensichtlich war? Immerhin wären die

\footnotetext{
I80 Meier, Kompromiss-Angebot (wie Anm. 86).

I8 I Cicero, de legibus 3,24: „quod enim est tam desperatum collegium, in quo nemo e decem sana mente sit".

I82 In der Tabula Bantina I (Galsterer, lex Osca [wie Anm. I67], I95) heißt es: „Magis rei publicae causa quam ullius gratiae aut inimicitiae causa“.
} 
Censoren für die Nichtbeachtung des Vetos fast bestraft worden (wobei freilich mächtige wirtschaftliche Interessen gegen sie zu Buche schlugen).

Aber vielleicht ist es überhaupt nicht angebracht, für die klassische Republik die tribunicische Interzession (soweit sie nicht im alten Sinne einfach das ius auxilii wahrnahm) als „Verbietungsrecht“ zu verstehen. War es nicht eher nur ein Einspruch, der zum Aufschub, also zu Verhandlungen oder neuen Überlegungen zu führen pflegte, um anschließend in aller Regel fallengelassen zu werden; unter der Autorität des Senats, angesichts von Widerständen im Volk, einmal gar auf energische Proteste römischer Frauen hin? ${ }^{183}$ In den seltenen Fällen, in denen die Interzession als Veto wirkte, wie gegen den höchst problematischen Antrag auf Kriegserklärung gegen Rhodos, sprach von der Sache her nur allzu viel für das Veto.

Am Ende der Auseinandersetzung pflegte die eine Seite nachzugeben; wobei Bedingungen gestellt werden konnten, zumal diejenige, daß der Senat zwar die Entscheidung treffen sollte, aber iuratus, unter Eid, was offenbar eine besondere Art der In-Pflicht-Nahme darstellte. ${ }^{84}$ Aber es konnte auch vom Senat darauf hingewirkt werden, daß Durchbrechungen der Regel nicht wieder vorkamen. Unverkennbar ist, daß der Senat sich normalerweise am Ende als der stärkere erwies, unter Umständen auch als der klügere, der sich, zumindest anfangs, zurückhielt, gelegentlich auch die Entscheidung der Volksversammlung überließ. Seine Autorität war größer, wenn von ihr zurückhaltender Gebrauch gemacht wurde.

So wird man jedenfalls feststellen können, daß die Kollisionen nicht einfach nur störende Nebenfolgen eines mangelnden Ausgleichs von Kompetenzen waren, sondern im Gegenteil große Vorteile boten. Verschiedene Kräfte konnten zu Wort kommen, verschiedene Adlige sich hervortun, empören (und am Ende für das Nachgeben belobigt) werden, Kräfteverhältnisse konnten gemessen werden, zusätzliche Gesichtspunkte die Debatte bereichern; die Materien konnten noch einmal bedacht werden. Man konnte die Volksversammlung einbeziehen. Mithin: ganze Teile der Bürgerschaft waren an der ständigen Arbeit der Ordnung, die ja auch in aller Öffentlichkeit erfolgte, beteiligt. Es entstand ein sehr günstiges Verhältnis zwischen Streit-

I83 Livius 34,2. - Erst in der späten Republik wird das anders, seit dem Veto des Octavius gegen Tiberius Gracchus. Von da ab geschieht es verschiedentlich, daß die Interzession als Verbot gemeint und verstanden, insofern verabsolutiert (und gelegentlich gewaltsam verhindert) wird. Interessanterweise ist sie gegen C. Gracchus nie eingelegt worden, soweit wir wissen.

I84 Livius 26,33,I 4; 30,40,I 2; 42,2 I,5 (vgl. 8,32,I 8) u.a.; Mommsen, Staatsrecht (wie Anm. I6), Bd. 3, 979. 
lizenz und Streitbegrenzung. Indem die Ordnung in diesen Auseinandersetzungen sich bewährte, konnte sich zudem unter den Beteiligten, zumal den Nachwachsenden, der Sinn für das Mögliche (und für das Angebrachte) schärfen.

Und - der Senat bekam Zeit und Gelegenheit, ein möglichst überzeugendes Votum vorzubereiten. Die Beobachtung der Streitigkeiten half ihm, die Kräfteverhältnisse zu taxieren, womit - sofern man sich denn danach richten wollte - eine gewissermaßen objektive Grundlage für die Entscheidung gewonnen wurde. Alle Parteiungen konnten sich durch das Haus hindurchziehen. Es war wichtig, daß man am Ende zum Konsens gelangte. Und es war ja nicht gleichgültig, wie viele am Ende für eine Sache waren, ob nur der größere (maior) oder ein großer (magna) oder gar der größte Teil (maxima pars) respektive der senatus universus. ${ }^{185}$ Weil es eben nicht nur um die bloße Mehrheit, sondern vielfach auch um die Entschiedenheit oder Geschlossenheit ging, die insgesamt zur Geltung gebracht wurde. Indem sie sowohl Streit wie Einigung ermöglichten, kamen die Kollisionen seinem Regime zugute.

6. „Moderne Verfassungen“ können „formal gültige Entscheidungen produzieren, die als solche von materiellem Konsens unabhängig sind. Sie setzen ferner einen Zwangsapparat voraus, der diese Entscheidungen im Konfliktfall gegen Widerstand durchzusetzen erlaubt [...] Vormoderne politisch-soziale Ordnungen verfügen über solche Verfahren und Apparate nicht in demselben Ausmaß; sie sind daher stärker auf Konsens und Aushandlung angewiesen. Wenn keine Übereinkunft herstellbar ist, tragen sie zahlreiche unausgetragene Konflikte und unvereinbare Rechtsansprüche dauerhaft mit sich herum“. ${ }^{86}$

Dies letztere, die dauerhafte Unausgeglichenheit, war in Rom gerade nicht der Fall. Aber das Angewiesensein auf Konsens und Aushandlung durchaus. Der Zwangsapparat fehlte, und gültige Entscheidungen wurden in vielen Fällen eben erst vermittels des Austrags von Kollisionen und der Herausbildung von Konsens erwirkt.

Insgesamt muß gelten, was Rudolf von Jhering formulierte: „Die stillschweigende Bedingung für die Ausübung aller jener Befugnisse ist das Dasein der Vorausset-

I85 Pars maiorz. B.: Livius I,32,I 2. 7, I 9,8 - magna: ebd. 26,32,I. 28,43,I. 3 I,48,I (vgl. 35,8,4). Sallust, Catilina 53,I - maxima: Livius 26,33,I 4 (was immerhin eine interessante Feststellung ist, auch wenn formal pars maior genügt: Mommsen, Staatsrecht [wie Anm. I6], Bd. 3, 993 Anm.5). Ferner oben Anm. I67 - universus 36,40,4. Livius 42,2 I,5: „ita ut ad unum omnes consentirent“.

I86 Barbara Stollberg-Rilinger, Verfassungsgeschichte als Kulturgeschichte, in: ZRG GA I27, 20I0, I-32, hier I I. 
zungen, welche ihren Gebrauch rechtfertigen ". ${ }^{187}$ Die Frage ist nur, worin sie bestanden oder besser: Wie man dazu kam, sie zu kennen oder abzuschätzen. Gewiß erzeugte sich ein relativ ausgeprägter Sinn für das Angebrachte; durch ständige Beobachtung von Politik in der Öffentlichkeit, eigene Erfahrung in Auseinandersetzung mit anderen, Akzeptanzbedürfnisse, wohl auch dank der vorherrschenden, relativ weitgehenden, zumindest im Endeffekt erreichten Übereinstimmungen im öffentlichen Urteil (wozu auch das Fehlen von Faktionen, welche die Beharrung auf gegensätzlichen Positionen hätte mit sich bringen können, Voraussetzung war). Hinzu kamen die Hemmungen und Kontrollen durch andere, eventuell rivalisierende Organe.

Die Frage ist nur, wie weit diese gleichsam selbsttätigen, teils innerlichen, teils äußerlichen Kontrollen ausreichten, um die angemessene Ausübung der formal kaum begrenzten Kompetenzen zu gewährleisten. Insbesondere fragt es sich, woher der Senat sein Vermögen nahm, das Ganze letztlich zu überwachen und im Gleis zu halten. Bedenkt man, was alles an Macht und Ehrgeiz im ganz und gar auf Politik (und Kriegführung) konzentrierten Adel zusammenkam, was an Konflikten, Gegensätzen, Eifersüchteleien und Machtkämpfen daraus hätte resultieren und dann natürlich auch in dessen gemeinsame Versammlung, eben den Senat hätte hineinreichen können: Mußte es da nicht nahezu einem Wunder gleichkommen, wenn dessen Angehörige sich nur von selbst oder angesichts von Widerständen anderer darauf beschränkt hätten, diszipliniert ihre Rolle zu spielen (und etwa darauf zu verzichten, die Volksversammlung in größerem Stil für sich ins Feld zu ziehen)? Bei aller Bereitwilligkeit, mit Wundern zu rechnen: kann man der Sache nicht genauer auf die Spur kommen? Alle Wahrscheinlichkeit scheint mir dafür zu sprechen, daß eine Instanz innerhalb des Senats zu wirken pflegte, die für die vielbeschworene Adelsdisziplin letztlich aufzukommen hatte.

7. Wie der Senat ${ }^{188}$ arbeitete, ist zum guten Teil den Prozeduren senatorischer Beratung und Beschlußfassung abzulesen. Nach dem Referat des die Versammlung leitenden Magistrats wurden die Senatoren - falls man nicht gleich zur Abstim-

I87 Rudolfvon Jhering, Geist des römischen Rechts auf den verschiedenen Stufen seiner Entwicklung. Bd. II I. 4.Aufl. Leipzig I880, 267.

I88 Der natürlich nur tagen konnte, wenn ein Obermagistrat oder ein Volkstribun ihn einberief. Doch konnten seine Mitglieder, zumal die Prominenten, fühlbaren Druck ausüben, daß das geschah: Kunkel, Magistratische Gewalt (wie Anm. I8), I6f. u. 20. 
mung schritt (sofern die Sache klar war) ${ }^{189}$ - einzeln um ihre sententiae gebeten. Aufgerufen wurden sie in der Reihenfolge der Senatsliste, nämlich nach dem höchsten von ihnen bekleideten Rang, erst kamen die gewesenen Consuln, anschließend die gewesenen Prätoren etc. Innerhalb der einzelnen Rangklassen galt Anciennität. Nur ein Platz wurde von den Censoren bei der Erstellung der Senatsliste außer der Reihe besetzt: der des princeps senatus, des Ersten (und Erstbefragten) unter den Senatoren. Ihn bekam in der Regel ein Patricier, und zwar einer, der nach dem Consulat auch die Censur bekleidet hatte. Er hatte seine Position zumeist bis zum Tod inne, gleichgültig wie es zuletzt um seine geistige Präsenz bestellt war. ${ }^{\text {I90 }}$

Daß den Voten des princeps senatus und der ihm unmittelbar folgenden Consulare besondere Autorität zugekommen sein muß, ist zum einen daraus zu schließen, daß ihnen doch wohl nicht ohne Grund der Ehrentitel der Ersten der Bürgerschaft (principes civitatis) zukam, zum andern aus einer einfachen Überlegung: Praktisch war diese Ordnung nicht unbedingt. Wer später befragt wurde, hatte die Gelegenheit, die Argumente aller Vorangegangenen zu widerlegen und einen neuen Vorschlag einzubringen. Und wie leicht geschieht es, zudem in einem Gremium, in dem es keine Fraktionen samt ihren Apparaten gibt, daß der, der jeweils zuletzt gesprochen hat, die folgenden nach sich zieht. ${ }^{\text {I9I }}$ Dagegen konnten die zuerst Aufgerufenen nicht noch einmal zu Wort kommen, waren also benachteiligt. Wohl konnte der Consul die Umfrage unterbrechen, um einzelne Senatoren noch einmal zu befragen, vielleicht gar einen ganz neuen Durchgang beginnen zu lassen. Doch mußte das die Ausnahme bleiben, sonst hätte der Brauch nicht aufrechterhalten werden können. Da eine Benachteiligung der Ersten aber nicht der Sinn der Ordnung des Aufrufs gewesen sein kann, ist anzunehmen, daß sie in der Regel so viel Respekt genossen, daß ihre Voten kaum das Risiko liefen, später beiseite gedrängt oder gar vergessen zu werden. Es wird viel Schneid dazugehört haben, war vielleicht auch nicht ganz risikolos, wenn Senatsmitglieder unterhalb des ersten Rangs ganz neue Vorschläge vor-

I89 Varro bei Gellius I4,7,9: per discessionem, si consentiretur, Mommsen, Staatsrecht (wie Anm. I6), Bd. 3, 983 Anm. 4; Heuß, Thematik (wie Anm. 94), I 307. Die Stelle ist übrigens ein guter Beleg dafür, wie wichtig in vielen Fällen regelrechte Senatsbeschlüsse waren.

I90 Christian Meier, Die Ersten unter den Ersten des Senats. Beobachtungen zur Willensbildung im römischen Senat. in: Dieter Nörr/ Dieter Simon (Hrsg.), Gedächtnisschrift für Wolfgang Kunkel. Frankfurt I 984 , I $85-204$.

I9I Cicero, Philippica 5,5. Mommsen, Staatsrecht (wie Anm. I6), Bd. 3, 98I. 
brachten; zumindest bei wichtigen Fragen. Mit Modifikationen allerdings könnte es sich anders verhalten haben.

Man nahm in der Curie (oder den Tempeln, in denen der Senat ebenfalls tagen konnte) zumal an den Längswänden in breiten Reihen Platz, nicht in fester Ordnung. ${ }^{192}$ Respektgebietend werden die Ersten des Senats dagesessen haben, manch einer mag sich demonstrativ an ihre Seite gestellt haben. So blieben sie im Mittelpunkt der Aufmerksamkeit. Sie verschossen nicht - wie es uns scheinen könnte - zu Anfang gleich ihr Pulver, sondern legten den Grund für die folgenden Meinungsäußerungen (die sich, je weiter man kam, immer mehr auf ein Ja oder Nein beschränkt haben werden, wenn nicht andere Formen der Ermittlung der Mehrheit gewählt wurden). In Angelegenheiten minderen Interesses und in entsprechend weniger gut besuchten Sitzungen mochte es anders sein.

Der princeps senatus wird sich - je wichtiger der Gegenstand war, um so eher nach vorheriger Verständigung mit dem Sitzungsleiter gedrängt gefühlt haben, einen Vorschlag zu machen, der für viele annehmbar war. Die hohe Autorität, die sich mit dieser Position verband, hätte sich über die Zeiten nicht erhalten können, wenn die, die sie innehatten, sie zu sehr dem Widerspruch ausgesetzt oder gar für persönliche Zwecke mißbraucht hätten. War man sich im obersten Rang zumindest überwiegend einig, wird es im Normalfall während des weiteren Verlaufs wenig Spielraum für Abweichungen gegeben haben. Der Einfluß der Führenden konnte denen, die dagegen aufbegehrten, geradezu als Ergebnis übler Machenschaften erscheinen. Sie sahen da eine factio am Werk. Einmal hören wir auch von einem Vorschlag, deswegen geheime Abstimmung einzuführen. Er wurde aber natürlich nicht verwirklicht. ${ }^{193}$

Die Frage ist, was geschah, wenn zwei oder mehr gewichtige Voten gegeneinander standen. Reichte dann ein einmaliger Durchgang? Wohl mochte den principes, wie gesagt, Gelegenheit gegeben werden, sich noch einmal - etwa zu während der Debatte neu aufgekommenen Gesichtspunkten - zu äußern, es mochte gar zu einem Wortwechsel, einem Disput (altercatio) kommen. ${ }^{\text {I94 }}$ Vielleicht nahm man aber auch

I92 Lily Ross Taylor/Russell T.Scott, Seating Space in the Roman Senate and the senatores pedarii, in: TAPhA I0o, I969, 529-582.

I93 [Sallust] ad Caesarem 2,I I,3 ff.

I94 A. O’Brien Moore, Art. „Senatus“, in: Paulys Realencyclopädie der classischen Altertumswissenschaft, Suppl. 6, I935, 660-800, hier $707 \mathrm{f}$. 
in einer weiteren Sitzung die Sache wieder auf? Oder gar in mehreren? Und weiter: tendierte man eher dazu, so lange zu beraten (oder zu warten), bis eine für möglichst viele akzeptable, also „gute“ Lösung gefunden war, etwa im Austrag von Kollisionen? Vielleicht setzte sich ja auch hier auf die Dauer die Bereitwilligkeit der Unterlegenen zum Nachgeben durch, indem viele lieber mit der (wenn auch zunächst eventuell nur knappen) Mehrheit stimmten als auf der schwächeren Seite zu verharren. Schließlich waren hier keine Faktionen am Werk. Oder ging es eher darum, eine wie immer geartete, sei es also auch knappe Mehrheit für einen der Vorschläge zu gewinnen?

Gewiß ist sowohl das eine wie das andere dieser Extreme und sind viele weitere Möglichkeiten dazwischen denkbar. Nicht selten mag es für die meisten gleichgültig gewesen sein, wie es auskam.

Bedenkt man, wie umfangreich die Agenda des Senats gewesen sein muß (da er eben weithin mit Gegenständen befaßt war, die sonst zumeist einer Administration aufgegeben sind), wie unterschiedlich auch die Interessen der je engagierten Patrone und Freunde waren, so ist kaum anzunehmen, daß man es oft auf längere Verhandlungen hinauslaufen lassen konnte. Da mußte es schnell zu Entscheidungen kommen. Da ging es nur darum, was die maior pars befand. Oft mögen dann auch die Senatssitzungen weniger stark besucht gewesen sein. ${ }^{195}$

Doch war das mitnichten durchweg der Fall. Der Senat war kein Parlament von Repräsentanten, die schadlos mit wer weiß wie knapper Mehrheit ihre Entscheidung hätten treffen können, sondern eine Versammlung von Männern, die aufgrund von Rang, Erfahrung, Weisheit (und Macht) Autorität beanspruchten; und dies doch wohl notwendig auf der Basis weitgehender Übereinstimmung. Mußte deswegen nicht den namhafteren unter seinen Entscheidungen eine gewisse inhaltliche Richtigkeit und „Überparteilichkeit“ zuerkannt werden können? Was doch wohl unter innerer Zerrissenheit gelitten, also eine zumindest annähernde Einig-

I95 Ebd.705. Sehr ausführlich: Francis X. Ryan, Rank and Participation in the Republican Senate. Stuttgart I 998, 27 ff. Dazu: Egon Flaig, in: Gnomon 76, 2004, 33 I-34I (auch zu Marianne Bonnefond-Coudry, Le sénat de la république romaine. Rom I989). Interessant ist, daß für bestimmte Gegenstände schon im 2.Jahrhundert Mindestanwesenheiten gesetzlich festgelegt wurden; s. Ryan, Rank, I3ff. Sei es ein Drittel (einhundert), was schon an die Hälfte der Infragekommenden heranreicht, gemessen an den Umständen (Verhinderung durch Alter, Krankheit, Amtspflichten), einmal ist aber auch von I50 Senatoren die Rede. Auch mochten Consuln darauf drängen, daß die Sitzungen in heiklen Fällen gut besucht wurden. Später ist dafür der Ausdruck senatus frequens bezeugt. 
keit vorausgesetzt hätte (samt Praktiken der Streitbegrenzung). Mußten die also nicht eher Sache seiner „Weisheit“ als einer einfachen Mehrheit sein? Ganz abgesehen davon, daß die Gefahr hätte bestehen können, daß knapp Unterlegene die Differenzen in die Öffentlichkeit trugen und etwa der Volksversammlung entsprechende Anträge vorlegten.

Es könnte sein, daß der Senat deshalb mitunter, zumal wenn es knapp wurde, eine Entscheidung lieber vermied. So scheint es sich im Jahre 264 verhalten zu haben ${ }^{196}$, als zur Debatte stand, ob man mit den Mamertinern in Messina ein Bündnis eingehen, also erstmals nach Sizilien übergreifen sollte. Da faßte der Senat keinen Beschluß. Dafür wandten sich die Consuln an die Volksversammlung, und die stimmte für das Bündnis (und für einen eventuellen Krieg gegen Syrakus, aus dem schließlich der erste Punische Krieg werden sollte). Anscheinend waren die Befürworter im Senat unterlegen. Oder die - allenfalls doch wohl relativ knappe - Mehrheit hatte sich gescheut, ihre Ansicht zum Beschluß werden zu lassen.

Weiterhin lassen sich bestimmte Verfahrensweisen und Selbstbeschränkungen senatorischer Politik beobachten, die das Ausbrechen größerer Streitigkeiten an der Wurzel zu kappen geeignet waren. So insbesondere, wie schon gesagt, bei den unter Umständen höchst empfindlichen Personalentscheidungen. Da konnte es zum Beispiel um die Zuweisung von Kommanden gehen oder darum, ob man etwa einem Feldherrn einen Triumph bewilligen sollte. Im ersteren Fall wäre wiederum zu unterscheiden. Wenn es sich darum handelte, welche Amtsbereiche von den Consuln versehen werden sollten, pflegte der Senat eine Entscheidung in der Sache zu treffen. Die Personalfrage, welchem der Consuln welcher Amtsbereich zufiel, mußte von ihnen selbst, sei es durch Vereinbarung, sei es durch das Los beantwortet werden. ${ }^{197}$ Wenn es dagegen um einen wichtigen Sonderauftrag ging, der nur einem Einzelnen erteilt werden konnte (oder um dessen Verlängerung), liebte es der Senat, die Entscheidung den Comitien zu überlassen. Weil es sonst vermutlich unter den Interessierten in seinem Innern höchst störende Streitigkeiten hätte geben können. Relativ großzügig dagegen konnte der Senat verfahren, wenn es sich um ein vermehrbares Gut handelte, also etwa die Verleihung eines Triumphs, obwohl es auch da Schwie-

I96 Alfred Heuß, Der Erste Punische Krieg und das Problem des römischen Imperialismus (I 949), in: ders., Schriften (wie Anm. 20), Bd. 2, I066-I I 47. Ähnlich: Livius: 5,36,9.

I97 Sofern man nicht das Volk entscheiden ließ: Livius 30,40. 
rigkeiten geben konnte. ${ }^{198}$ Eine Ausnahme bildeten seine mehrfach bezeugten Vorschläge für die Position eines Dictators. ${ }^{199}$ Hier diktierte die Not das Handeln. Und letztlich ging es in Fällen großer innerer Spannungen wiederum um eine Delegation: Der Dictator sollte regeln (und konzedieren), wozu der Senat vermutlich so leicht nicht in der Lage war.

Verschiedentlich aber waren doch unbequeme Entscheidungen nicht zu umgehen. Worum es sich dann handelte, mußte unterschiedlich sein; unter anderm je nachdem, wie aufgeladen die Situation war. Weswegen es bei Kollisionen so wichtig sein konnte, daß die Senatoren die Streitigkeiten zunächst einmal beobachten konnten, um daraus eine Abschätzung der Kräfteverhältnisse abzuleiten, mithin eine gewisse Objektivierung der Entscheidungsgrundlage.

Doch konnte es bei gewissen Fragen natürlich auch darum gehen, daß nicht nur die maior, sondern eine magna oder gar maxima pars des Senats, wenn nicht der senatus universus (und im äußersten Fall ein geschlossenes, demonstratives Auftreten der Senatoren in der Öffentlichkeit) sich für etwas einsetzte.

Wir hören, wie neuerdings gezeigt ${ }^{200}$, für die späte Republik mehrfach von großen Mehrheiten, die sich für etwas entschieden. Es wird dabei jeweils vermerkt, daß es sich um Ausnahmen handelte. Offenkundig um Fälle, die sehr wichtig im Sinne des Senats waren. Insofern ist es höchst unwahrscheinlich, daß dessen Mitglieder in der Regel einfach einem Konsensbedürfnis nachgegeben haben. Oder wenn doch, so weil es dabei eben auf den Konsens besonders ankam.

Es fragt sich, wie dies alles möglich wurde. Die Macht, die im Senat zusammenkam, kann ja nicht von selbst dagegen gefeit gewesen sein, daß Differenzen sie spalteten. Wie also konnte er dazu gebracht werden, in wichtigen Fällen geschlossen zu handeln? Und weiter: Wie ließ sich überhaupt verhindern, daß er in Faktionen zerfiel, wie wir sie etwa aus Griechenland kennen; Gruppen, die auf verschiedenen Feldern der Politik nach Macht strebten - oft gegen andere, die das ebenfalls taten. Daß es dazu in Rom zumindest in aller Regel nicht gekommen ist, ist ziemlich klar. ${ }^{201}$

I98 Lundgreen, Regelkonflikte (wie Anm.46), I $78 \mathrm{ff}$.

I99 Mommsen, Staatsrecht (wie Anm. I6), Bd. 2, I50f.; Kunkel, Staatsordnung (wie Anm. I), I92.

200 Jan Timmer, Auseinandertreten, wenn alle einer Meinung sind - Überlegungen zur discessio, in: Klio 9I, 2009, 384-405.

20 I S. oben Anm. I 5 sowie S.645f. Gerade wenn Senatoren sich im Kampf gegen einen herausragenden Mann wie Scipio Africanus und seine engeren Freunde, die factio Scipionum ein Stück weit zusammentaten, geschah es im Interesse der senatorischen Allgemeinheit. 
Aber wie gelang es, das auszuschließen? Mußte da nicht auch möglichen Anfängen gewehrt werden? Reicht es, dafür auf das Bindungswesen zu verweisen, das es schwierig machte, daß sich die Verpflichteten entsprechend gruppierten?

8. Etwas allgemeiner formuliert: Die Frage ist doch, ob die vielfältigen mentalen Bindungen und Ausrichtungen schon des Denkens, die vielen Selbstverständlichkeiten sowie die Mechanismen des Zusammen- und Gegeneinanderwirkens ausreichten, um die römische Ordnung instandzusetzen, über viele mögliche Differenzen und Konflikte hinwegzukommen. Brauchte es dazu nicht eine Instanz, die Senat und Senatoren einigermaßen im Zaum zu halten vermochte? So viel an Disziplin aufgrund verschiedener Mechanismen in den Abläufen römischen Lebens vorgegeben war, brauchte es nicht auch Männer, welche darauf hinwirkten, daß diese Disziplin immer wieder geübt und eingeschärft wurde? Nicht zuletzt zum Zweck und aufgrund der immer neu herzustellenden Geschlossenheit des Senats?

Es müßte, auf die Regel gesehen, ein ungefähr gleichbleibender Kreis gewesen sein. Und dafür kommt eigentlich keiner in Frage außer der obersten Rangklasse des Senats, also den Consularen oder zumindest einem Kern der Herausragenden unter ihnen. Sie verdankten ihre Position nicht einem Macht- oder Faktionskampf, nicht der stets neuen Organisation von Einfluß, sondern der Absolvierung einer mehrstufigen Laufbahn. Wenn sich mit den verschiedenen Positionen innerhalb der Bürgerschaft sowohl Rechte wie Pflichten verknüpften, konnten die Höchsten im Senat davon kaum ausgenommen werden. ${ }^{202}$ Ich vermute also, daß sie sich, wo es nottat, gegebenenfalls unter Hintanstellung von persönlichen und familiären Interessen, gemeinsam (zumindest in der großen Mehrheit) die Sache des Senats zu eigen machten - etwa wo schädliche Exempel Schule zu machen drohten oder wenn große Einzelne sich über die grundlegende (wenn auch gegliederte) Gleichheit der Senatoren erheben wollten oder wenn Streit überhand zu nehmen drohte respektive wo Ansätze der Faktionsbildung zu bekämpfen gewesen wären ${ }^{203}$, wenn also der Senat Stärke

202 Direkt bezeugt finde ich es nur später bei Cicero, pro Sestio 98: „Fundamenta [...] membra quae tuenda principibus vel capitis periculo defendenda“. Ein Beispiel: Livius 40,46. Nach Bonnefond-Coudry, Sénat (wie Anm. I95), 6I 4 ff., zählen die bei Livius verschiedentlich erwähnten seniores dazu. Sollte sich wirklich die oberste Rangklasse der Consulare erst am Ende des 3.Jahrhunderts deutlicher herausgeschält haben (Martin Jehne, The Rise of the Consular as a Social Type in the Third and Second Centuries BC, in: Hans Beck u.a. [Eds.], Consuls and Res Publica. Cambridge 20I I, 2 I I-23 I), so müßte es einen vergleichbaren Kreis führender Männer doch auch vorher schon gegeben haben.

203 Dank Alter und Rang waren sie ein Stück weit aus der Alltagsbetriebsamkeit herausgehoben. Ande- 
und Einmütigkeit zeigen mußte. Sofern im Einzelfall dieser oder jener persönlichen Interessen nachgab, mochte das hingenommen werden. ${ }^{204}$ Der Kern (oder das Gros) der principes aber mußte, wenn es darauf ankam, die Sache des Senats verfechten. Und dafür mußten sie auf die Mehrheit der Senatoren rechnen können.

Jedenfalls kann der Senat kaum ohne ein Zentrum der Willensbildung seine große Autorität bewahrt und bewährt und in Politik umgesetzt haben. So viele Faktoren zusammenkommen mußten, um das über so lange Zeit sich erstreckende erfolgreiche Funktionieren der so eigenartigen römischen Ordnung zu ermöglichen ohne diesen Kern der Beaufsichtigung und Lenkung ist es kaum vorstellbar. Er konnte seiner Aufgabe nur gerecht werden mit Augenmaß und vielfacher Rücksichtnahme, mußte sich bestimmte Regeln zu eigen machen, vielleicht besser noch: bestimmte Weisen zu denken, und mußte auch elastisch sein können, denn die Einschätzung der Kräfteverhältnisse konnte empfehlen, dies oder jenes auch einmal hinzunehmen, etwa daß durch die plebejische Versammlung wichtige Gravamina behoben wurden. Oder daß die Comitien in die Exekutive eingriffen. Man wußte (und konnte darauf vertrauen), daß es Ausnahmen blieben, die die Regel nicht weiter beeinträchtigten, sie vielleicht gar entlasteten (indem sie etwa über Situationen der Schwäche des Senats hinweghalfen). Was die Sache leichter machte. Gegebenenfalls wurde bei Streitfällen die Sache konzediert, aber darauf geachtet, daß daraus keine gefährlichen Exempel erwuchsen. Kurz: Regelmäßige Geschlossenheit des Senats, wo immer es darauf ankam, war die Voraussetzung seines Regimes; das aber bedeutete, daß ein Kreis von Senatshäuptern das Haus dirigierte.

9. Es ist ein höchst eigentümliches Bild, das sich ergibt, wenn man das Funktionieren der römischen Ordnung (in ihren Grundrissen) zu verstehen sucht. Alle Möglichkeiten des Irrtums vorbehalten, scheint sich aber doch verstehen zu lassen, warum und wie diese - auf den ersten Blick höchst unvollkommene - Ordnung befriedigend arbeiten konnte. Unter Beteiligung der verschiedensten Kräfte, bei immer neuer Austarierung eines gedeihlichen Verhältnisses zwischen Streitlizenz und Streitbegrenzung, also von Freiheit und Verantwortung.

Das „der römischen Gesellschaft [...] innewohnende Regulationsvermögen“

rerseits befanden sich in ihren Reihen diejenigen, um die sich am ehesten Faktionen hätten bilden können; was eben unterbunden werden mußte - zugunsten der Autorität des Senats, die im wesentlichen die ihre war.

204 Man mochte auch gelegentlich Zugeständnisse an den Ehrgeiz einzelner Herren oder Geschlechter machen, um sie so besser einzubinden. Vgl. oben Anm.70. 
(Heuß) gehorchte mithin nicht nur einem „unsichtbaren Gesetz“, sondern durchaus auch einer „ordnenden und ausrichtenden Kraft“. Sie hatte einen Namen: Es war der Senat, in dem alle Macht vereint war und der davon einen zurückhaltenden, aber letztlich ausschlaggebenden, auf verschiedene Weise hochdisziplinierten Gebrauch zu machen pflegte (auf der Basis verschiedener Voraussetzungen, die in ihm wie in der ganzen Bürgerschaft mehr oder weniger tief angelegt waren).

\section{VIII.}

I. Wie also ist die Ordnung der klassischen Republik zu begreifen, die, wie man sieht, für jeden ordnenden Verstand eine Zumutung darstellt, mit der die Römer aber offenbar glänzend zurechtgekommen sein müssen?

Daß das von Theodor Mommsen konstruierte System des „Staatsrechts“ im alten Rom keine Entsprechung hatte, ist communis opinio. Ob die Römer ein „Verfassungsrecht“ hatten, mag eine Frage der Definition sein. Indes - worin hätte es bestanden? Wie ließe es sich, für sich genommen, etwa im Blick auf die „Verfassungsorgane“ als ein irgend zusammenhängendes Ganzes ausmachen, entsprechend etwa unseren Verfassungen in ihrem spezifischen Zuschnitt, ihrer Systematik und der Relation zu ihrer Ambiance? Wie vor allem ließe sich eine derart anzunehmende Verfassung auch nur analytisch aus dem Ganzen des römischen Zusammenlebens herauslösen und gegebenenfalls zu dessen übrigen Teilen in ein Verhältnis setzen?

Was Alfred Heuß im Singular die „äußere Verfassungsapparatur“ nennt, wäre ein Gerippe ohne Fleisch, Sehnen und Nerven gewesen. Die von ihm postulierte „ordnende Kraft, die ihren ,richtigen“ Gebrauch gewährleistete“, ist bis in die Einzelheiten hinein so eng mit den „Verfassungsorganen“ verwoben, daß man zu lauter Fehlschlüssen käme, falls man deren Rechte, deren Schranken, deren Wirken aus diesem Zusammenhang herauslösen wollte. Weil alle Teile der „äußeren Apparatur“ dem wohlgeordneten umfassenden Corpus der römischen Bürgerschaft unmittelbar aufsaßen (oder darin eingebettet waren), statt daß es zum wie mangelhaft auch immer durchkonstruierten Gebäude einer „Verfassung“ gekommen wäre.

Wenn der Wirkungsradius von Magistraten, Senat und Volksversammlungen formal nahezu unbegrenzt war, muß dessen Gebrauch an Bedingungen gebunden gewesen sein, die sich in keiner von der „sozialen“ zu unterscheidenden „Rechtsordnung“ unterbringen ließen. Wenn mit dem Wort Ordnung mehr gemeint ist als ein 
Sammelsurium von Institutionen und Regeln, so kann eine derart von der sozialen getrennte Rechtsordnung gar nicht existiert haben.

Wenn die hier angestellte Betrachtung, zumindest aufs Ganze gesehen, nicht in die Irre gegangen ist, haben wir es in der „klassischen Republik“ mit einer Ordnung zu tun, zu der sich die gesamte Bürgerschaft gleichsam mit Haut und Haaren auf sehr bestimmte Weise zusammenfügte.

Denn was in Rom aus frühen Gegebenheiten und (zumal „Stände“-) Kämpfen an Ordnung hervorgegangen und schrittweise weiter gewachsen ist, bestand zu wesentlichen Teilen in der Formung der Bürgerschaft; insgesamt, speziell aber insofern ihre Mitglieder in irgendeinem Sinn, direkt oder indirekt, an politischen Funktionen teilhatten. Um es pointiert zu sagen: Die römische Bürgerschaft hatte weniger eine Ordnung, als daß sie in ihrer quasi ständischen Gliederung, ihren Bindungen, ihren Institutionen sowie - und das ganz besonders - in ihren intellektuellen, mentalen, auch rituellen Ausrichtungen und Dispositionen eine Ordnung war.

Sie war es in der Selbstverständlichkeit ihres von alters her überkommenen Aufbaus; an der Spitze ein Adel von unangefochtener hoher Autorität (auch Standescharisma); begrenzt offen für Aufsteiger, die sich ihm weitgehend zu assimilieren hatten; dessen Mitglieder nicht nur das Recht und die Pflicht hatten, sich dem Dienst am Gemeinwesen zu widmen und sich an einen strengen Comment zu halten. Vielmehr mußte jeder auch die Beziehungen zu einer Unzahl von Bürgern pflegen, welche auf diese Weise eine ganz spezifische indirekte Vertretung fanden (im übrigen nur gelegentlich an der Politik beteiligt waren). Dieser Adel gliederte sich mit der Zeit seinerseits nach Rängen. Seine Angehörigen unterlagen damit, je höher sie hinauswollten, der Notwendigkeit, sich verschiedentlich einer Wahl zu stellen.

Sie war es in den weitgehend vorgegebenen Weisen der Sozialisation, der anerzogenen wie „anerwarteten“ Fähigkeit, sich dem Ganzen einzufügen, aber auch der unmittelbaren Inanspruchnahme zumal der Adligen durch Pflichten, aufgrund derer das Überkommene, das in den Sinnen der Beteiligten wie in den politischen Vollzügen sich reproduzierende Bestehende alternativlos weitgehend das Vorstellen, Denken und Verhalten bestimmte. Die damit gegebene Einmütigkeit, folglich auch Eindeutigkeit der Erwartungen verzahnte sich mit den im Endeffekt zuverlässigen Weisen, in denen ihnen genügt wurde.

Sie war es in der weitgehenden Festlegung von Hoch und Niedrig nicht nur auf bestimmte Wege, die als machtvoll angesehenen überirdischen Gewalten zu bannen sowie das Überkommene zu wahren, sondern auch auf verschiedene einengen- 
de Formen des politischen Vollzugs, etwa der Volksversammlungen, in der Festlegung aber auch auf die Wahrnehmung der Rollen, die den verschiedenen Organen und Teilen der Bürgerschaft herkömmlich (und sinngemäß) zukamen.

Sie war es schließlich von Situation zu Situation, indem sich jeweils in ihrer Mitte, innerhalb gehegter Kräfteverhältnisse stets neu herausstellte, was die Ordnung verlangte.

So blieb die ganze Bürgerschaft im Politischen in hohem Maß ausgerichtet auf das Überkommene, das zugleich das Gegenwärtige war, auch im Wechsel der Generationen.

2. Das Verhältnis zwischen den politischen Organen - Senat, Magistrate, Volksversammlungen -, die Verteilung von Aufgaben und Rechten, die Weisen der Kontrolle sowie die Sicherung auch der Rechte der Bürger war im wesentlichen im Lauf der Zeit herangewachsen. Nur der geringste Teil dieses Konglomerats beruhte auf Gesetzen oder Vereinbarungen.

Vereinbarung (im Sinne der Anerkennung ertrotzter Ansprüche) lag allerdings den Rechten der Plebs zugrunde, jenes Sonderzusammenschlusses innerhalb des Gemeinwesens, seiner Befugnis, in eigenen Versammlungen zusammenzutreten und eigene Amtsträger, die Volkstribunen, zu wählen. Die Plebs erhielt dadurch die Möglichkeit, allgemein die Freiheitsrechte der römischen Bürger zu sichern sowie von Fall zu Fall Abhilfe in akuten Notlagen zu schaffen. Womit zugleich der politische Instrumentenkasten bereichert wurde, zumal durch die Volkstribunen, welche sich Rechte teils der Verbietung, teils des Einspruchs ertrotzten und dadurch Möglichkeiten der Auseinandersetzung sowie der Kontrolle römischer Magistrate hervorbrachten. Mit der Zeit sind diese merkwürdigen Institutionen in die Ordnung der Republik hineingewachsen.

Daß die Befugnisse von Senat, Magistraten und Volksversammlungen formal nahezu unbegrenzt waren, gehörte zu deren Statur. Sie sollten nicht durch Bestimmungen gegängelt werden - außer daß etwa ihre Polizeigewalt eingeschränkt wurde, zwecks Sicherung von Freiheitsrechten. Sie hatten allerdings ihre Pflichten und hatten entsprechend zu handeln: Weitgehend im Rahmen der sich bildenden Üblichkeiten (wobei sie einen Sinn für das je Angebrachte auszubilden pflegten), darüber hinaus im Widerspiel mit anderen Organen, angesichts von Billigung oder Mißbilligung der Öffentlichkeit; wenn das nicht reichte, unter der Autorität des Senats.

Da sich die Befugnisse potentiell überschnitten, bedurfte es stets neuen Aus- 
gleichs. Er wurde erleichtert durch die Erwartung, daß Unterlegene rasch nachgaben. Letztlich waren die Unausgeglichenheiten eine spezifische Form immer neu sich herstellender Ausgeglichenheit.

Oberste Instanz war die Gruppe der Führenden, das heißt der Ranghöchsten im Senat, denen es, wie es sich eingespielt hatte, aufgegeben war, letztlich unter Hintanstellung aller Partikularinteressen für dessen Geschlossenheit und damit für seine Durchsetzungskraft im Sinne der Ordnung zu sorgen.

3. Um diese Ordnung im Gleis zu halten, bedurfte es - im Rahmen der sich stets reproduzierenden Festlegungen - bestimmter Kanalisierungen aristokratischen Ehrgeizes, der eigentümlichen Festlegung eines cursus honorum und der Ränge im Senat sowie bestimmter Kombinationen von Streitlizenz und Streitbegrenzung. Ambitionen, Querelen, potentiell auch Feindschaften ließen sich keineswegs einfach unterdrücken. Sehr vieles mußte ausgetragen werden können, mochte auch nützlich sein - aber in Grenzen.

Was im Ergebnis vielfach als „Adelsdisziplin“ charakterisiert wird, war in der Ordnung verankert. Es war weniger das Verdienst der einzelnen Adligen als das des Standes respektive der Ordnung, die er hervorgebracht hatte und die sich im Vollzug stets neu regenerierte. Es war in allgemeinen Einstellungen (Erwartungen) und Verfahrensweisen abgesichert. Neue Regeln mochten von Fall zu Fall erdacht und eingeschärft werden im Rahmen einer gewissen Kontrolle durch die Häupter des Senats. Römische Adlige lernten es, die je sich ausbildenden Kräfteverhältnisse (in die auch bestimmte Auffassungen von dem, was je rechtens war, eingingen) abzuschätzen und sich danach zu richten; also gegebenenfalls nachzugeben, sobald sie sich jeweils herausgestellt hatten.

Zudem war es der Senatspolitik eigen, daß das Haus möglichst keine Personalentscheidungen traf (sie vielmehr zumeist an die Volksversammlung delegierte). Seine Entscheidungen sollten möglichst von persönlichen Motiven (und Streitigkeiten) abgetrennt, insofern „objektiviert“" werden. ${ }^{205}$

4. Die Institutionen der römischen Ordnung wiesen an ihrer Peripherie einige

205 Vielleicht sollte man in dem Bestreben, Streitigkeiten möglichst dadurch einzugrenzen, daß man die Entscheidungsspielräume verengte, gar eine wichtige Voraussetzung für die Herausbildung der römischen Rechtswissenschaft sehen. Auch privatrechtliche Streitigkeiten konnten wegen der Beteiligung adliger Patrone (aufgrund des Bindungswesens) zur Quelle größerer Störungen werden. Insofern hätten da Herausforderungen gelegen, die juristischen Voraussetzungen richterlicher Entscheidung immer differenzierter zu bestimmen, also eben zu objektivieren. 
Elastizität auf. Man konnte verschiedenes mit ihnen versuchen. Aber sie hatten einen harten Kern. Am Ende erwiesen sich ihre Möglichkeiten regelmäßig als einigermaßen begrenzt. Entsprechend sind viele Aussagen über sie mit dem Beisatz „letztlich“ oder „im Endeffekt“ zu versehen.

5. Eine sehr eigentümliche Stellung nahmen in Rom die Volksversammlungen ein. Ihnen oblagen nicht nur die Wahlen zu den Magistraten, sondern auch eine große Zahl von Beschlüssen, die eben Sache der Gesamtheit waren (Krieg und Frieden, Verträge, Verleihung außerordentlicher Kommanden, Triumphe etc.); zudem die Gesetzgebung. Sie traten aber auch als Öffentlichkeit vielfach in Funktion.

Man sprach die in ihnen versammelten Bürger respektvoll als Herren der Republik an. Sie wurden umworben, konnten auch Beschlüsse gegen den Senat fassen (was freilich Ausnahme blieb und der Regel eher zugutekam, indem es Konflikte rasch beendete). Die Herren der Republik pflegten jedoch in der Regel zu tun, was ihnen abverlangt wurde; von Senat und Adligen, unter anderm zu deren Entlastung. Als Öffentlichkeit nahmen sie dafür in Anspruch, über alles Wichtige orientiert zu werden. Sie mochten Beifall oder Mißfallen artikulieren, überwiegend vermutlich im Sinne des von der Ordnung Gebotenen. Wer dabei jeweils als Volk firmierte, ist nicht festzustellen. Kaum je hat sich aber ein Eigenwille (also ein engerer politischer Zusammenhang) irgend beachtlicher Teile der Bürgerschaft geregt, der über einzelne Situationen hinausgereicht hätte. Die Interessen blieben zumeist vereinzelt und wurden im Rahmen persönlicher Verpflichtungen verfochten. So pflegte sich „das Volk“ ganz und gar (und unter Wahrung einiger Rechte) dem aristokratisch geprägten Gemeinwesen einzufügen.

6. Es herrschte Übereinstimmung darüber, daß die Ordnung so, wie sie überkommen war, richtig, modern formuliert: daß sie legitim war. Oder nein, vielmehr: Man kam gar nicht darauf, daß sie das nicht sein könnte. Man war ganz und gar in sie eingespannt. Generation nach Generation wuchs in ihre Selbstverständlichkeit hinein. Nie war ein Zweifel daran stark genug, nie geschah etwas mit ihr gar nicht Verträgliches, um sie in Frage geraten zu lassen, um einen Bruch mit ihr herbeizuführen. Selbst in der späten Republik mit ihren schweren Konflikten ist es nicht dazu gekommen. Da hat sie nur nicht mehr richtig funktioniert. ${ }^{206}$ Folglich mußte sie sein, wie sie war, oder sie war keine.

206 Meier, RPA (wie Anm. 2) - aber da müßte einiges im Lichte der Ausführungen dieser Arbeit noch einmal bedacht werden. 
Natürlich konnte sie nicht in allem und jedem gleich bleiben. Aber die Veränderungen, die sie durchmachte, sind vermutlich, weil sie auf sie mit kleinen Korrekturen zu reagieren vermochte, als solche kaum wahrgenommen worden, haben jedenfalls den überwältigenden Eindruck des Gleichbleibens kaum gestört.

7. In dieser Ordnung war keiner der Bürger einfach zur Passivität verurteilt, keiner ohne Rechte; Freiheitsrechte waren durch Gesetze garantiert und wurden durch Volkstribunen und Patrone gegebenenfalls eingeklagt. Man konnte in der Volksversammlung, in der contio, im Gefolge großer Herren, als Client, auch vermittels der Teilhabe an gemeinsamen Riten mitwirken; konnte sich, symbolisch inszeniert, immer wieder als wohlrespektierter Teil eines großen Ganzen erfahren.

Gerade die Riten waren von großer Bedeutung: Wo (abgesehen von Außenpolitik und Krieg) vergleichsweise wenige große Entscheidungen zu treffen waren, wo eher im Lauf der Zeit erworbener Rang als die Fähigkeit, Einfluß geradezu auf längere Frist und in großem Stil zu organisieren ${ }^{207}$ die politischen Positionen bestimmte, zählte die Ehren-, die symbolische Seite der Macht, der erwiesene Respekt samt seiner Formelhaftigkeit zu den wichtigsten Gütern. Ein gerüttelt Maß an Ehrgeiz, auch an Stolz und Zufriedenheit konnte sich im Zeremoniellen verwirklichen.

Bedeutende Gelegenheiten, sich nicht nur der Gemeinsamkeit der Republik, sondern auch der Ungleichheit innerhalb der Bürgerschaft zu vergewissern und sie zugleich abzufedern, waren rituelle Vollzüge, die die Ordnung so widerspiegelten, wie sie sie zu ihrem Teil ausmachten: die Triumphe mit der großartigen Herausstellung des Feldherrn, mit staunenerregenden Bildern der Kriegführung und anschließenden Beköstigungen sowie die Demonstrationen der Größe und des Ruhms der Adelsgeschlechter in den fulminanten Leichenbegängnissen (auch in öffentlichen Bauten). Je imponierender die Adligen dabei auftraten, um so eindrucksvoller war es, wenn sich die Angehörigen der gleichen Geschlechter vor dem Volk als Herrn der Republik verbeugten. Gelegentliche harte Eingriffe wurden durch Gesten der Jovialität ausgeglichen.

Schließlich konnte die gesamte Bürgerschaft sich selbst, mit der Zeit übrigens nach Ständen gegliedert, in den Wagenrennen, im Theater, nicht zuletzt in den blutigen Tierhatzen und - zunehmend - in den für uns grauenvoll anmutenden, mörderischen Gladiatorenkämpfen auf der ungeheuren Höhe ihrer Möglichkeiten erfah-

207 Vgl. Meier, RPA (wie Anm. 2), I 8of. zur Cethegi factio, einem intriganten Spiel großen Ausmaßes, wie es aber offenbar einzig dastand. 
ren (um sich um so besser der Ordnung einzufügen). Wie mußte sich ein Volk fühlen, dem zum Schauspiel immer wieder tapfere Männer zu blutigen, auch tödlichen Kämpfen antraten und das am Ende über das Leben der Unterlegenen mitentschied!

8. In etwa so, als starke Prägung der gesamten Bürgerschaft bis ins Denken und Vorstellen, bis in die mehr oder weniger selbstverständliche Ausübung vorgegebener Pflichten hinein, ist, scheint mir, die Ordnung der Republik zu begreifen. Es treffen in ihr Vielfalt und Geschlossenheit, Freiheit und Mechanismen ihrer Begrenzung, Elastizität und Härte zusammen; innerhalb einer besonders dichten alternativlosen Wirklichkeit. Man könnte sie als gemäßigtes Adelsregime klassifizieren; allein, was wäre damit gewonnen? Mit griechischer Verfassungstypologie und der modernen Souveränitätskategorie kommt man da so wenig heran wie mit Mommsens Staatsrecht. Ob man das Ganze systematisch überzeugend ordnen kann, ist mir zweifelhaft.

Wenn uns vieles oder, genau besehen, alles daran recht seltsam anmutet, so kann das nicht wundernehmen: Jeder Blick in den Geschichtsatlas oder in den Ploetz zeigt, daß Roms Geschichte ein Maß an Seltsamkeit aufweist, wie es in der Weltgeschichte so leicht keine Parallele findet. Wie hätte seine Ordnung davon ausgenommen bleiben können? Was man am Ende als höchst komplizierten, aber sinnvollen Zusammenhang rekonstruieren kann, muß sich am Anfang vielen ganz ungewöhnlichen Umständen sowie ebenso ungewöhnlichen Weisen, darauf zu reagieren, verdankt haben - eben mit ganz außerordentlichen Folgen.

\section{Zusammenfassung}

Die römische Republik kannte kein in rechtlichen Kategorien zu fassendes Institutionengefüge, das sich - unsern Verfassungen entsprechend - aus dem Ganzen ihrer Ordnung herauslösen ließe. Damit ergibt sich die Frage, wie die Ordnung der Republik dann zu begreifen ist; was alles sie ausgemacht hat, wie alles im Endeffekt zusammenwirkte, wie es sich zu einem Ganzen zusammenschloß und wie es funktionierte. Gefragt wird nach den älteren, weichenstellenden Voraussetzungen (Erbe des Königtums; Patriciat; Begründung der Republik; Magistrate; „Ständekämpfe“), ferner nach den Volksversammlungen, nach den Grundbedingungen, die das Arbeiten der Ordnung durchwalteten, sowie nach den Weisen, in denen es sich vollzog; letztlich unter Aufsicht der führenden Senatoren. Es ergibt sich, daß die Organe der 
Römischen Republik so tief in besondere Eigenarten der Bürgerschaft verwickelt und durch sie bedingt waren, daß diese Bürgerschaft ihre Ordnung nicht eigentlich hatte, sondern sie war - in ihrem quasi ständischen Gefüge, ihren Bindungen, ihren Institutionen sowie in ihren intellektuellen, mentalen und rituellen Ausrichtungen und Dispositionen. Einfachen (oder auch komplizierten) begrifflichen Klassifikationen oder systematischen Rekonstruktionen entzieht sie sich. Sie steckte in denen, die sie lebten. Ohne ein gedeihliches Verhältnis von Freiheit und Verantwortung konnte sie nicht wirken.

Prof. Dr. Christian Meier, Institut für Alte Geschichte der Universität München, Geschwister-Scholl-Platz I, 80539 München 